\title{
ESTIMATING FUEL OCTANE NUMBERS FROM HOMOGENEOUS GAS-PHASE IGNITION DELAY TIMES
}

\author{
NIMAL NASER ${ }^{*}$, S. MANI SARATHY ${ }^{*}$, SUK HO CHUNG \\ King Abdullah University of Science and Technology (KAUST), \\ Clean Combustion Research Center (CCRC), Thuwal, Saudi Arabia \\ *Corresponding authors: nimal.naser@kaust.edu.sa; mani.sarathy@kaust.edu.sa
}

\section{To cite this article:}

Naser, N., Sarathy, S.M. and Chung, S.H., "Estimating fuel octane numbers from homogeneous gas-phase ignition delay times.". Combust. Flame, 188 (2018), pp. 307-323.

\begin{abstract}
Fuel octane numbers are directly related to the autoignition properties of fuel/air mixtures in spark ignition engines. This work presents a methodology to estimate the research and the motor octane numbers ( $R O N$ and $M O N$ ) from ignition delay time (IDT) data calculated at various pressures and temperatures. The hypothesis under investigation is that at specific conditions of pressure and temperature (i.e., RON-like and MON-like conditions), fuels with IDT identical to that of a primary reference fuel (PRF) have the same octane rating. To test this hypothesis, homogeneous gas-phase IDTs with a detailed gasoline surrogate chemical kinetic model have been calculated at various temperatures and pressures. From this dataset, temperatures that best represent RON and MON have been correlated at a specified pressure. Correlations for pressures in the range of 10-50 bar were obtained. The proposed correlations were validated with toluene reference fuels (TRF), toluene primary reference fuels (TPRF), ethanol reference fuels (ERF), PRFs and TPRFs with ethanol, and multi-component gasoline surrogate mixtures. The predicted RON and MON showed satisfactory accuracy against measurements obtained by the standard ASTM methods and blending rules, demonstrating that the present methodology can be a viable tool for a first approximation. The correlations were also validated against an extensive set of experimental IDT data obtained from literature with a high degree of accuracy in RON/MON prediction.
\end{abstract}


One of the limiting factors in increasing thermal efficiency of spark ignition (SI) engines with higher compression ratio is autoignition characteristics of fuel related to knocking phenomenon [1]. Especially, modern SI engines with turbocharging and downsizing significantly alter in-cylinder pressure and temperature history as compared with conventional engines. In this regard, understanding fuel's chemistry and engine interactions at a fundamental level is important.

Knocking propensities of gasoline fuel have been introduced by Graham Edgar [2] in 1927 based on primary reference fuel (PRF) mixtures of $n$-heptane and iso-octane (2,2,4-trimethylpentane), which are paramount to oil and gas industry in fuel production. Gasoline fuels are characterized by the research octane number (RON) and the motor octane number (MON), which are specified by ASTM D2699 and D2700 [3, 4], respectively, and are measured with a Cooperative Fuel Research (CFR) engine. The engine operating condition in the RON test is with intake air temperature of $325 \mathrm{~K}$ and an engine speed of $600 \mathrm{rpm}$, for the MON test the intake mixture temperature, i.e., fuel-air mixture is set at $422 \mathrm{~K}$ and an engine speed of $900 \mathrm{rpm}$ and the knocking behavior is compared with that of PRF. Based on the test method, the volume percentage of iso-octane in the matching PRF mixture represents the RON or the MON of the fuel. The higher operating temperatures in the MON test and the absence of negative temperature coefficient (NTC) [5, 6] behavior in practical automotive fuels lead to the knock characteristics in a MON test to match a PRF lower than that it matched at the RON test due to strong NTC behavior exhibited by PRFs [7].

To extend the effects of engine operating conditions on anti-knock quality of fuels, Kalghatgi [8, 9] proposed the octane index (OI), an engine-fuel metric that considers the autoignition quality of a fuel at different engine operating conditions, which is defined as

$$
\begin{array}{r}
O I=(1-k) R O N+k M O N \\
O I=R O N-k S
\end{array}
$$

where $k$ is a constant representing an engine operating condition and $S$ is the octane sensitivity defined as RON - MON. Thus, $k=0$ (1) corresponds to RON (MON) condition. It has been shown that the $k$ factor is shifting towards negative values in modern SI engines with downsizing and turbocharging, implying that they are operating away from RON/MON range [10].

Numerous efforts have been performed to advance fundamental understanding of the relationship between octane number and fuel chemistry. The earliest attempt in understanding the effect of molecular structure on fuel's antiknock quality was done by Lovell and co-workers [11, 12, 13, 14, 15], wherein they studied the knock characteristics of 27 paraffins [11], 25 aliphatic olefins [11], 69 naphthenes [13] and 22 aromatics [14] using aniline as a standard for rating fuels. They were able to establish a consistent 
connection with molecular structure and knock propensity. Lovell's work paved the way for a systematic approach in comprehending engine knock from a chemical kinetic perspective followed by Downs et al. [16, 17], Pahnke et al. [18], Walcutt et al. [19], Walsh [20], and Westbrook et al. [21].

Studies linking molecular structure and chemical kinetics were closely followed by determining RON and MON from chemical composition [22, 23, 24, 25, 26] as gasoline is composed of many hydrocarbons [27], whose compositions are subject to great variability [28]. This complex compositional variability has initiated the need for surrogate fuels that can accurately predict specified target properties depending on the application. Morgan et al. [29] developed nonlinear blending rules for ternary surrogates composed of toluene, iso-octane and $n$-heptane, termed toluene primary reference fuels (TPRF). Empirical correlations between TPRF surrogates and RON/MON were developed by Kalghatgi et al. [30] where RON/MON of TPRF surrogates were obtained with standard ASTM tests [3, 4]. There remains a continued interest in determining RON and MON values of gasoline fuels using surrogate mixtures; this study correlates simulated ignition delay times (IDT) of various surrogate mixtures with their RON and MON values. The RON and the MON used for developing the correlations were determined via blending rules [30, 31], experimental RON/MON measurements done at Saudi Aramco's Research and Development Center (R\&DC) [32] and in many cases obtained from literatures [33, 30, 34, 31].

IDT is an important target property in surrogate fuel formulation, among many others, including chemical composition, $\mathrm{H} / \mathrm{C}$ ratio, RON/MON/AKI (antiknock index, $\mathrm{AKI}=\frac{\mathrm{RON}+\mathrm{MON}}{2}$ ) [35, 36, 37, 38], density, and distillation characteristics [39, 40, 41. 42]. Insights into the chemical aspects of octane sensitivity $(S=R O N-M O N)$ were reported by Leppard [7], attributing octane sensitivity to the NTC behavior of paraffinic PRF mixtures whose autoignition chemistries are different from those of aromatics, olefins, and cycloalkanes found in gasoline. Recently, Westbrook et al. [43] attributed the octane sensitivity of various fuels (e.g., alcohols, olefins, aromatics, etc.) to the effects of electron delocalization on low temperature reactivity. Griffiths et al. [44] attempted to correlate IDT with octane rating, but were unable to find suitable correlations between them, instead they proposed that minimum autoignition temperature could lead to better correlation between octane numbers.

Mehl et al. [35] correlated the slope of IDT curves in Arrhenius plots with octane sensitivity of the fuel. A higher slope in NTC regime corresponded to higher sensitivity of the fuel. They were also able to correlate AKI to IDT at an initial pressure of $P_{0}=$ $25 \mathrm{~atm}$ and initial temperature $T_{0}=825 \mathrm{~K}$. Sarathy et al. [45] proposed IDT measurements at $20 \mathrm{~atm}$ and $835 \mathrm{~K}$ could be correlated with RON. The proposed correlations were validated with isomers of octane and it was observed that the predicted RON was in close agreement with measured RON. Ahmed et al. [40] further validated these conditions with gasoline surrogates. Badra et al. [46] reported relationships between RON and MON and simulated IDT of PRF, toluene $/ n$-heptane mixtures (toluene reference 
fuel, TRF) and TPRF. In their work, pressure and temperature conditions providing suitable relationships between octane rating and IDT were identified and correlations for those conditions were reported. Four conditions were identified in [46] where RON and MON could be correlated with IDT, for RON predictions, simulated IDTs at 50 atm and $850 \mathrm{~K}$ provided the best fit. For MON predictions in [46], variable volume profiles, wherein the cylinder volume profile during standard MON tests in CFR engine along with their pressure and temperature histories, served as input for IDT calculations, that were subsequently used in estimating MON.

Most studies have put forward correlations of ON/sensitivity with IDT at one specific condition of pressure and temperature, and in most cases the conditions where $\mathrm{RON}$ and MON are correlated have different pressure. While the present work attempts correlations at multiple pressures, and in addition the RON-like and MON-like temperature for each pressure are also given. This could be of particular use to experimentalists employing shock tubes (ST) and rapid compression machines (RCM), to measure IDT at one particluar pressure, due to changes in the experimental configuration/settings. To the authors' best knowledge, this is also the first attempt in linking IDT (obtained from simulations) to OI in homogeneous reactors; Bradley and Head followed a similar approach [47] that relies on OI obtained from engine experiments. Although OI is not an intrinsic fuel property, it is a measure of the autoignition resistance of a fuel at a specified condition. The OI is a combination of physical operating conditions taken into account by the " $k$ " factor and the chemical characteristics taken into account by the fuel's autoignition quality, RON and MON. Correlations between IDT and OI at conditions "beyond RON", where modern SI engines operate, are also provided.The " $k$ " factor are determined experimentally with engine tests, and in such cases are subject to uncertainties. However, in our studies the conditions at which " $k$ " achieves certain values (i.e., $k=0.5,-0.5,-1.0$ ) are identified. The " $k$ " value conditions presented in this work may not exactly match to " $k$ " value conditions measured in an engine, but the approach is applicable in assessing the autoignition resistance of fuels in STs and RCMs at conditions relevant to modern SI engines.

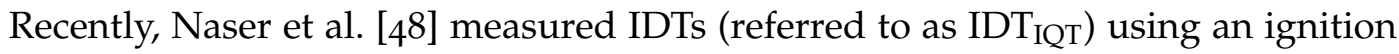
quality tester (IQT) for gasolines and their surrogates, which have relatively long IDT $_{\mathrm{IQT}}$ as compared to diesel fuels such that the contribution of physical delay times (such as spray evaporative cooling and mixing) are relatively short, thus the IDT $\mathrm{IQT}_{\mathrm{I}}$ can be reasonably related to chemical delay time. A methodology has been developed to correlate RON and MON of gasoline-like fuels to $\mathrm{IDT}_{\mathrm{IQT}}$ data. This work clearly implies that simulated IDT and IDT measured in STs and RCMs can be correlated to knocking propensities of gasoline fuels. The methodology in [48] related the IDT $\mathrm{IQT}_{\mathrm{IQT}}$ of a non-PRF to that of a PRF at a fixed pressure and equivalence ratio and multiple temperatures. The difference in $\mathrm{IDT}_{\mathrm{IQT}}$ of the non-PRF compared to PRFs were related to the RON and MON of the test fuel. A fuel that has an IDT IQT matching that of PRF X at multiple temperatures has zero sensitivity, so will behave like PRF X at both 
RON and MON conditions. On the other hand, a fuel that has an IDT $_{\text {IQT }}$ matching that of PRF $X$ at one temperature and an IDT $\mathrm{IQT}_{\mathrm{IQT}}$ matching that of PRF $\mathrm{Y}$ at another temperature has octane sensitivity, more details are available in [48].

Chemical kinetic models have expanded to model large molecules up to $C_{20} n$ - and iso-alkanes [49], and keep on expanding to include molecules covering many gasoline hydrocarbon classes. Nevertheless, detailed chemical kinetic models still often fail to predict ignition behavior of practical fuels, when tested across a wide range of temperature and pressure conditions [42]; which could either be due to errors in the choice of surrogates, the chemical kinetic model itself, or a combination of both. One among many target properties in surrogate fuel formulation is $\mathrm{ON}$, the RON/MON of the surrogate fuel is estimated with blending rules available in literature [35, 40]. Motivated by our previous work [48], the present work attempts to correlate IDTs calculated from a detailed kinetic mechanism to knock propensities of gasoline fuels to develop an ON estimation tool. The correlations developed could be considered an additional target property in surrogate fuel formulation, since surrogate performances are evaluated in IDT space [40], this could lead to better surrogate fuel formulations. PRF, TRF and TPRF fuels are used to establish a methodology that has been extended to ethanol mixtures to validate the methodology. The methodology has been extended to existing measured IDTs from ST and RCM to test the predictive capability from such canonical experiments in estimating knock propensity.

Many researchers [50, 51, 52, 53, 54, 55] have suggested that the octane numbers be replaced with a better fuel metric for antiknock quality. However, octane numbers are ubiquitous in the oil and gas industry. Replacing these metrics requires aggressive fuel policies, which is a challenging effort because refinery operations have become accustomed and calibrated to these important, yet old fuel metrics. Such a move could be easily avoided if the existing fuel metrics could be used to infer fuel behavior in modern engines; this was Kalghatgi's idea of octane index [8, 9], wherein a physical parameter was introduced to represent a real engine's operating conditions with respect to the CFR engine's RON and MON conditions. The intention with the present work is not to replace the standard methods ASTM D2699 and D2700 [3, 4] for RON and MON, but instead as an initial screening tool to estimate a fuel mixture's RON and MON. This approach helps isolate the autoignition chemistry from the competing effects of charge cooling, residual gases, equivalence ratio variations (0.9-1.1), and flame speed, which may affect knocking tendency. The difference in flame speed affects the unburned gas pressure- temperature history, but it is also observed that for most high carbon number hydrocarbons the laminar flame speeds are reasonably similar. There are differences in flame speed due to turbulence, but it is the autoignition chemistry of the end gas that plays the major role in defining the knock characteristics [1]. Residual NO remaining in the cylinder after exhaust valve closure has an influence on the flame speed and ignition chemistry, as shown in a recent study by Foong et al. [56]. These factors play 
an important role in predicting knock onset with chemical kinetic models coupled with computational fluid dynamics.

The objective of our work is to correlate the ignition characteristics in a complex CFR engine environment with an ideal chemical kinetic metric, specifically the homogeneous gas-phase ignition delay time. One of the reasons this study correlates homogeneous gas-phase IDT with RON and MON is because the former is a fundamental kinetic parameter and goes beyond any industry accepted measurement. By linking a practical metric, such as RON/MON, to the fundamental IDT, the present work demonstrates that the widely accepted metric could be replaced by parameter that is intrinsically less uncertain and also more relatable to various engine configurations and operating conditions.

Our approach is focused on the chemical aspect of knock neglecting physical effects. This could help provide better chemical kinetic insights for fuel design of higher antiknock quality of fuels. When designing fuel formations, it is important to have reasonable estimates of the mixture's RON and MON. For ASTM D2699 and D2700 [3, 4], sufficient amount of fuel is required to measure RON and MON, and the testing can become time consuming and expensive. Furthermore, blending rules for many hydrocarbon components and oxygenates may not be readily available or are not well validated. The correlations proposed herein allow estimation of a fuel mixture's RON and MON from simulated IDT, or with as little as, say $250 \mathrm{~mL}$ of fuel by conducting IDT measurements in ST and RCM at specific conditions. Finally, the operating conditions of modern SI engines have shifted from the standard RON and MON tests. Although these tests are still followed in oil refineries worldwide to benchmark automotive fuels, this paper identifies the conditions in ST and RCM that are relevant to modern SI engines, which is essential to design fuels for future engines.

\section{METHODOLOGY}

End gas autoignition results from a cumulative effect of a specific pressure-temperature trajectory and compression due to the advancing flame front. The overall process is recognized as being extremely complex. Both chemical kinetic and physical properties play an important role in predicting knock onset with chemical kinetic models and computational fluid dynamics. Our approach is focused on the chemical aspect of knock and neglects the physical effects. By doing so, the aim is to provide better chemical kinetic insights for fuel design of higher antiknock quality of fuels. The methodology presented in this paper is based on the assumption that at specific conditions of pressure and temperature, the IDT of gasoline fuel and its RON/MON are correlated.

This study is not the first one approximating the cumulative effects of ignition characteristics along a specific pressure-temperature trajectory by examining ignition delay at one condition, in fact many studies are based on this approximation [35, 45, 46. 32]. Note that RON and MON tests represent specified initial temperature and engine 
speed conditions, which in turn alter the end gas temperature and pressure conditions where autoignition occur ahead of spark-initiated flame front to reach. To account for varying engine operating condition and its effects on end gas, Kalghatgi et al. [57] proposed $T_{\text {comp } 15}$ as a representative of unburned bulk gas temperature at specified pressure of 15 bar. This work identifies a specific temperature for a given pressure at which RON and MON are correlated with IDT, which are designated as "RON-like" and "MON-like" temperatures. The correlations are then used to predict RON and MON of various fuels mixtures.

The basic premise is that any fuel mixture having the same IDT as that of a PRF mixture (at the same conditions) should have the same octane number as the PRF. Thus, at RON-like (or MON-like) conditions, the ON of a fuel relates to the RON (or the $\mathrm{MON}$ ) values of corresponding PRF. It is possible that fuels with different RON/MON values have the same IDT particularly at very high temperatures $\left(T_{0}>1000 \mathrm{~K}\right)[42,58]$ and very low temperatures $\left(T_{0}<700 \mathrm{~K}\right)$ for low RON fuels [58]. However, in the temperature regime corresponding to the NTC region, IDT has strong dependence on ONs as indicated by many studies [59, 35, 58], which has motivated the present work to investigate IDTs in the NTC region.

All fuel mixtures used here are available in the Supplementary Material (SM) listed in Tables $\mathrm{S}_{1}$ to $\mathrm{S}_{7}$. Table $\mathrm{S}_{1}$ lists the composition of PRF mixtures that are used in developing correlations between ON and IDT. Tables $\mathrm{S}_{2}$ and $\mathrm{S}_{3}$ list the compositions of TRFs and TPRFs, respectively. The RON and the MON for TRF and TPRF mixtures were determined according to the blending rule proposed by Kalghatgi et al. [30], which is based on a set of extensive experimental engine data. This blending rule was able to predict the RON and MON of TPRFs available in literature extremely well indicated by high correlation coefficients $R^{2}$ of $0.9998 / 0.9976$ for RON/MON, respectively, reported in [30]. Although, the effectiveness of this rule can be quantifiably assessed against real measured data, due to limitations of extensive RON/MON measurements of TRF and TPRF, the TPRF blending rule [30] is used here. Tables $\mathrm{S}_{4}$ and $\mathrm{S}_{5}$ list the compositions of ethanol reference fuels (ERFs; binary mixtures of ethanol and $n$-heptane) and ethanol primary reference fuels (EPRFs; ternary mixtures of ethanol and PRFs), respectively. Table S6 lists the composition of ethanol toluene primary reference fuels (ETPRFs; quaternary mixtures of ethanol and TPRFs). Several measured RON and MON for ethanol mixtures were available, however for certain mixtures the limited data required $\mathrm{RON} / \mathrm{MON}$ to be determined with the blending rule from AlRamadan et al. [31]. This blending rule was demonstrated to be applicable for a wide range of ON for PRFs and TPRFs mixed with ethanol. Table $S_{7}$ lists the compositions of various multi- component surrogate blends (MCSB) comprising $n$-heptane, iso-octane, toluene, 1-hexene, and 1,2,4-trimethylbenzene (124-TMB), and cyclopentane (CPT) whose RON and MON were determined with standard test methods prescribed by ASTM D2699 [3] and ASTM D270o [4], respectively, at Saudi Aramco [32]. 
The following naming convention is used throughout this paper, PRF $X: X$ vol.\% of iso-octane and remaining $n$-heptane, TRF $\mathrm{X}: \mathrm{X}$ vol.\% of toluene and remaining $n$-heptane and for TPRF X-Y: X vol.\% of toluene, $\mathrm{Y}$ vol.\% of iso-octane and remaining $n$-heptane. ERF and EPRF follow the same naming convention as those of TRF and TPRF with ethanol replacing toluene, while for ETPRF X-Y-Z: $X$ indicates vol.\% of ethanol, $Y$ vol. $\%$ of toluene, $Z$ vol. $\%$ of iso-octane and remaining $n$-heptane. No naming convention is followed for MCSBs and they are identified by their blend numbers in Table $\mathrm{S}_{7}$

Homogeneous gas-phase IDTs of all mixtures were simulated using a batch reactor code in Cantera [60] with the KAUST-LLNL-NUIG gasoline surrogate chemical kinetic model [42] that has been validated against ST and RCM as reported in [42]. All IDTs were calculated at stoichiometric conditions $(\phi=1)$ with pressures in the range 10-50 bar at 5 bar intervals. For each pressure, IDT at $10 \mathrm{~K}$ interval in the initial temperature range of $T_{0}=700-1000 \mathrm{~K}$ were calculated. IDT was defined as the time interval from the initial reactor temperature to a reactor temperature $400 \mathrm{~K}$ above the initial temperature. This criteria for ignition yields similar values as using the maximum change in temperature versus time $(\max \mathrm{d} T / \mathrm{d} t)$, and is commonly used in chemical kinetic studies [38, 42, 45]. The correlations presented later are developed using simulated IDTs; however, as shown later, experimental IDT values have also been utilized to further test the applicability of the methodology.

\subsection{RON-like and MON-like conditions}

The proposed methodology can best be explained by presenting an example at a specified pressure of 20 bar. Figure 1 shows IDTs of various PRFs calculated with the KAUST-LLNL-NUIG gasoline surrogate chemical kinetic model [42] along with IDTs of several TRFs. The IDTs of PRFs clearly show the characteristic NTC behavior, i.e., increasing IDT with increasing temperature in the range of initial temperature $T_{0}=800-900 \mathrm{~K}$. This PRF data serves as baseline data in our methodology. 

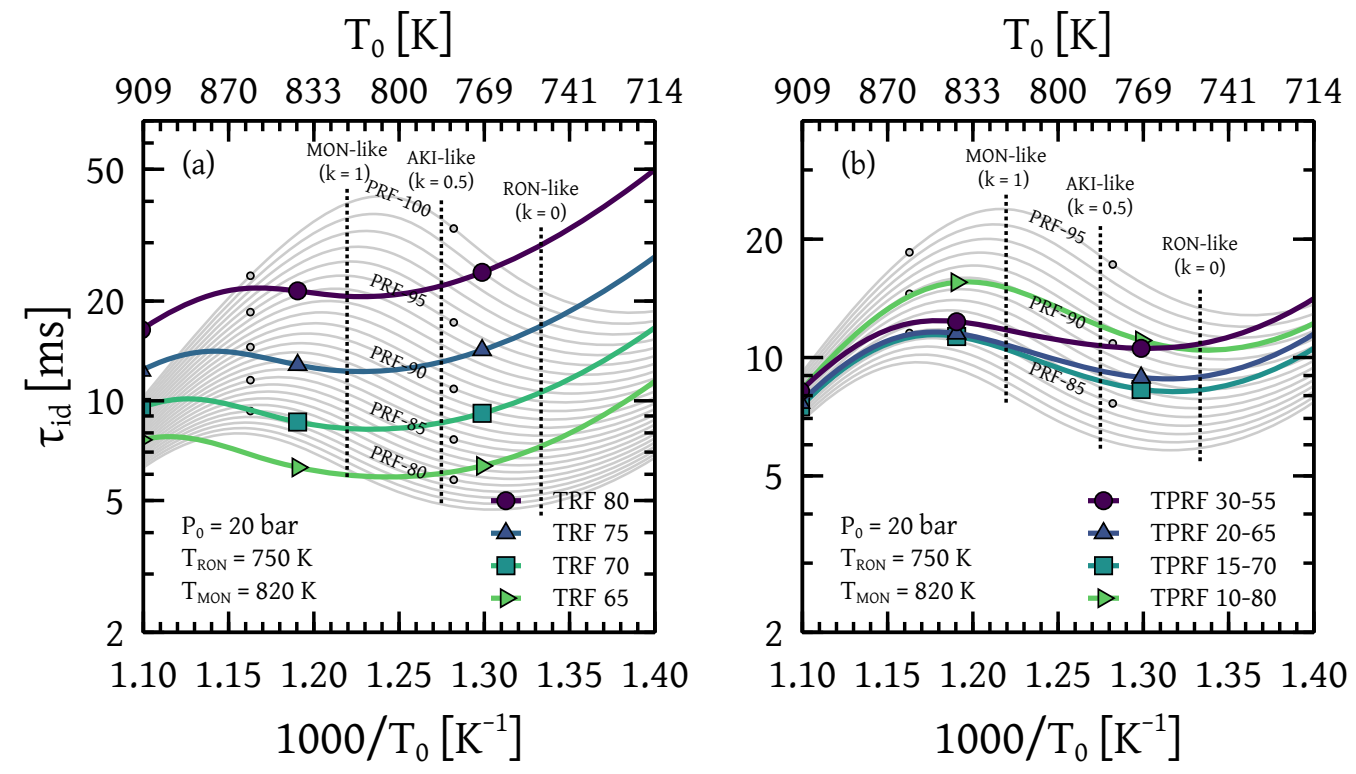

Figure 1: Simulated IDTs of various PRFs (gray lines) and TRFs and TPRFs (colored lines) at $P_{0}=20$ bar. Temperatures corresponding to RON-like, MON-like, and AKI-like conditions are denoted by the dotted lines.

Various correlations between octane numbers and calculated IDTs have been proposed for specific temperature and pressure conditions in [35, 46, 45]. Motivated by the methodology used in our previous work on relating octane number with $\mathrm{IDT}_{\mathrm{IQT}}$, i.e., $\tau_{i d}$ in IQT experiments [48], a relation of the following form is sought in relating ON and $\tau_{i d}[\mathrm{~ms}]$.

$$
O N=a \times \tau_{i d}^{n}+b
$$

where $a, b$, and $n$ are the coefficients and exponent, respectively, at specified temperature and pressure. This equation relates $\mathrm{ON}$ as a linear function of $\tau_{i d}^{n}$. Note that for PRFs, octane numbers are prescribed by definition (say at RON and MON conditions from ASTM D2699 and D2700 [3, 4]). Proceeding in a similar manner, the IDT of PRF (i.e., simulated $\tau_{i d}$ ) is fit by Eq. (2) using an ordinary least squares method for each temperature in the range of $700-1000 \mathrm{~K}$. As 31 different temperature points are available in this range at $10 \mathrm{~K}$ intervals, 31 sets of coefficients and exponent (i.e., $a, b$, and $n$ ) were obtained for one particular pressure.

The coefficients and exponents vary across the entire temperature and pressure range, as IDT of PRFs varies with temperature and pressure. Using simulated IDT of non-PRFs, i.e., TRFs and TPRFs these 31 sets of coefficients and exponent are then tested at one particular pressure. IDT of a non-PRF at one specific temperature with 
constants at the same temperature and pressure were used in estimating the ON. At a given pressure, two specific temperatures were identified, such that the estimated ONs best matched the available RON and MON. These temperatures are identified as the RON-like and MON-like temperatures for a given pressure. The steps are repeated for other pressures to identify the RON-like and MON-like temperature at the respective pressures. Note that these temperatures are not the end gas temperatures observed in an SI engine rather conditions in a homogeneous reactor such as ST or RCM where IDT and RON/MON are correlated.

The present methodology identifies temperature and pressure conditions at which ON can be predicted based on IDT obtained from chemical kinetic simulations; for example, the variation of ON with IDT at 20 bar is shown in Fig. 2 The black curves in Fig. 2 depict correlations that were generated with IDT of PRF at 20 bar for RON-like and MON-like conditions using Eq. (2). These figures are shown only to provide a qualitative idea on the variation of ON with IDT. The variations of IDT with RON and $\mathrm{MON}$ at other pressures are shown in Figs. $\mathrm{S}_{1}$ and $\mathrm{S}_{2}$.
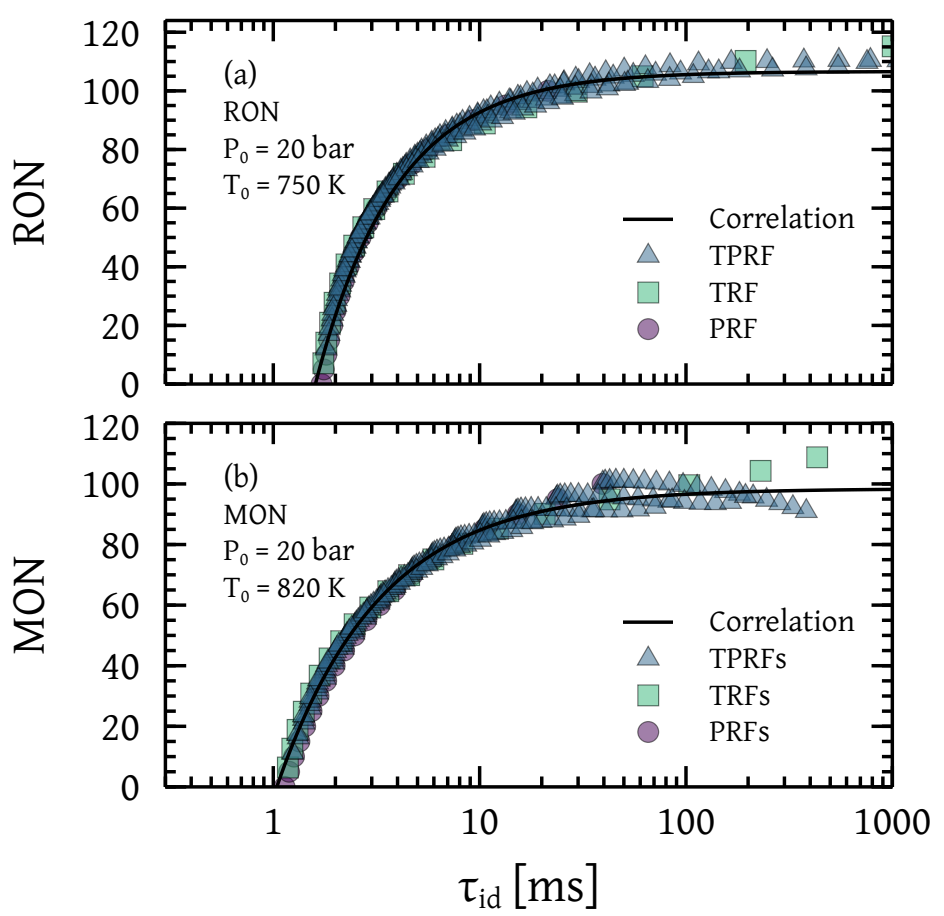

Figure 2: Variation of RON and MON with IDT at 20 bar of PRFs, TRFs and TPRFs. Solid lines indicate correlations obtained with IDT of PRF, in the functional form given by Eq. (2). 
As an example, the IDT of TRF 50 at $P_{0}=20$ bar and $T_{0}=720 \mathrm{~K}$, is $5.44 \mathrm{~ms}$. At the condition, the constants $a, b$, and $n$ are $-420.47,111.94$ and -1.35 , respectively. Substituting the IDT and the constants in Eq. (2), the predicted ON is 69.2 as compared with the measured RON of 65.1. The IDT of TRF 50 at other temperatures, corresponding constants were used in estimating ON. Among these data set, the best fit temperature for RON estimation can be found. The same steps were followed to identify the temperature that best predicted MON. Applying these steps to all the non-PRFs, the RON-like (MON-like) temperature $T_{R O N}\left(T_{M O N}\right)$ that can best represent nominal RON (MON) for TRF and TPRF fuels determined from either standard ASTM tests or using blending rule [30] has been found to be $T_{R O N}=750 \mathrm{~K}$ and $T_{M O N}=820 \mathrm{~K}$ as marked in Fig. I.

Figure 1 also shows that the IDT data of TRFs and TPRFs intersects the IDTs of PRFs. Take for example TRF 75, for which the IDT at 20 bar and $750 \mathrm{~K}$ intersects with the IDT of PRF 97, and at $820 \mathrm{~K}$ intersects with the IDT of PRF 87. This implies that for a specified pressure, octane number varies with temperature. Now one can select RON-like and MON-like temperatures such that determined octane numbers from the calculations best match nominal RON and MON values of test fuels (TRF in this case). For example, if one selects RON (MON)-like temperature as $750(820) \mathrm{K}$, the estimated $\mathrm{RON} / \mathrm{MON}$ of TRF 75 is $97 / 87$, respectively, which is close to the nominal RON/MON of TRF 75 being 94/83, respectively. For the specified TRF fuel, the IDT intersects with that of a lower octane PRF as the temperature increases (i.e., MON is lower than RON).

As an another example, consider the IDT of TPRF 30-55 at 20 bar in Fig. I(b). At the RON-like temperature of $750 \mathrm{~K}$ (refer to Table 1 ), TPRF 30-55 and PRF 92 have the same IDT. This suggests that TPRF $30-55$ has a RON of 92. The nominal RON for this mixture determined using empirical correlations in [30] is 91. At the MON-like temperature of $820 \mathrm{~K}$, TPRF $30-55$ and PRF 87 have similar IDT, thereby providing a MON prediction of 87. Empirical correlation in [30] provide a MON 86 for TPRF 30-55. It can be observed that an increase in octane sensitivity (larger difference between RON and MON) with increasing toluene percentages in the TPRF mixture. These observations are consistent with Leppard's explanation [7] on the origins of octane sensitivity of gasolines. Note that the MON-like condition is observed in the NTC regime of PRFs, consistent with the findings of Leppard [7].

\section{RESULTS AND DISCUSSION}

This section presents details on the selection of RON-like and MON-like conditions, the use of correlations to estimate RON and MON from simulated IDT, and verification of the approach using various chemical kinetic models. Validations at conditions typical to modern IC engines known as "beyond RON" conditions are also presented. 

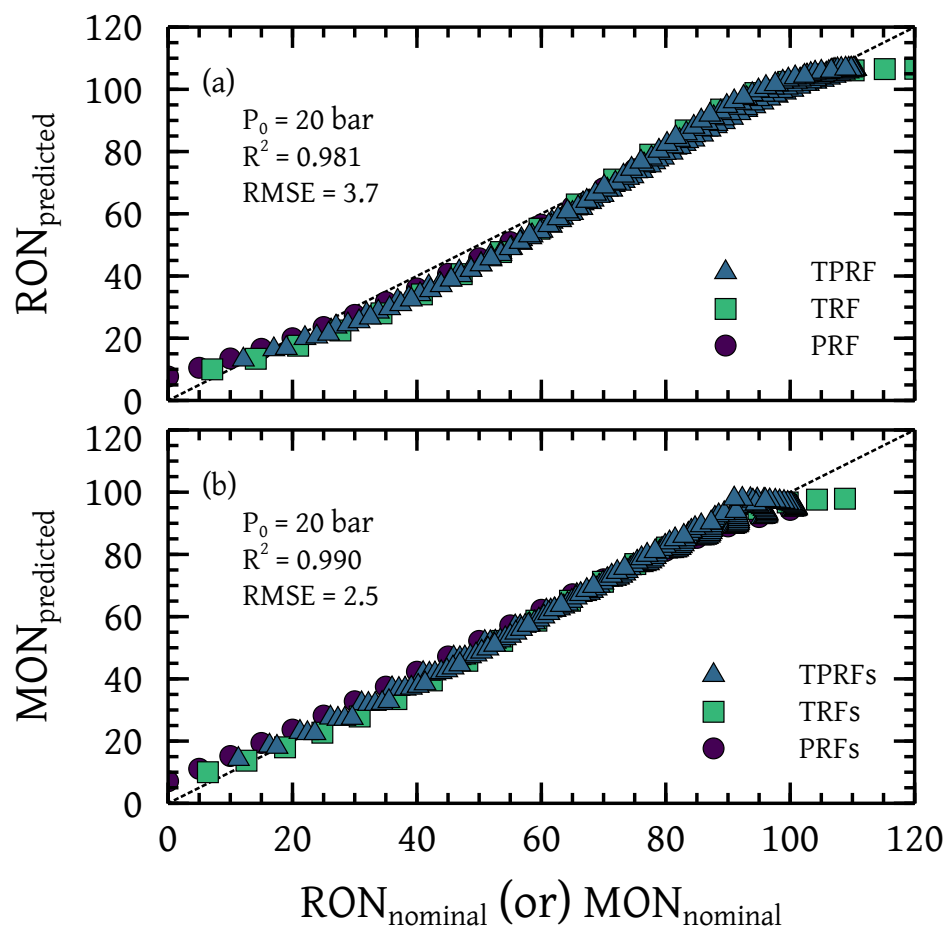

Figure 3: Predicted and nominal (a) RON and (b) MON of PRF, TRF and TPRF with IDT calculated using the KAUST-LLNL-NUIG gasoline surrogate model [42] at $P_{0}=20$ bar

Figure 3 shows predicted RON and MON at 20 bar for PRF, TRF and TPRF mixtures with $a, b$ and $n$ as $-179.68,106.60$ and -1.11 for RON and $-101.85,98.45$ and -0.87 for MON, respectively. As mentioned above for 20 bar, the IDTs for RON and MON predictions are to be evaluated at $750 \mathrm{~K}$ and $820 \mathrm{~K}$, respectively. The predictions at other pressures will be discussed later. The predicted values are in satisfactory agreement with nominal values as indicated by the small root mean square error (RMSE) of 3.7 and 2.5 for RON and MON, respectively. The absolute error in the predictions of RON and MON with IDT at 20 bar along with the ASTM RON and MON repeatability and reproducibility limits are shown in Fig. $\mathrm{S}_{3}$. The average errors in the predictions of RON for PRF/TRF/TPRF are 2.7/4.4/3.0, respectively, and for the MON predictions are 3.0/2.5/1.7. Note, the agreement deteriorates for the TRF fuels for RON and MON values higher than say 100, which can be partially understood since the scales for PRFs are between $o$ and 100, such that extrapolations are required. In spite of the above shortcomings, the correlations are able to predict RON and MON with substantial degree of accuracy indicated by the high $R^{2}>0.981 / 0.990$ and RMSE $<3.7 / 2.5$ for RON and MON, respectively.

The sources for these errors are multiple, including errors associated with RON/MON measurements as discussed in the ASTM standards [3, 4]. Mixing of 
primary reference fuels and other surrogate fuels could also be subject to errors which are difficult to quantify. The most important source of error is the discrepancy in chemical kinetic models in accurately simulating IDTs of hydrocarbon fuels. However, the present methodology works with widely varying chemical kinetic models developed by different groups. By calibrating the model with PRF IDT simulations, this approach cancels many errors associated within the kinetic models for predicting IDT of an unknown fuel. A thorough quantification of all sources of error in every measurement and correlation is beyond the scope of the present work and not discussed hereafter.

Comparison of the estimated and nominal RON/MON values of PRFs, TRFs, and TPRFs with simulated IDT obtained from other kinetic models was also assessed, and are given in the Supplementary Material. Three other models were selected and utilized in the present study, specifically: (i) LLNL detailed gasoline surrogate model [61], (ii) RWTH optimized gasoline surrogate model [62], and (iii) POLIMI PRF surrogate model [63]. As discussed in the Supplementary Material, RON and MON predicted using simulated IDT with different chemical kinetic models show close agreement with nominal values, with some deviations primarily in lower octane number range.

The previous comparisons demonstrate the validity and broad applicability of the present RON and MON prediction methodology. The coefficients determined in Eq. (2) are useful in estimating RON and MON of fuels whose IDT are experimentally measured at RON-like and MON-like conditions (experimental validations provided later) or calculated with another chemical kinetic model (given in Supplementary Material). As the methodology is able to predict RON and MON of PRF, TRF and TPRF with sufficient degree of accuracy, it was next extended to mixtures containing ethanol and multicomponent gasoline surrogates.

\subsection{Validation with other mixtures}

In this section, $\mathrm{RON}$ and $\mathrm{MON}$ predictions for mixtures containing ethanol (ERF/EPRF/ETPRF), and multicomponent surrogate blends are discussed. Nominal RON and MON values for ERF, EPRF, and ETPRF mixtures were obtained from [34, 64, 31]. The IDT of all mixtures in [34, 31] were calculated using the KAUSTLLNL-NUIG gasoline surrogate model [42]. Predicted RON and MON of different mixtures are shown in Fig. 4 for IDT calculated at 20 bar with the same conditions, coefficients and exponent used for the previous TRF and TPRF predictions.

Figure 4(a) and (b) shows predictions of mixtures containing ethanol. Small errors for RON and MON can be observed at 20 bar, as indicated by $R^{2}=0.975 / 0.952$, RMSE $=3.2 / 3.7$ for RON and MON, respectively, demonstrating the accuracy of correlations in predicting $\mathrm{RON}$ and $\mathrm{MON}$ with simulated IDT. 

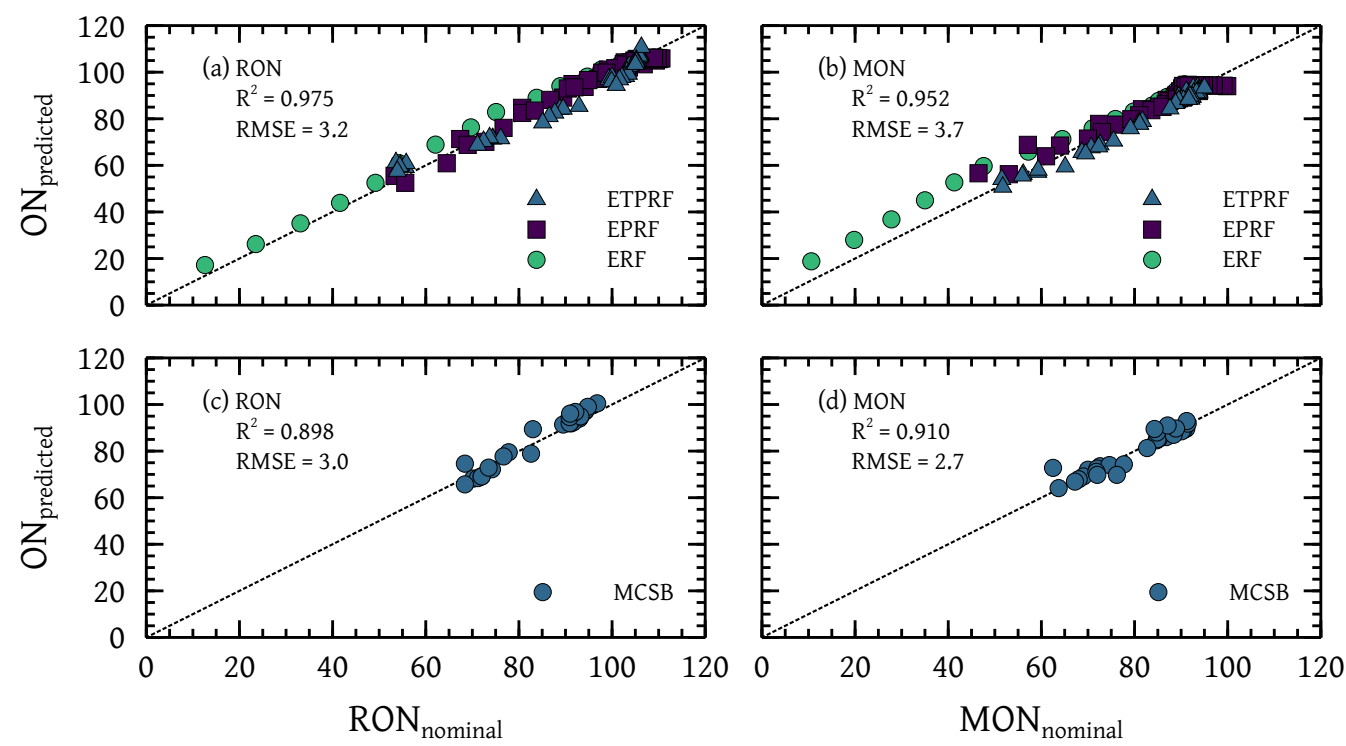

Figure 4: Predicted and nominal RON (left) and MON (right) of ethanol mixtures (top), multicomponent surrogates (bottom), IDT calculated using the KAUST-LLNL-NUIG gasoline surrogate model [42] at $P_{0}=20 \mathrm{bar}$

For fuels with high ethanol content, charge cooling due to ethanol's high latent heat of vaporization (HoV) increases the mixture's RON as discussed in Foong et al. [65]; this is one of many studies [66, 67, 68] that attributes increased knock resistance of ethanol and gasoline-ethanol blends to higher $\mathrm{HoV}$ of ethanol. The standard RON test [3] prescribes the temperature of air upstream of the carburetor to be $323 \mathrm{~K}$, so fuels with high $\mathrm{HoV}$ cool the charge by evaporative cooling. This decreases in-cylinder temperature compared to a PRF and enhances the octane rating of such high $\mathrm{HoV}$ fuels. A recent study attributes the $\mathrm{HoV}$ effect as a thermal contributor to octane sensitivity [69]. Studies in [69] indicate that for fuels with fixed octane sensitivity and varying $\mathrm{HoV}$, the anti-knock quality of fuels correlated with the fuels' RON, and HoV provided no additional benefit [69]. Our predictions of RON of mixtures containing ethanol are with fully homogeneous gas-phase IDTs, and no charge cooling effects are considered. It should be noted that the MON test [4] prescribes temperature downstream of the carburetor, so that the charge cooling effect of ethanol does not play a role in the octane test.

The model was also tested by simulating IDT of MCSBs (at 20 bar, 750 and $820 \mathrm{~K}$ ) and then predicting their RON and MON. The mixtures comprised $n$-heptane, iso-octane, toluene, 1-hexene, 1,2,4-trimethylbenzene, and cyclopentane (CPT) and their RON and MON were measured in [32] by standard ASTM methods D2699 and D270o [3, 4]. Nominal RON and MON values are given in Table $S_{7}$. Comparison between predicted 
and nominal RON and MON are shown in Figs. 4(c) and (d) for MCSBs, respectively, for IDT calculated at 20 bar. Although predictions are somewhat poor compared to other mixtures $\left(R^{2}=0.898 / 0.910, \mathrm{RMSE}=3.0 / 2.7\right.$ for RON and MON, respectively $)$, the correlations are able to estimate the approximate range of $\mathrm{ON}$, which is helpful for initial surrogate fuel screening procedures.

\subsection{Pressure effect}

The methodology was subsequently tested with simulated IDT for all the above mixtures at other pressure conditions. As discussed in the methodology section, the RON-like and MON-like temperatures identified at each pressure condition is given in Table 1 . and plotted in Fig. 5. marked as $k=0$ and 1, respectively for RON and MON. The MON- like temperatures at each pressure were higher than RON- like temperatures; this was consistent with the standard MON and RON tests [3, 4], wherein the MON test has higher intake mixture temperature and engine speed, thus higher end-gas temperatures. Table 1 lists the exponent, $n$, and the coefficients $a$ and $b$ that correspond to each pressure and temperature condition. The temperatures shown in Fig. 5 denote the temperatures at which IDT of any unknown mixture should be determined and then substituted in Eq. (2) for RON/MON with corresponding exponent and coefficients given in Table 1 to determine the mixture's RON/MON. Figure 5 also shows pressure and temperature conditions for $k$ values other than o and 1 that will be explained later in this section. The variation of the exponent and coefficient with pressure is given in Fig. $S_{4}$ in Supplementary Material. 
Table 1: Exponent $n$ and coefficients $a, b$ in Eq. (2) to predict RON and MON

\begin{tabular}{cccccccccc}
\hline & \multicolumn{4}{c}{$\mathrm{RON}$} & \multicolumn{5}{c}{$\mathrm{MON}$} \\
\cline { 2 - 3 } \cline { 8 - 9 } $\mathrm{P}_{0}[\mathrm{bar}]$ & $\mathrm{T}_{0}[\mathrm{~K}]$ & $\mathrm{n}$ & $\mathrm{a}$ & $\mathrm{b}$ & & $\mathrm{T}_{0}[\mathrm{~K}]$ & $\mathrm{n}$ & $\mathrm{a}$ & $\mathrm{b}$ \\
\hline 10 & 730 & -0.99 & -296.01 & 106.11 & & 780 & -0.85 & -206.26 & 97.68 \\
15 & 740 & -1.04 & -234.57 & 106.60 & & 800 & -0.88 & -138.00 & 97.83 \\
20 & 750 & -1.11 & -179.68 & 106.62 & & 820 & -0.87 & -101.85 & 98.45 \\
25 & 760 & -1.19 & -132.07 & 106.10 & & 840 & -0.88 & -85.05 & 99.32 \\
30 & 770 & -1.23 & -95.91 & 105.58 & & 860 & -0.90 & -74.92 & 100.29 \\
35 & 780 & -1.21 & -73.28 & 105.64 & & 880 & -0.93 & -67.81 & 101.47 \\
40 & 790 & -1.14 & -61.85 & 106.59 & & 900 & -0.98 & -61.22 & 102.59 \\
45 & 810 & -1.07 & -56.32 & 108.05 & & 920 & -1.10 & -53.35 & 103.15 \\
50 & 820 & -1.02 & -51.65 & 109.45 & & 940 & -1.29 & -43.19 & 103.10 \\
\hline
\end{tabular}

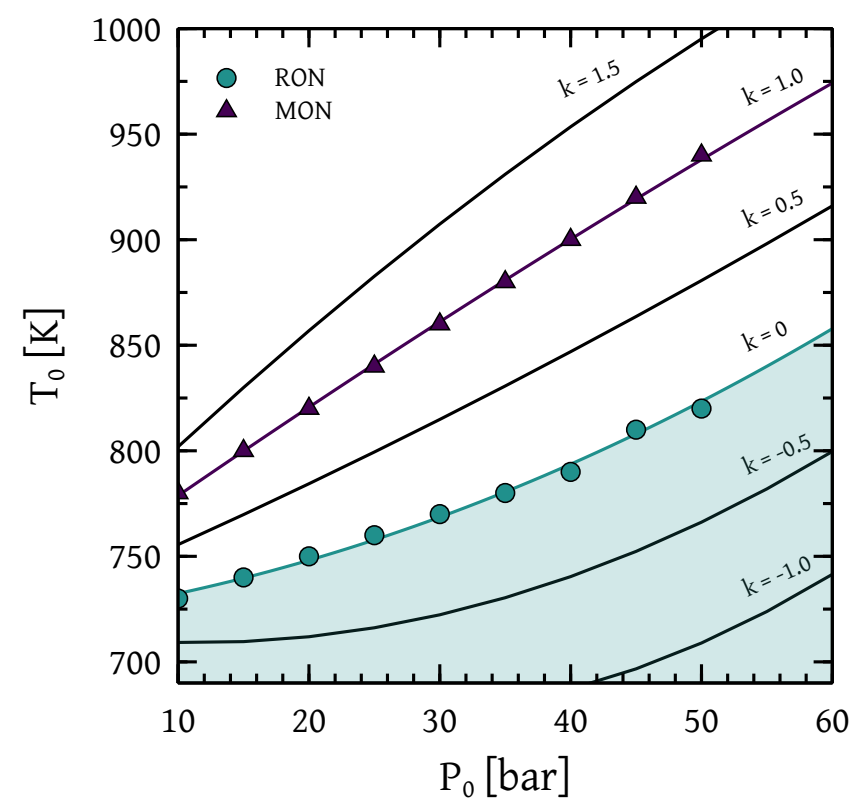

Figure 5: Simulated RON-like and MON-like temperature conditions for various pressures

Figure 5 shows the possible values of $k$, a linear weighting factor given in Eq. (1). Note that $k$ is a factor that depends entirely on physical conditions (temperature and pressure) in an SI engine [57] and takes into account how far the condition is from the actual RON and MON test conditions. By definition, $k=0$ in the RON test and $k=1$ in the MON test. Lines denoting a range of $k$ values from IDT simulations of PRF are shown in Fig. 5 that were determined by linear interpolation and extrapolation as $k$ is observed to be linear with $T_{\text {comp } 15}$ for two temperature ranges [57] as given by Eq. (3). Since the domain of interest is $k<\mathrm{o}$ which has $T_{\text {comp } 15}<825 \mathrm{~K}$ and was linear, the extrapolations were also carried out linearly. 
Recently Szybist and Splitter's [70] study showed that the relation given by Eq. (3) was not universally applicable. They proposed a new relation based on comparison of CA5o variation at knock limited spark advance (KLSA) conditions in SI engines. The use of $\mathrm{CA}_{50}$ to rate knock characteristics of fuels and thereby OI may yield different results than the method used by Kalghatgi [8, 57] where spark timing was used. The difference in methods were also explicitly stated by Szybist and Splitter [70].

Inspite of these differences a linear relation was obtained in Szybist and Splitter's study [70], and in the present work relations obtained in [57] are used. It is to be noted this temperature is the unburned bulk temperature observed in engine experiments and not the homogeneous reactor temperature.

$$
k=\left\{\begin{array}{l}
0.0056 T_{\text {comp } 15}-4.68 \quad \forall \quad T_{\text {comp } 15}<825 \mathrm{~K} \\
0.0426 T_{\text {comp } 15}-35.20 \quad \forall \quad T_{\text {comp } 15}>825 \mathrm{~K}
\end{array}\right.
$$

More details on $k$ and its physical significance are available in [10, 71, 72]. Values of pressure and temperature at $k$ values other than o and 1 are also shown in the figure. The interpretation of $k$ values can be understood with an example. The IDT at 20 bar and $785 \mathrm{~K}$ relates to the antiknock index (AKI), defined as $(\mathrm{RON}+\mathrm{MON}) / 2$ as this condition corresponds to $k=0.5$. The "AKI-like" temperature at pressure 20 bar is shown in Fig. $1(\mathrm{~b})$ at which IDTs of TPRF $30-55$ and PRF 89 are the same, providing an AKI value of 89. In modern SI engines, the value of $k$ can be negative [10, 71, 72], so IDT measurements of fuels at conditions in the blue shaded region in Fig. 5 are of interest for future advanced SI engines.

Comparisons of $\mathrm{RON} / \mathrm{MON}$ predictions with the above mixtures at pressures from 25-40 bar are shown in Figs. 6 to 8 , predictions at other pressures are available in Figs. $S_{7}$ to $S_{9}$ in SM. The estimated RON/MON of PRFs, TRFs and TPRFs using the KAUST-LLNL-NUIG detailed gasoline surrogate model is shown in Figs. 6(a) and 6(b). As indicated by the $R^{2}$ and RMSE, the predictions had great degree of accuracy, with the highest RMSE (least accurate) of 6.3 and 4.3 for RON and MON, respectively, observed at 50 bar. Predictions of $\mathrm{RON}$ and MON of ethanol containing mixtures are given in Figs. $7(\mathrm{a})$ and $7(\mathrm{~b})$, respectively. The predictions show sufficient degree of accuracy indicated by the high $R^{2}$ and small values of RMSE, the least $R^{2}$ and highest RMSE is 0.859 and 6.5 for MON predictions at 40 bar. The error in predictions of RON and MON are give in Figs. $\mathrm{S} 5$ and $\mathrm{S6}$.

The RON and MON of multicomponent surrogates are also predicted at different pressures giving reasonable accuracy in estimations, comparisons are shown in Figs. 8(a) and $8(\mathrm{~b})$. The $R^{2}$ and RMSE are in the range of $0.783^{-0.886}$ and 4.5-3.1. The prediction capabilities are lesser than the reproducibility and repeatability limits of ASTM tests. As mentioned above, ASTM tests are time consuming and expensive, such that composition based correlations could be used to estimate RON and MON for a complex mixture for initial screening. However, such correlations are not always accurate, especially when dealing with mixture containing ethanol. Even the well-regarded model by 
Ghosh et al. 26] has difficulties to apply because non-linear interaction parameters are not provided for all the compositional variations that one encounters in real surrogate fuel formulation (i.e., some of interaction parameters have been kept confidential). The present approach also provides a way of estimating RON and MON for a mixture of hydrocarbons where no ASTM measurement has been taken. This could be achieved by either simulating IDT or performing a ST or RCM experiment.

With correlations for multiple pressures, it was imperative to test the accuracy of the correlations with pressure. To this end, the $R^{2}$ and RMSE of all the mixtures tested in the present work at various pressures are shown in Figs. $S_{11}$ and $S_{12}$, respectively. When all fuels are considered the most accurate predictions for RON and MON were obtained at 20 bar. This is expected as most experiments for validation of chemical kinetic models are carried out close to 20 bar, improving the accuracy of the models at 20 bar. The higher accuracy of the correlations at 20 bar makes it practically convenient for experiments involving STs and RCMs that are typically done at 20 bar. Amongst all the fuels tested, the least accurate correlations were obtained for 50 bar, this could be possibly due to the scarcity of data at high pressures to validate chemical kinetic model. 

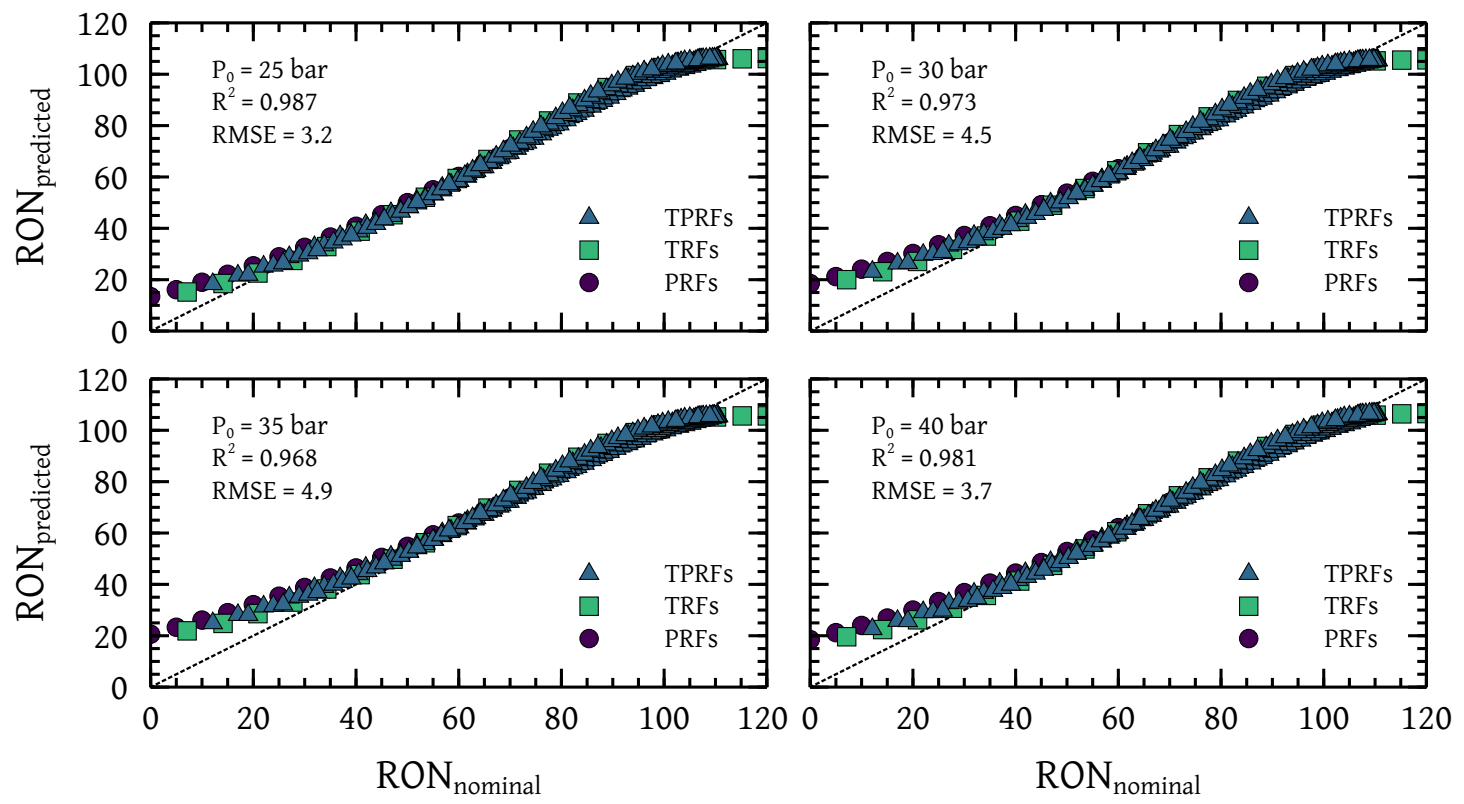

(a)
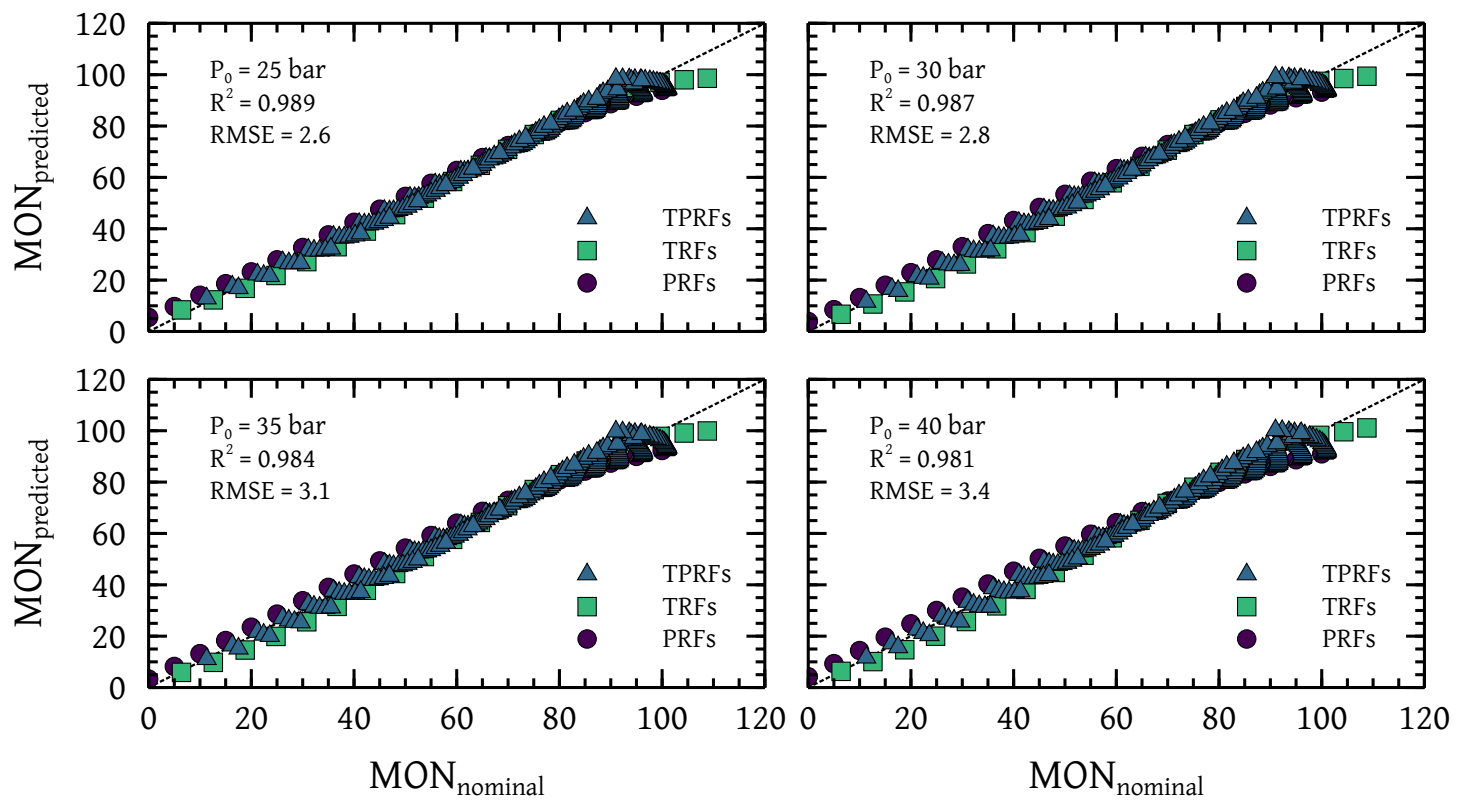

(b)

Figure 6: Predicted and nominal (a) RON and (b) MON of PRF, TRF and TPRF with IDT calculated using the KAUST-LLNL-NUIG gasoline surrogate model [42] at different pressures 

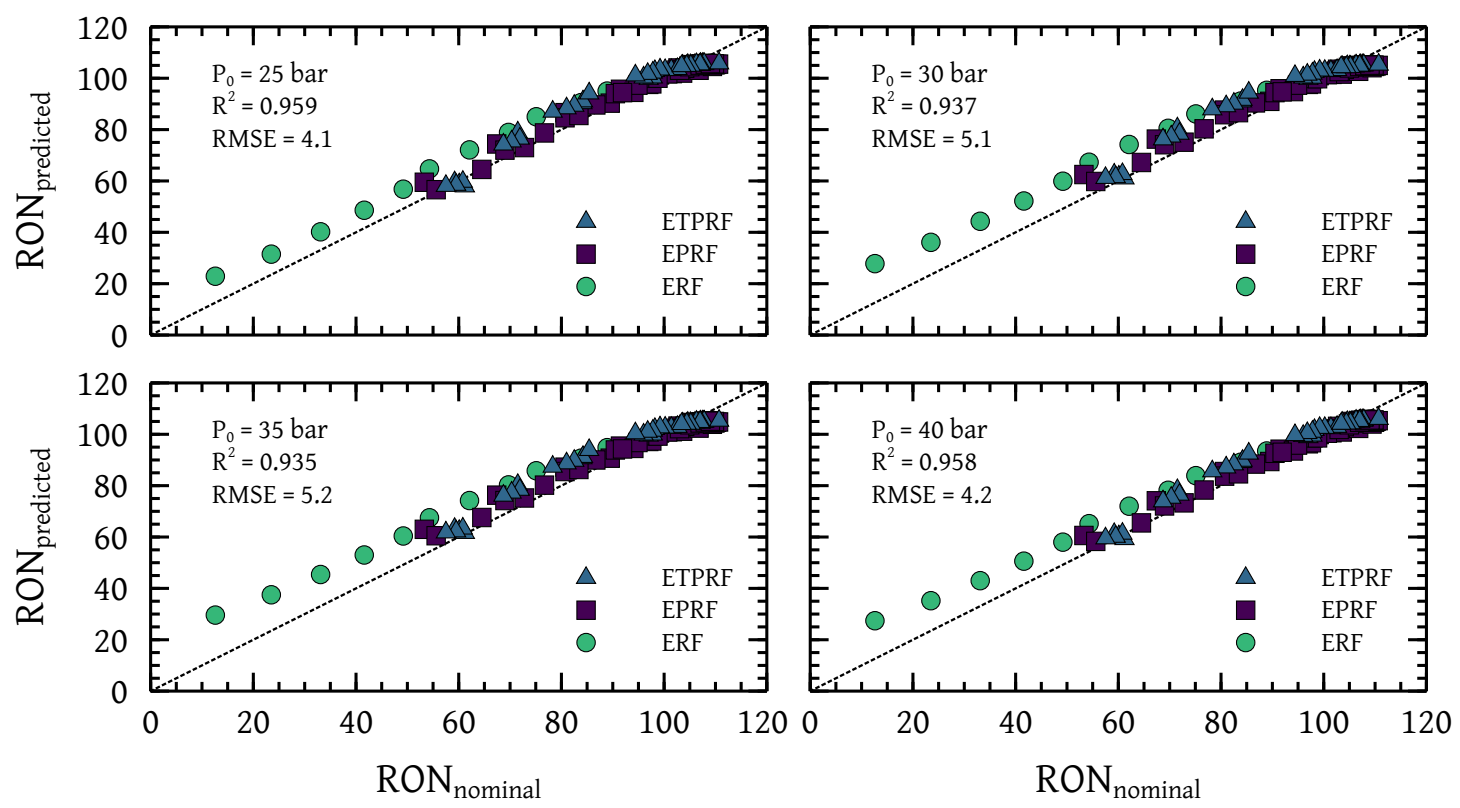

(a)
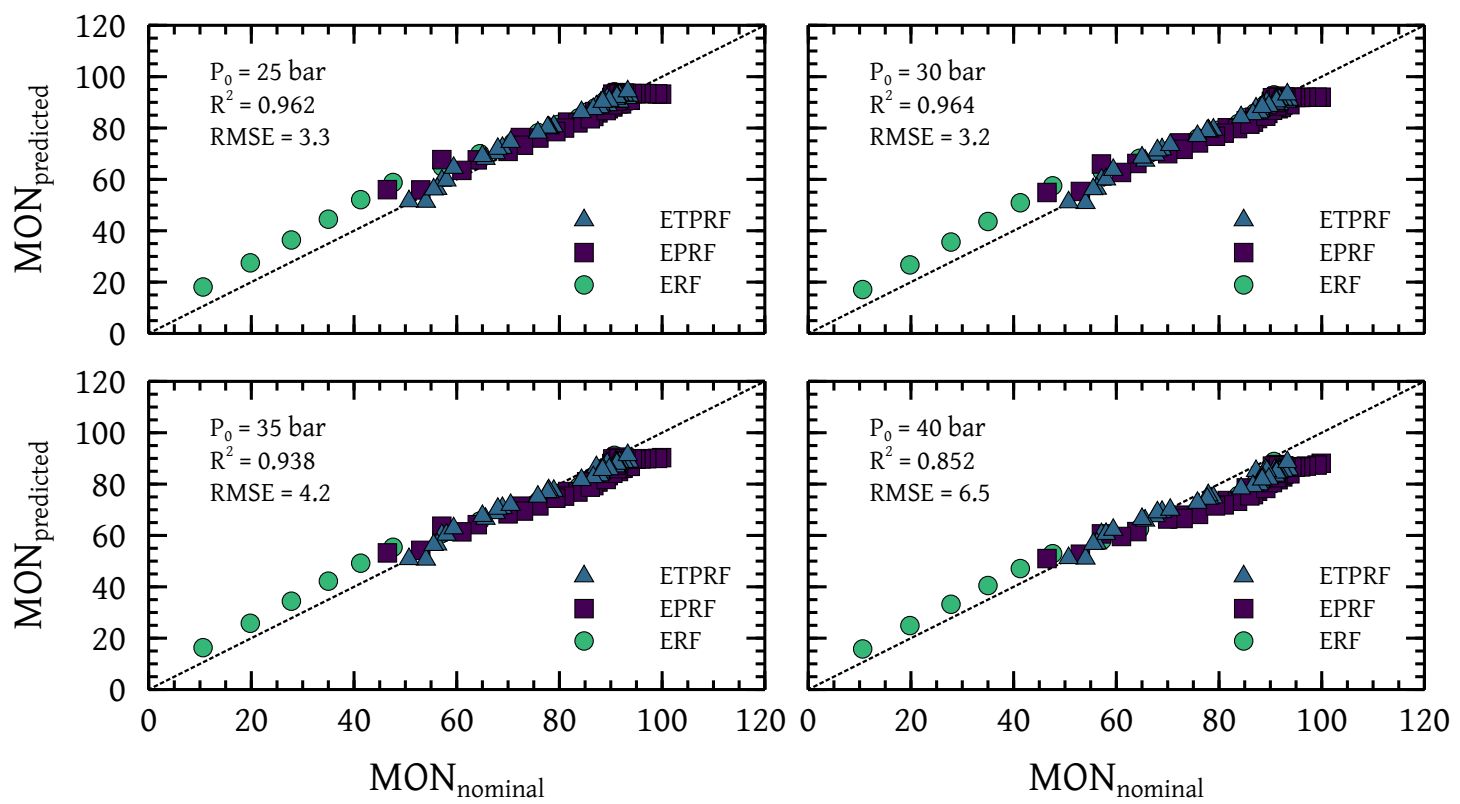

(b)

Figure 7: Predicted and nominal (a) RON and (b) MON of ERF, EPRF and ETPRF with IDT calculated using the KAUST-LLNL- NUIG gasoline surrogate model [42] at different pressures 

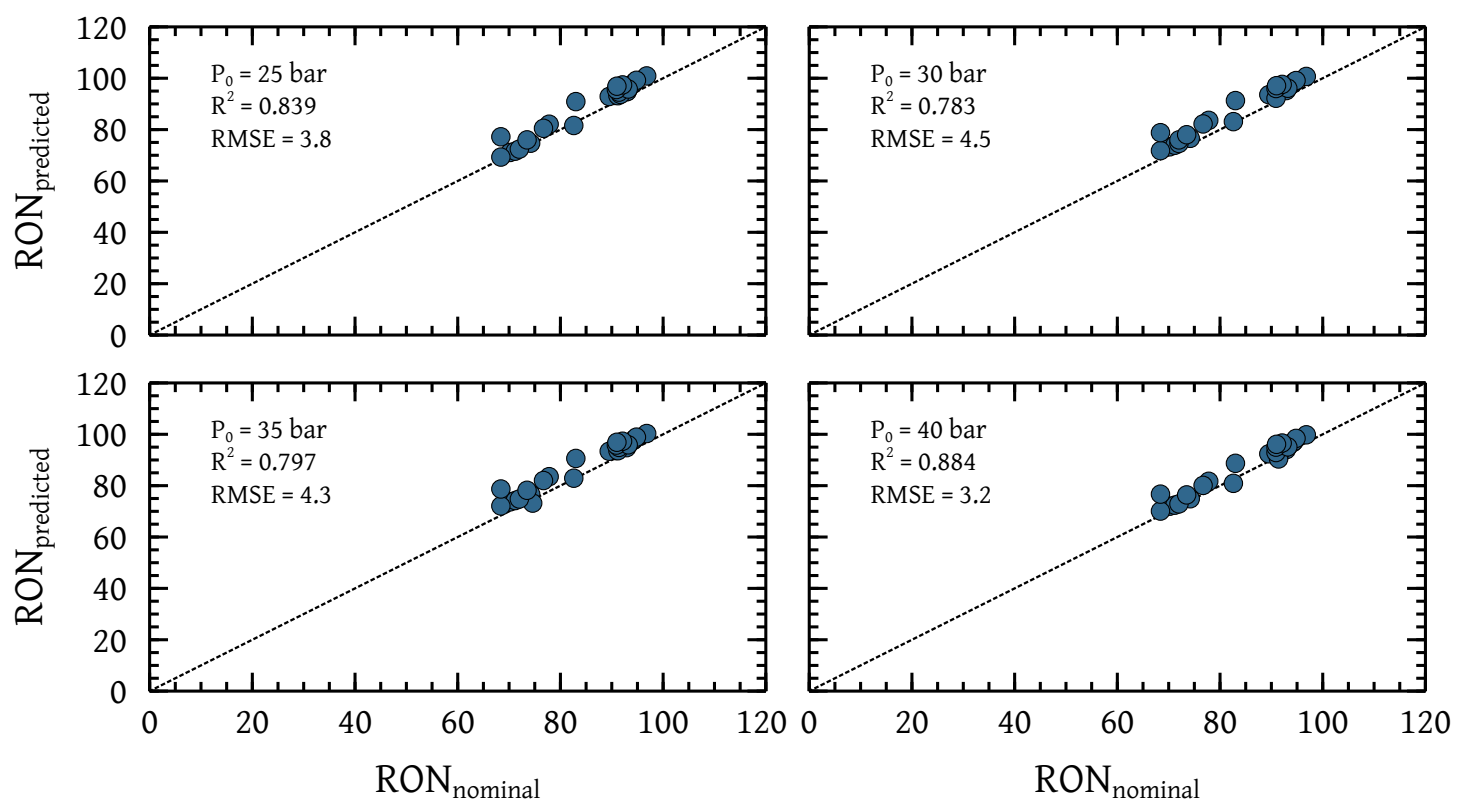

(a)
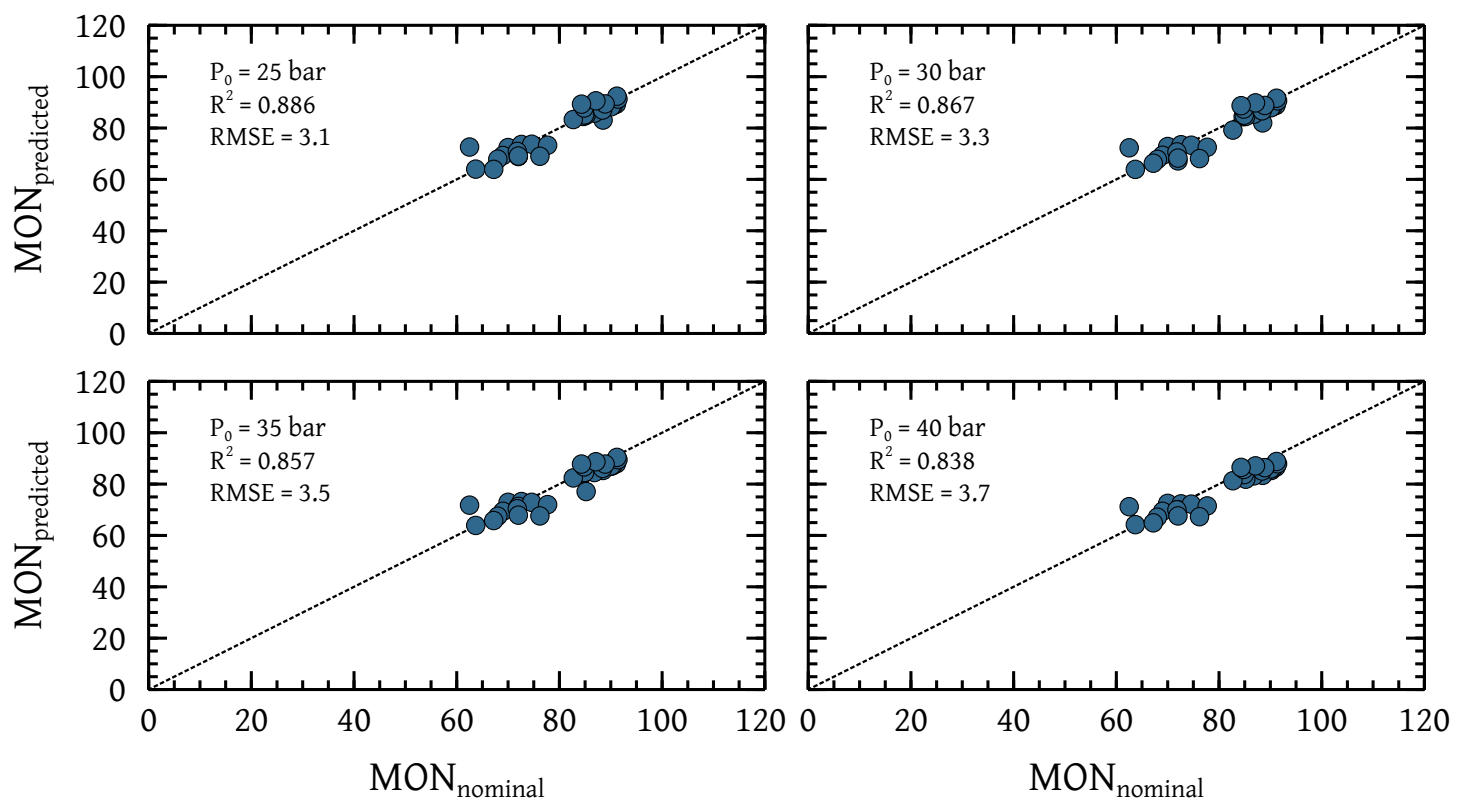

(b)

Figure 8: Predicted and nominal (a) RON and (b) MON of MCSB with IDT calculated using the KAUST-LLNL-NUIG gasoline surrogate model [42] at different pressures 
The present methodology has been shown to be applicable for a range of mixtures wherein the IDT is simulated using a chemical kinetic model. However, the methodology could be equally valuable in predicting the RON and MON of mixtures for which only experimental measurements of homogeneous gas-phase IDT are available. A prediction methodology based on experimental measurements could be valuable in situations wherein detailed chemical kinetic models do not exist or when real gasoline fuel mixtures are studied and simulating their IDT requires complex surrogate mixtures. It is to be noted that STs and RCMs have non-idealities [73, 74, 75] associated with IDT measurements particularly for fuels with longer IDT [75, 76]. Bradley et al. [77] investigated the differences in IDT of stoichiometric iso-octane in 7 different RCMs available worldwide; observing differences in IDTs at low and intermediate temperatures. The differences in measured IDT were attributed to three possible causes as discussed in [77]: (i) heat loss after the end of compression (ii) reactions that could occur during compression (iii) rebound of the piston and non- uniform ignition. More details on uncertainties and issues with RCM operation are available in [76].

To this end, the correlations in Eq. (2) obtained using simulated IDT are validated against an extensive set of experimental IDTs obtained from literature. IDTs obtained from STs and RCMs are used for validation; all IDTs used in the present study are given in Table 2 along with the facility used and their references. Some measurements employ RCM for low temperature measurements and ST for high temperature measurements and are indicated in Table 2 as ST (HT). In some cases, the IDT required to predict $\mathrm{RON} / \mathrm{MON}$ at the respective measurement pressures were not available, so the IDT was obtained by linear interpolation as indicated in Table 2, Experimental IDT measurements at pressures other than those used in the present study were also observed in certain cases, so the exponent $n$ and coefficients $a$ and $b$ were obtained by linear interpolation as indicated in Table 2 the linear interpolation of the exponent $n$ and coefficients $a$ and $b$ are shown in Fig. $S_{4}$ in Supplementary Material.

Comparisons between predicted and nominal RON/MON are given in Fig. 9 The correlations obtained are able to predict $\mathrm{RON} / \mathrm{MON}$ with great degree of confidence, particularly in the higher $\mathrm{ON}$ range. It is to be noted that the ON measurements by ASTM standards [3, 4] utilize a digital counter setting for RON/MON greater than 40. Per the standard, RON/MON measurements are acceptable only above ON 40, and in spite of this, the RON/MON measurements of pure components below 40 were reasonably well predicted as shown in Table 2. The error in predictions of RON and MON with experimentally obtained IDT is shown in Fig. S10. 


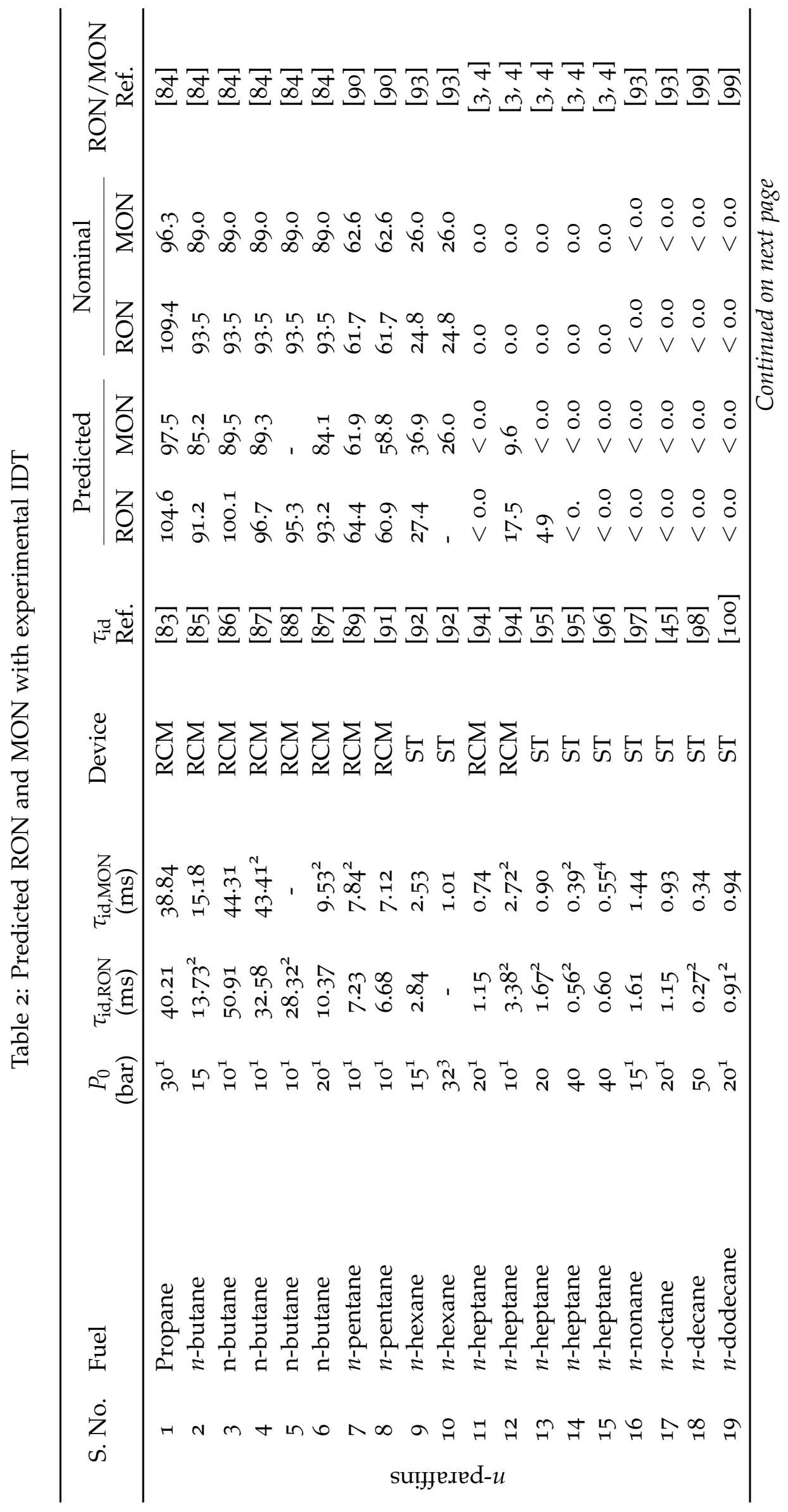




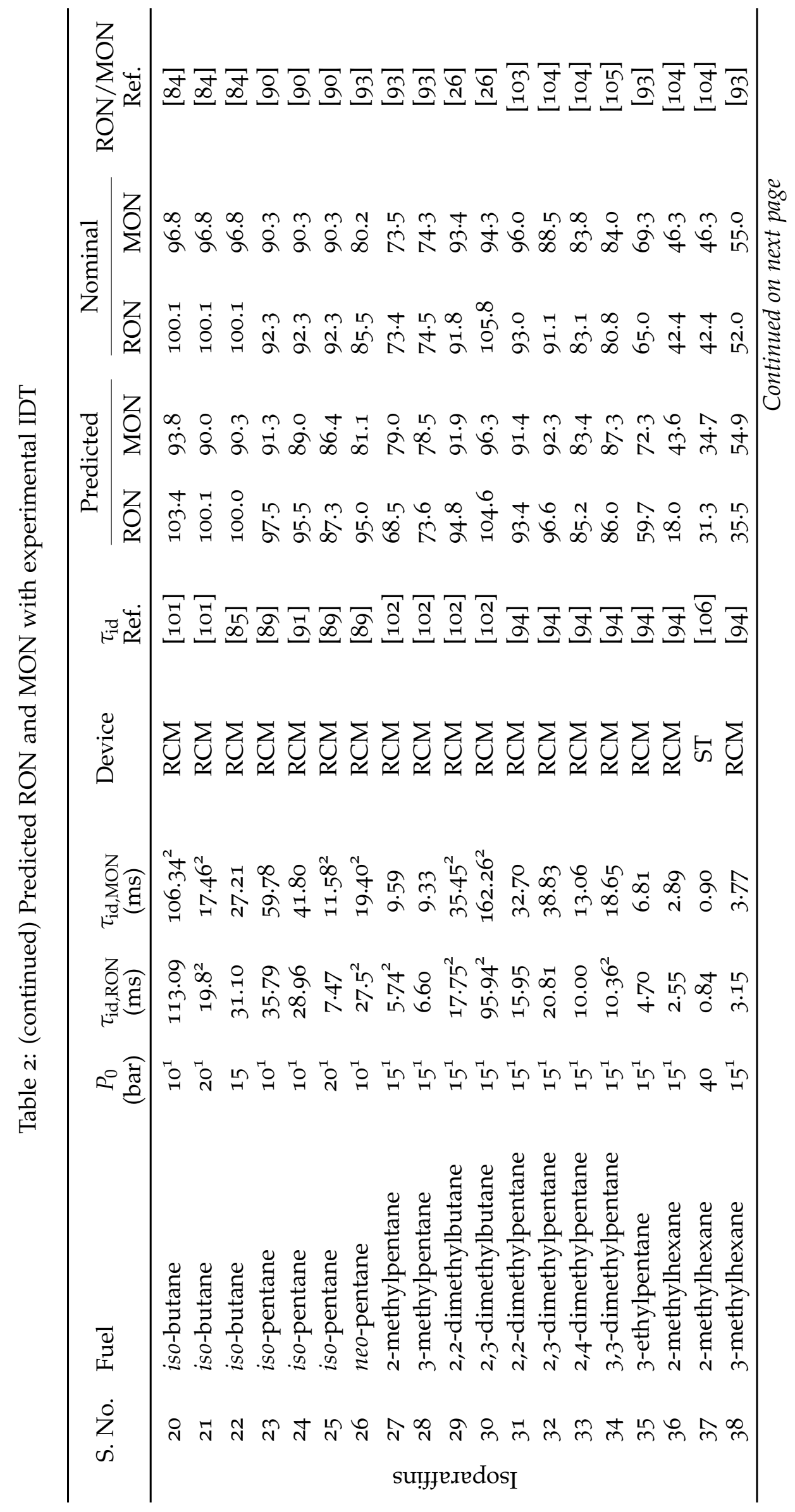




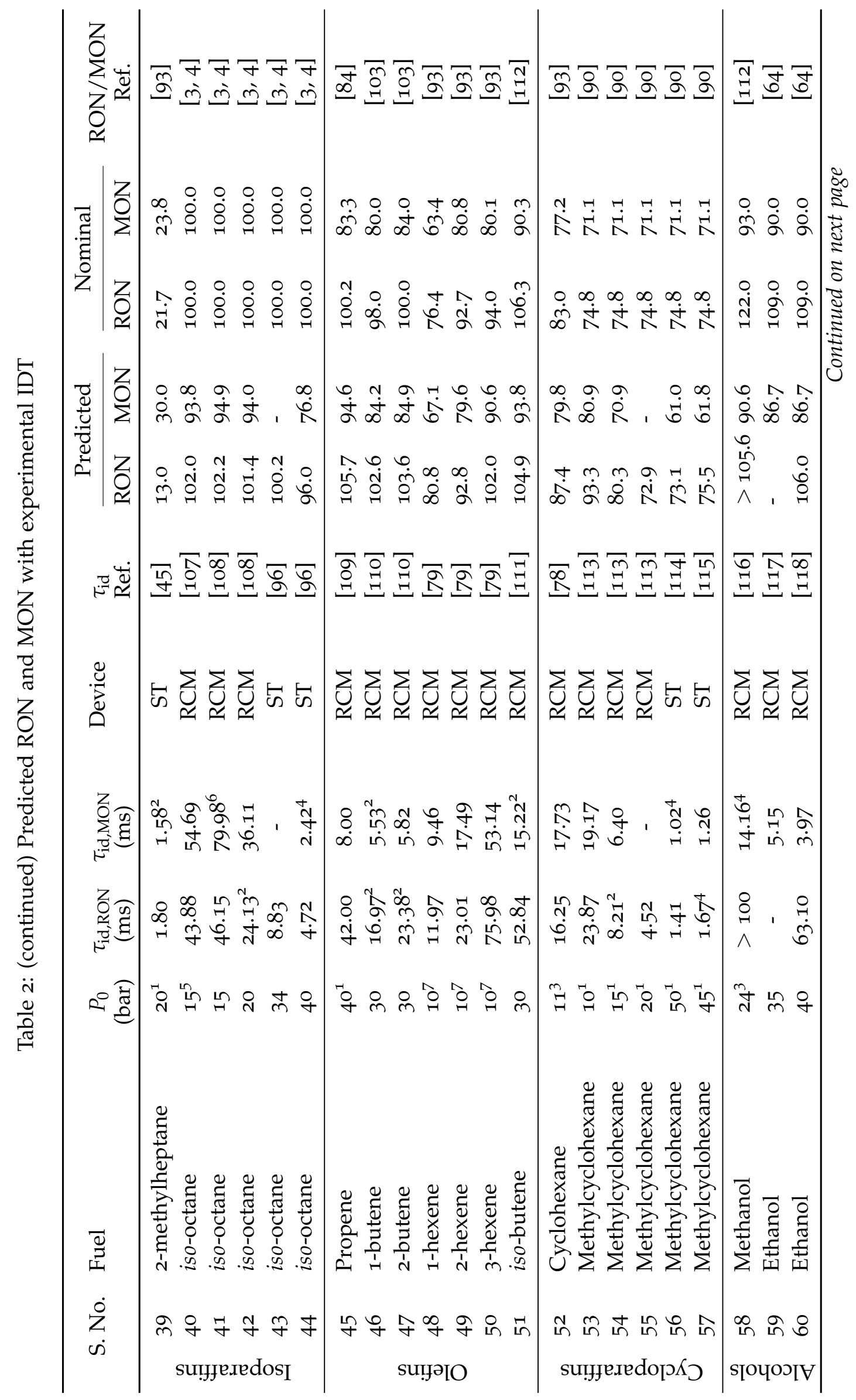




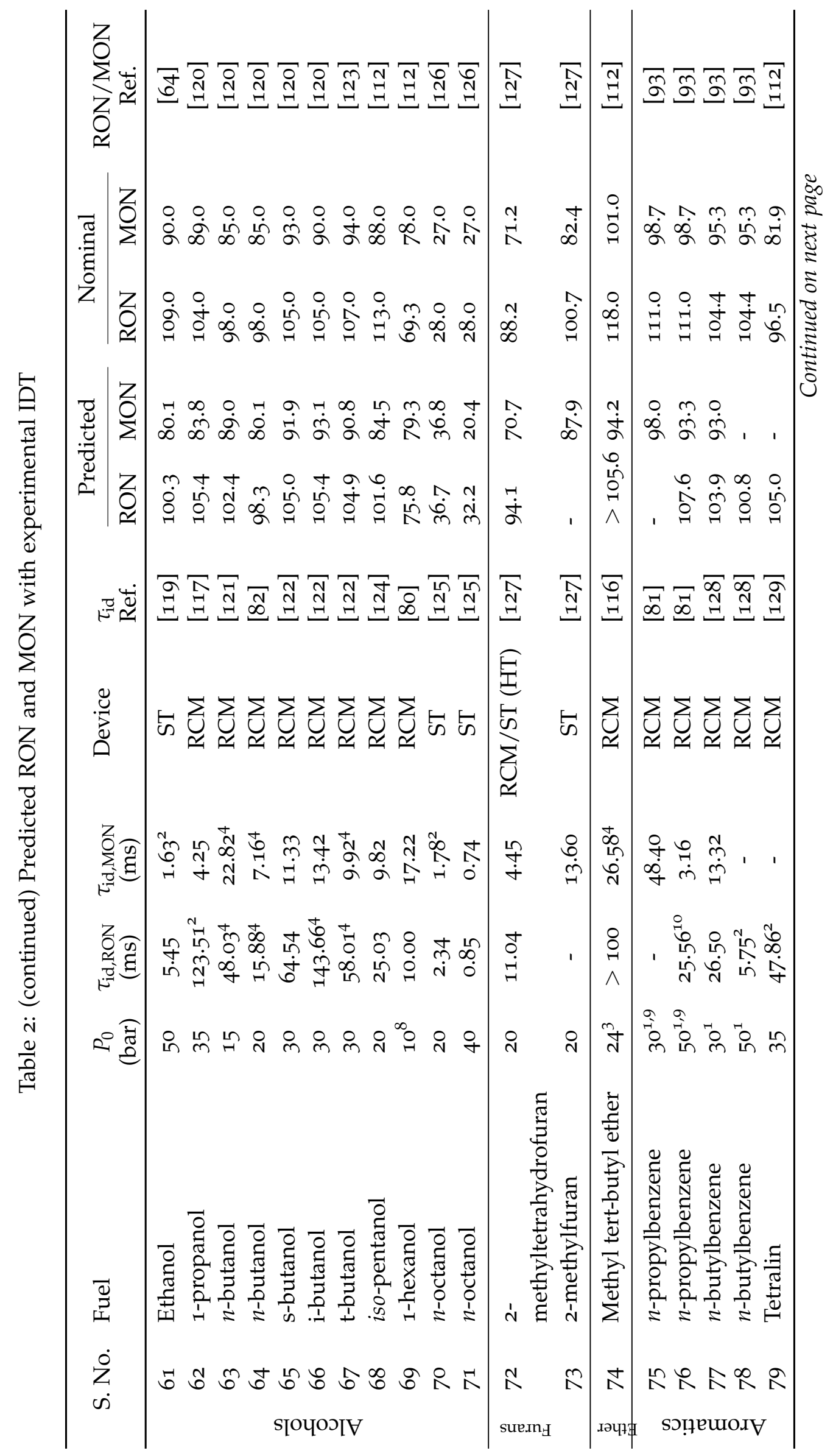




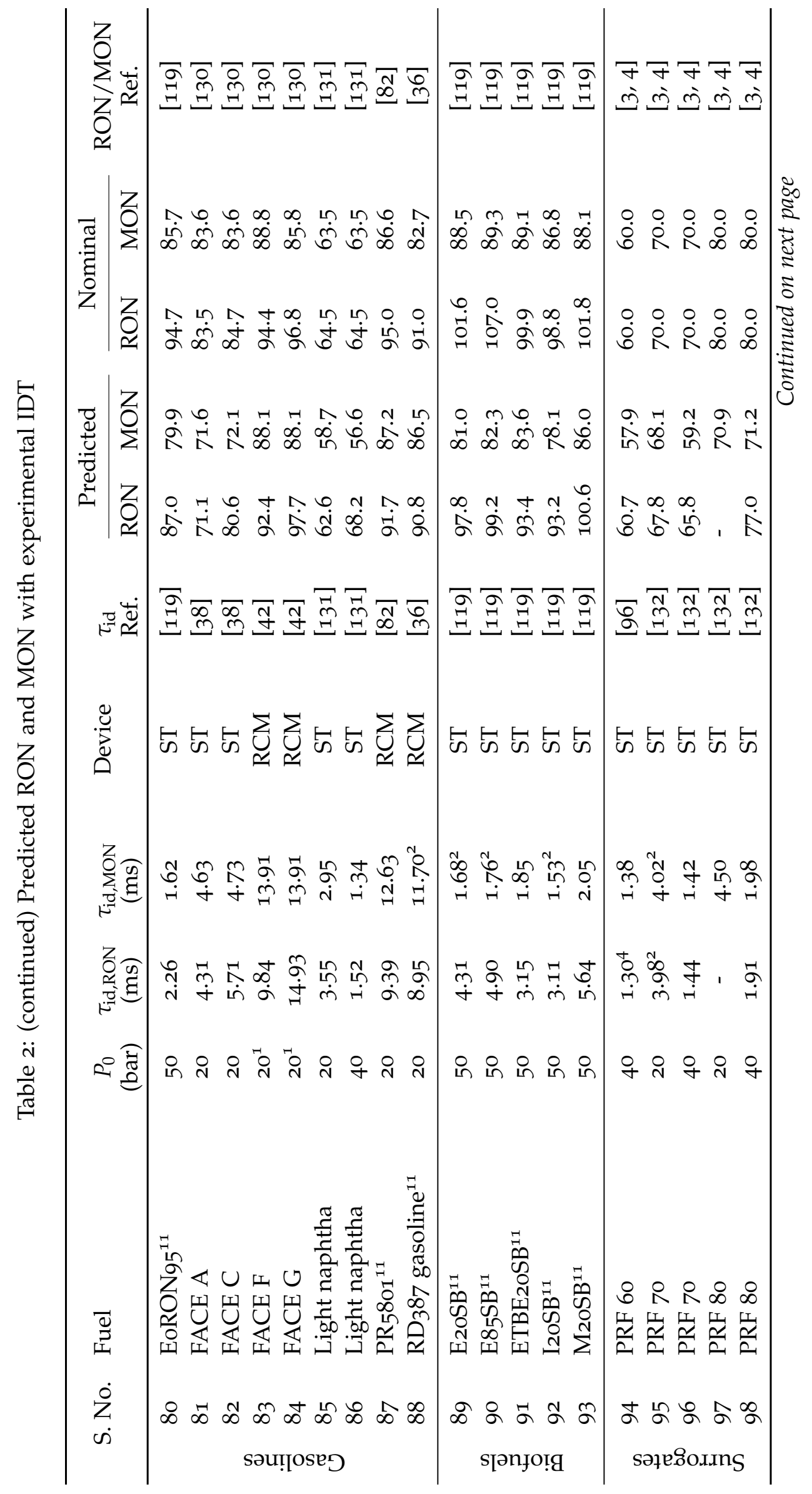




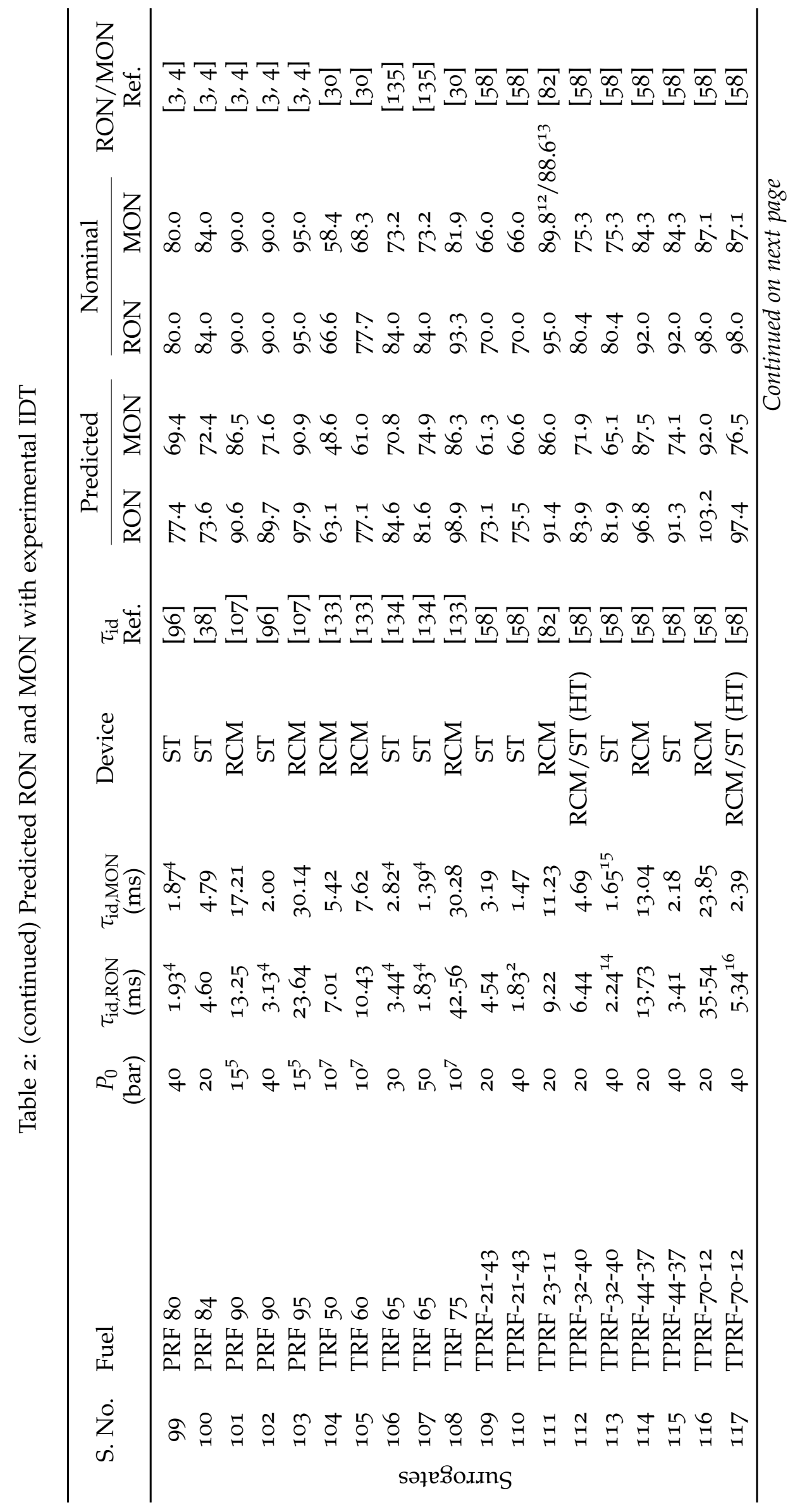




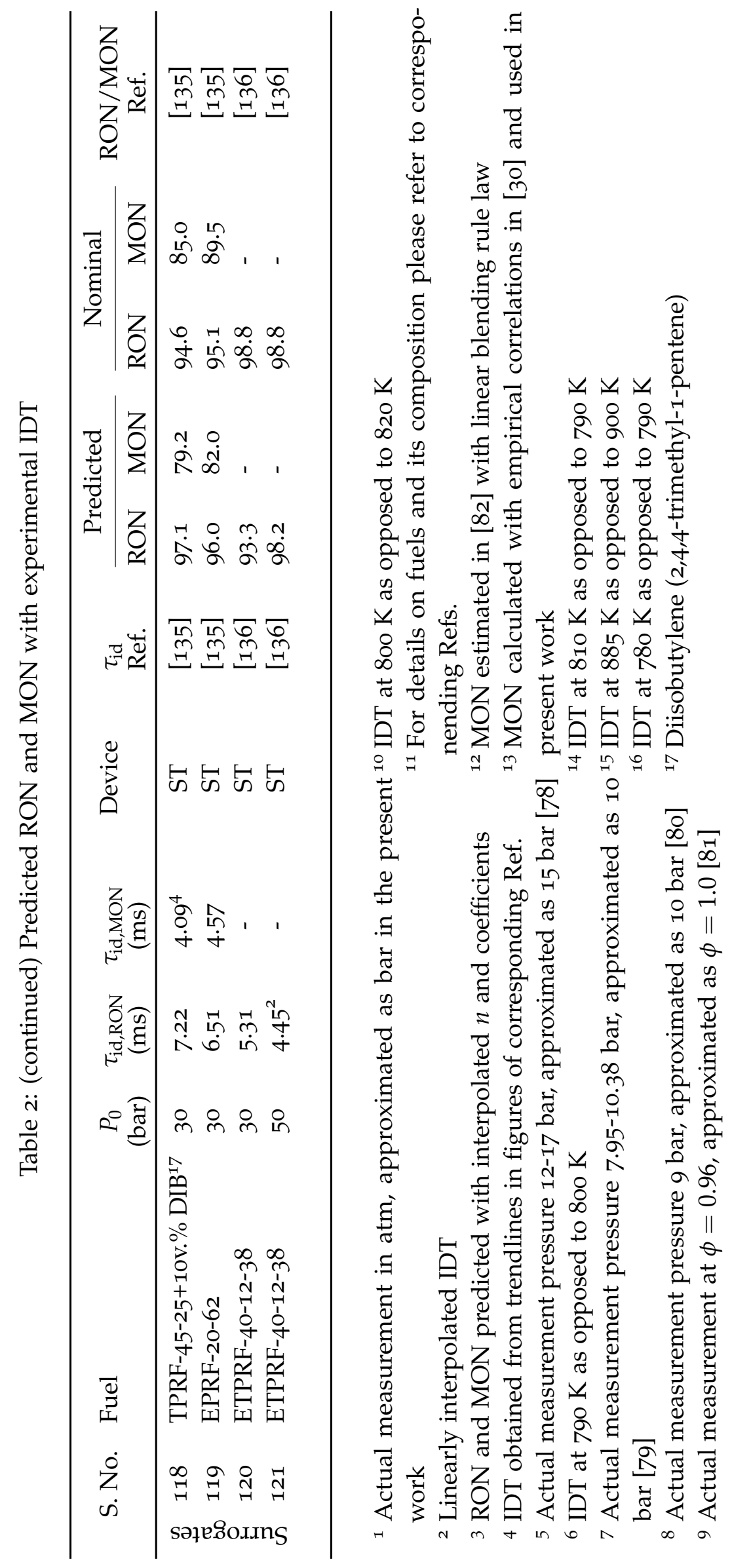



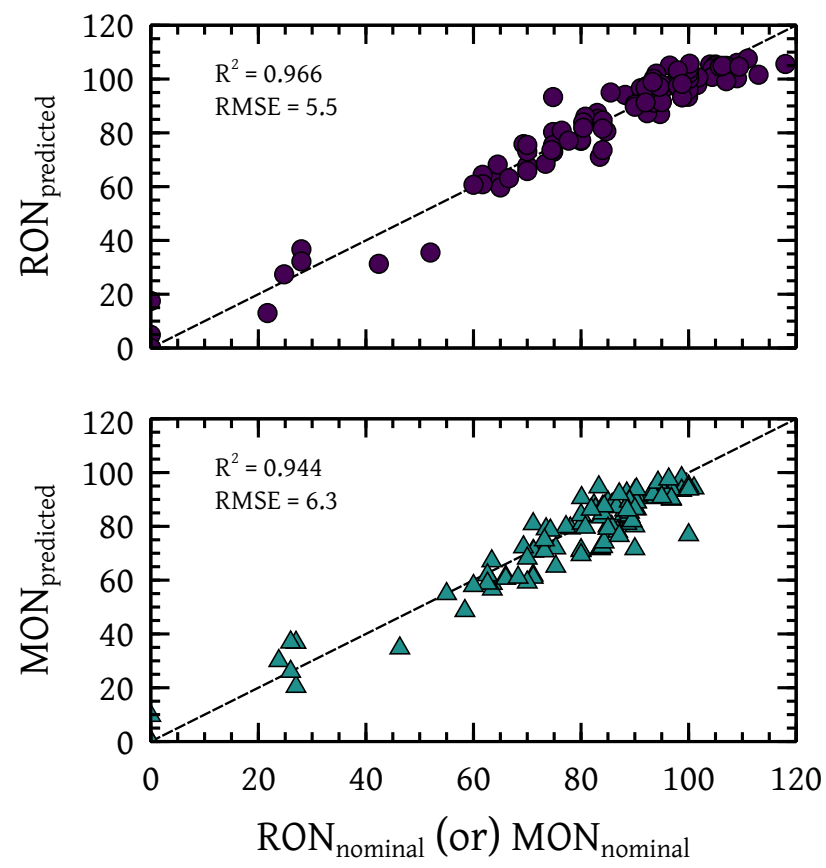

Figure 9: Comparison between predicted and nominal RON/MON with experimental IDT in Table 2

\subsection{Validation with condition "beyond $\mathrm{RON}^{\prime}$}

As pressure/temperature history in modern SI engines have deviated from typical conditions in CFR engines [59, 10, 48, 137], it is imperative to identify conditions in homogeneous reactors that are relevant to such modern SI engines. It should be noted that while end-gas autoignition near the peak cylinder temperature and pressure, the chemical reactions leading to ignition start much earlier. It is not unrealistic to expect that the end-gas partially reacts at $600-700 \mathrm{~K}$ during the compression stroke and while the flame is propagating. The partially reacted mixture will have modified chemistry at the time of ignition. The understanding of autoignition chemistry at these conditions could provide insights on tailoring future fuels for such engines.

For quantitative evaluations of the antiknock quality of fuels at conditions "beyond RON", correlations were developed with the same methodology as discussed above. With RON-like and MON-like temperatures given in Table $\mathrm{I}$, the the temperatures corresponding to $k=0.5,-0.5$ and -1.0 were determined by linear interpolation and extrapolation to obtain temperatures where IDT could be related with AKI $(k=0.5)$, and OI (at $k=-0.5,-1.0)$. From the previously obtained 31 set of coefficients and exponents, i.e., correlations with IDT in the same functional form as Eq. (2), the coefficients and exponents $a, b$ and $n$ corresponding to these temperatures were obtained 
and used in estimating AKI $(k=0.5)$, and OI (at $k=-0.5,-1.0)$ with IDT of TRFs and TPRFs at the same temperatures. The exponent and coefficients for $k=0.5,-0.5$ and -1.0 is given in Tables 3 and 4 . Comparisons with predicted and nominal OI at different $k$ values are shown in Fig. 10. Panel $10(\mathrm{a})$ shows predicted AKI, i.e., at $k=0.5$ at 40 bar with the nominal values, while panel $\mathrm{IO}(\mathrm{b})$ shows predicted values at $k=-0.5$ at 20 bar and panel $1 \mathrm{O}(\mathrm{c})$ shows $k=-1.0$ at 45 bar. It can be observed that the high $R^{2}$ values indicate great degree of accuracy in predicting OI at these conditions, which enables future IDT measurements to be focused on conditions relevant to modern SI engines.

Table 3: Exponent $n$ and coefficients $a, b$ in Eq. (2) to predict AKI.

\begin{tabular}{ccccc}
\hline $\mathrm{P}_{0}[$ bar $]$ & $\mathrm{T}_{0}[\mathrm{~K}]$ & $\mathrm{n}$ & $\mathrm{a}$ & $\mathrm{b}$ \\
\hline 10 & 750 & 0.90 & -230.34 & 103.04 \\
15 & 770 & 0.92 & -150.67 & 103.25 \\
20 & 790 & 0.91 & -108.84 & 103.74 \\
25 & 800 & 0.93 & -86.87 & 103.87 \\
30 & 820 & 0.90 & -70.81 & 104.67 \\
35 & 830 & 0.90 & -60.36 & 105.01 \\
40 & 850 & 0.86 & -54.13 & 106.33 \\
45 & 870 & 0.83 & -50.78 & 108.22 \\
50 & 880 & 0.84 & -46.05 & 108.86 \\
55 & 900 & 0.85 & -44.26 & 111.12 \\
60 & 920 & 0.89 & -41.72 & 113.44 \\
\hline
\end{tabular}

Table 4: Exponent $n$ and coefficients $a, b$ in Eq. (2) to predict OI.

\begin{tabular}{|c|c|c|c|c|c|c|c|c|}
\hline \multirow[b]{2}{*}{$\mathrm{P}_{0}[\mathrm{bar}]$} & \multicolumn{4}{|c|}{$k=-1.0$} & \multicolumn{4}{|c|}{$k=-0.5$} \\
\hline & $\mathrm{T}_{0}[\mathrm{~K}]$ & $\mathrm{n}$ & $\mathrm{a}$ & $\mathrm{b}$ & $\mathrm{T}_{0}[\mathrm{~K}]$ & $\mathrm{n}$ & a & $b$ \\
\hline 10 & - & - & - & - & 710 & -1.06 & -482.06 & 112.39 \\
\hline 15 & - & - & - & - & 710 & -1.28 & -558.90 & 111.97 \\
\hline 20 & - & - & - & - & 720 & -1.35 & -420.47 & 111.94 \\
\hline 25 & - & - & - & - & 720 & -1.49 & -452.25 & 111.79 \\
\hline 30 & - & - & - & - & 730 & -1.48 & -308.31 & 112.06 \\
\hline 35 & - & - & - & - & 730 & -1.58 & -316.35 & 111.98 \\
\hline 40 & - & - & - & - & 740 & -1.56 & -217.71 & 112.11 \\
\hline 45 & 700 & -1.83 & -1340.68 & $117 \cdot 56$ & 750 & -1.52 & -151.98 & 112.45 \\
\hline 50 & 710 & -1.80 & -800.67 & 117.73 & 760 & -1.48 & -109.87 & 112.76 \\
\hline 55 & 720 & -1.77 & -491.01 & 117.93 & 780 & -1.32 & -67.22 & 113.45 \\
\hline 60 & 750 & -1.55 & -145.16 & 118.48 & 800 & -1.19 & -48.21 & 114.19 \\
\hline
\end{tabular}




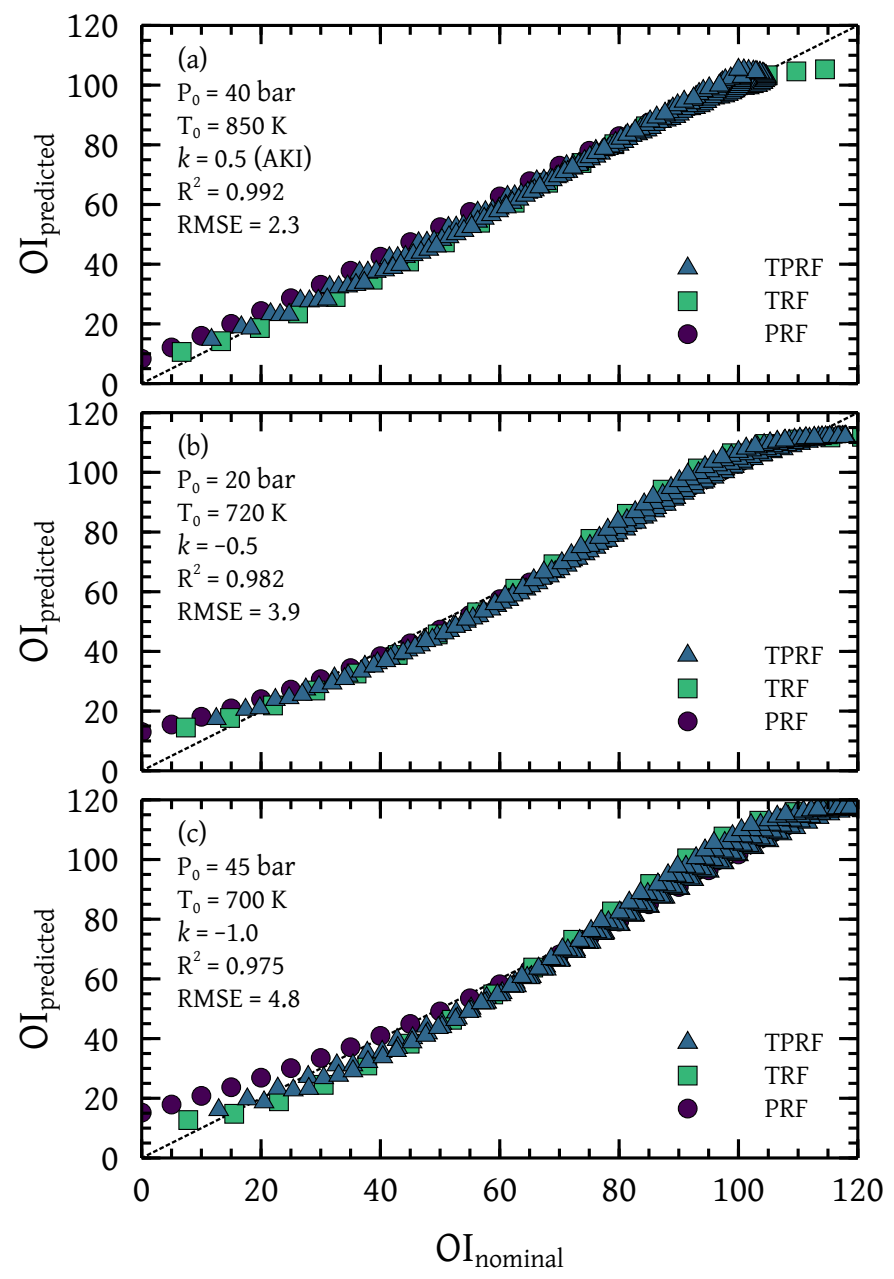

Figure 10: Comparison between predicted and nominal OI at (a) $P_{0}=40$ bar and $k=0.5(\mathrm{AKI})(\mathrm{b}) P_{0}=20$ bar and $k=-0.5$ (c) $P_{0}=45$ bar and $k=-1.0$

\section{UNCERTAINTY ANALYSIS}

IDT measurements in ST and RCM are subject to uncertainties from several sources, which stem from uncertainties in pressure, temperature, and mixture composition. Details on uncertainties in ignition delay measurements in ST and RCM are available in [76, 138]. Note that these uncertainties are not random errors, but systematic errors that arise due to facility effects. A detailed uncertainty analysis of the chemical kinetic model used requires the use of Monte Carlo techniques and Bayesian-like methods: minimization using polynomial chaos expansion. The application of such techniques 
Table 5: Uncertainty in coefficients $a, b$ in Eq. 2) to predict RON and MON

\begin{tabular}{cccccc}
\hline & \multicolumn{2}{c}{ RON } & \multicolumn{2}{c}{ MON } \\
\cline { 2 - 3 } \cline { 5 - 6 } $\mathrm{P}_{0}[\mathrm{bar}]$ & $\mathrm{a}$ & $\mathrm{b}$ & $\mathrm{a}$ & $\mathrm{b}$ \\
\hline 10 & $296.01 \pm 40.89$ & $106.11 \pm 2.31$ & & $206.26 \pm 26.32$ & $97.68 \pm 2.09$ \\
15 & $234.57 \pm 34.64$ & $106.60 \pm 2.56$ & & $138.00 \pm 18.31$ & $97.83 \pm 2.21$ \\
20 & $179.68 \pm 28.35$ & $106.62 \pm 2.75$ & & $101.85 \pm 13.68$ & $98.45 \pm 2.35$ \\
25 & $132.07 \pm 21.89$ & $106.10 \pm 2.79$ & $85.05 \pm 11.70$ & $99.32 \pm 2.55$ \\
30 & $95.91 \pm 16.22$ & $105.58 \pm 2.73$ & $74.92 \pm 10.79$ & $100.29 \pm 2.84$ \\
35 & $73.28 \pm 12.16$ & $105.64 \pm 2.67$ & $67.81 \pm 10.37$ & $101.47 \pm 3.24$ \\
40 & $61.85 \pm 9.89$ & $106.59 \pm 2.76$ & $61.22 \pm 10.24$ & $102.59 \pm 3.77$ \\
45 & $56.32 \pm 8.79$ & $108.05 \pm 2.99$ & $53.35 \pm 10.20$ & $103.15 \pm 4.47$ \\
50 & $51.65 \pm 7.92$ & $109.45 \pm 3.24$ & & $43.19 \pm 9.89$ & $103.10 \pm 5.42$ \\
\hline
\end{tabular}

and methods is beyond the scope of the present work. A simplified approach was following where we assumed that IDT calculated from chemical kinetic simulations have a worst case uncertainty of $100 \%$. The uncertainty in ON measurement was taken as the reproducibility limit for RON, i.e., 1.2 [3]. For the uncertainty in IDT and ON measurement, the uncertainty in the predictions of fit parameters and the ON obtained with Eq. (2) was calculated with [139], which predicted the uncertainty by linear error propagation theory. The uncertainties in fit parameters are shown in Table 5 . The uncertainty in predictions of $\mathrm{ON}$ considering the uncertainties stated above are shown in Fig. S20, indicated by the prediction band. The uncertainties in ON prediction at other pressures are shown in Fig. $S_{22}$.

The uncertainty in the prediction of $\mathrm{RON} / \mathrm{MON}$ with uncertainties relevant to practical devices is discussed here. Uncertainties associated with ignition delay measurements are typically in the range of $10-20 \%$ [138, 140, 141]. Assuming a maximum uncertainty of $\pm 20 \%$ together with the uncertainties in the fit parameters given in Table 5, the uncertainties associated with estimation of RON and MON at 20 and 40 bar are shown in Fig. 11 . Uncertainties in the estimation of RON and MON at different pressures with $\pm 20 \%$ uncertainty in IDT is given in Fig. S22. As can be observed, large uncertainties occur in the lower $\mathrm{ON}$ range due to steeper variation of $\mathrm{ON}$ with IDT. However, for longer IDT, where most uncertainties in measurements occur due to departure from idealities, the uncertainty in $\mathrm{RON} / \mathrm{MON}$ estimations are very low. In the range of $\mathrm{ON}$ measurements. i.e., 40-100 the average uncertainties of $\mathrm{RON} / \mathrm{MON}$ predictions were calculated to be $\pm 4.0 / 3.2$ and $\pm 3.8 / 4.3$ at 20 and 40 bar, respectively. The lower uncertainties in the higher $\mathrm{ON}$ range make the method ideal for estimating $\mathrm{ON}$ of gasoline like fuels, however, for reactive fuels the estimations are subject to large uncertainties. 

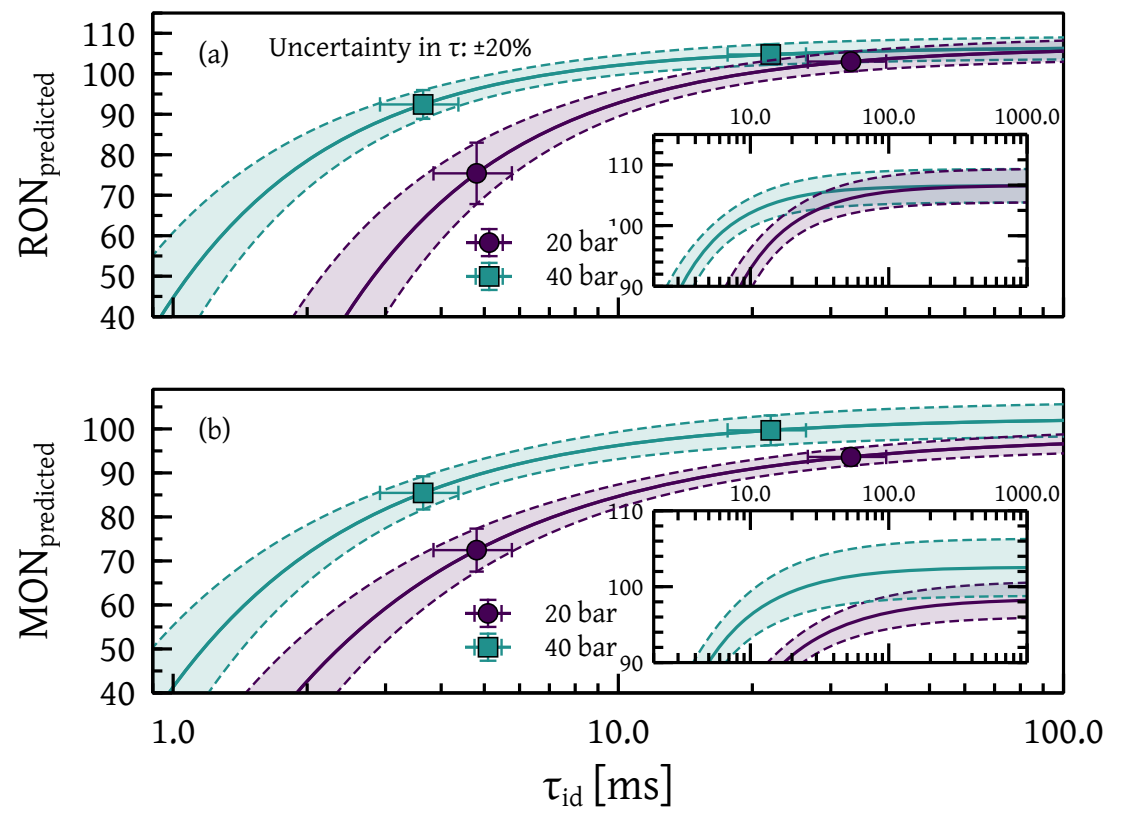

Figure 11: Uncertainty in estimation of (a) RON and (b) MON (bottom) at 20 and 40 bar for $\pm 20 \%$ uncertainty in IDT . Inset represents higher ON range.

\section{CONCLUDING REMARKS}

This work presents correlations of RON and MON with homogeneous gas-phase IDT at different pressures. The basic premise of this work is that at specific conditions of pressure and temperature, the IDT of a PRF and its RON/MON are correlated. The correlations were developing using IDT simulations of PRF using the KAUST-LLNLNUIG gasoline surrogate chemical kinetic model. The correlations obtained with PRF were then tested using simulated IDT from other chemical kinetic models, and similar trends in various models demonstrated the broad applicability and robustness of the present methodology. The correlations were also extended to predict $\mathrm{RON}$ and MON of TRF, TPRF, ERF, EPRF, ETPRF, and multicomponent surrogate mixtures. The RON and MON predicted with the correlations showed a reasonable level of accuracy, making it appropriate as first approximation of a fuel's antiknock quality.

As all the RONs and MONs were predicted with IDT calculated from chemical kinetic models, it was imperative to test the correlations with experimentally obtained IDT from literature data. The correlations, when applied to experimental IDT from literature, were able to predict RONs and MON with reasonable accuracy. Equations to predict IDT for a fuel with given RON and MON are also provided, which provides an idea on the ignition delay a fuel would have at RON- like and MON-like conditions at 
different pressures. During the course of this work, a large amount of data at RON-like and MON- like conditions was not available, particularly at RON-like conditions, as these fall in the low temperature regime which has gathered considerable interest in recent years. In some cases, IDT at the exact RON-like and MON-like conditions were not available, hence had to be interpolated to validate the correlations. Future measurements of IDT at the proposed RON-like and MON-like conditions would be highly beneficial in evaluating RON/MON and thereby sensitivity, as modern trends of downsizing and turbocharging spark-ignition engines demand fuels that have lower MON for a given RON. Uncertainty analysis was also carried out to assess uncertainties in estimating RON/MON with experimentally obtained IDT. For long IDTs, the uncertainties associated with RON/MON estimation were low in comparison to the large uncertainties that could occur during experimental measurements.

\section{ACKNOWLEDGMENTS}

The research reported in this paper was funded by Saudi Aramco and the Clean Combustion Research Center at King Abdullah University of Science and Technology under the FUELCOM program. 


\section{REFERENCES}

[1] G. T. Kalghatgi, Fuel/engine interactions, SAE Internationaldoi:10.4271/R-409.

[2] G. Edgar, Measurement of knock characteristics of gasoline in terms of a standard fuel, Industrial \& Engineering Chemistry 19 (1) (1927) 145-146. doi:10.1021/ ie50205a049.

[3] ASTM D2699-13b, Standard test method for research octane number of sparkignition engine fuel, ASTM Internationaddoi:10.1520/D2699.

[4] ASTM D2700-16, Standard test method for motor octane number of spark-ignition engine fuel, ASTM Internationaldoi:10.1520/D2700-16.

[5] J. Griffiths, Negative temperature-coefficient of reaction rate during hydrocarbon oxidation, Journal of the Chemical Society D: Chemical Communications (9) (1969) 483b-484. doi:10.1039/C2969000483B.

[6] I. A. Leenson, G. B. Sergeev, Negative temperature coefficient in chemical reactions, Russian Chemical Reviews 53 (5) (1984) 417-434. doi:10.1070/ RC1984v053n05ABEH003060.

[7] W. R. Leppard, The chemical origin of fuel octane sensitivity, SAE Technical paper 902137. doi:10.4271/902137.

[8] G. T. Kalghatgi, Fuel anti-knock quality - Part I. Engine studies, SAE Technical Paper 2001-01-3584. doi:10.4271/2001-01-3584.

[9] G. T. Kalghatgi, Fuel anti-knock quality - Part II. Vehicle studies-how relevant is motor octane number MON in modern engines?, SAE Technical Paper 2001-013585. doi:10.4271/2001-01-3585.

[10] V. Mittal, J. B. Heywood, The shift in relevance of fuel RON and MON to knock onset in modern SI engines over the last 70 years, SAE International Journal of Engines 2 (2009-01-2622) (2009) 1-10. doi:10.4271/2009-01-2622.

[11] W. G. Lovell, J. M. Campbell, T. A. Boyd, Detonation characteristics of some paraffin hydrocarbons, Industrial \& Engineering Chemistry 23 (1) (1931) 26-29. doi:10.1021/ie50253a015.

[12] W. G. Lovell, J. M. Campbell, T. A. Boyd, Detonation characteristics of some aliphatic olefin hydrocarbons, Industrial \& Engineering Chemistry 23 (5) (1931) 555-558. doi:10.1021/ie50257a021.

[13] W. G. Lovell, J. M. Campbell, T. A. Boyd, Knocking characteristics of naphthene hydrocarbons, Industrial \& Engineering Chemistry 25 (10) (1933) 1107-1110. doi:10.1021/ie50286a011. 
[14] W. G. Lovell, J. M. Campbell, T. A. Boyd, Knocking characteristics of hydrocarbons determined from compression ratios at which individual compounds begin to knock under specified conditions, Industrial \& Engineering Chemistry 26 (10) (1934) 1105-1108. doi:10.1021/ie50298a019.

[15] W. G. Lovell, Knocking characteristics of hydrocarbons, Industrial \& Engineering Chemistry 40 (12) (1948) 2388-2438. doi:10.1021/ie50468a033.

[16] D. Downs, A. D. Walsh, R. W. Wheeler, A study of the reactions that lead to 'knock' in the spark-ignition engine, Philosophical Transactions of the Royal Society of London A: Mathematical, Physical and Engineering Sciences 243 (870) (1951) 463-524. doi:10.1098/rsta.1951.0009.

[17] D. Downs, S. Griffiths, R. Wheeler, Preflame reactions in the spark ignition engine. the influence of TEL and other antiknocks, J. Inst. Petrol 49 (469) (1963) 8.

[18] A. J. Pahnke, P. M. Cohen, B. M. Sturgis, Preflame oxidation of hydrocarbons in a motored engine, Industrial \& Engineering Chemistry 46 (5) (1954) 1024-1029. doi:10.1021/ie50533a058.

[19] C. Walcutt, J. M. Mason, E. Rifkin, Effect of preflame oxidation reactions on engine knock, Industrial \& Engineering Chemistry 46 (5) (1954) 1029-1034. doi: 10.1021/ie50533a059.

[20] A. Walsh, The knock ratings of fuels, in: Symposium (International) on Combustion, Vol. 9, Elsevier, 1963, pp. 1046-1055. doi:10.1016/S0082-0784(63) 80110-1.

[21] C. K. Westbrook, W. J. Pitz, W. R. Leppard, The autoignition chemistry of paraffinic fuels and pro-knock and anti-knock additives: a detailed chemical kinetic study, SAE Technical Paper 912314. doi:10.4271/912314.

[22] P. C. Anderson, J. M. Sharkey, R. P. Walsh, Calculation of the research octane number of motor gasolines from gas chromatographic data and a new approach to motor gasoline quality control, Journal of the Institute of Petroleum 58 (560) (1972) 83 .

[23] M. E. Myers Jr, J. Stollsteimer, A. M. Wims, Determination of gasoline octane numbers from chemical composition, Analytical Chemistry 47 (13) (1975) 23012304. doi:10.1021/ac60363a015.

[24] J. J. Kelly, C. H. Barlow, T. M. Jinguji, J. B. Callis, Prediction of gasoline octane numbers from near-infrared spectral features in the range $660-1215 \mathrm{~nm}$, Analytical Chemistry 61 (4) (1989) 313-320. doi:10.1021/ac00179a007. 
[25] J. A. Van Leeuwen, R. J. Jonker, R. Gill, Octane number prediction based on gas chromatographic analysis with non-linear regression techniques, Chemometrics and intelligent laboratory systems 25 (2) (1994) 325-340. doi:10.1016/ 0169-7439(94)85051-8.

[26] P. Ghosh, K. J. Hickey, S. B. Jaffe, Development of a detailed gasoline compositionbased octane model, Industrial \& engineering chemistry research 45 (1) (2006) 337-345. doi:10.1021/ie050811h.

[27] W. Pitz, N. Cernansky, F. Dryer, F. Egolfopoulos, J. Farrell, D. Friend, H. Pitsch, Development of an experimental database and chemical kinetic models for surrogate gasoline fuels, SAE technical paper (2007-01-0175) (2007) 0175. doi: 10.4271/2007-01-0175.

[28] T. Wallington, E. Kaiser, J. Farrell, Automotive fuels and internal combustion engines: a chemical perspective, Chemical Society Reviews 35 (4) (2006) 335-347. doi:10.1039/B410469M

[29] N. Morgan, A. Smallbone, A. Bhave, M. Kraft, R. Cracknell, G. Kalghatgi, Mapping surrogate gasoline compositions into RON/MON space, Combustion and Flame 157 (6) (2010) 1122-1131. doi:10.1016/j.combustflame.2010.02.003.

[30] G. Kalghatgi, H. Babiker, J. Badra, A simple method to predict knock using toluene, iso-octane, n-heptane blends (TPRF) as gasoline surrogates, SAE International Journal of Engines 7 (2015) 663-672. doi:10.4271/2015-01-0757

[31] A. S. AlRamadan, S. M. Sarathy, M. Khurshid, J. Badra, A blending rule for octane numbers of PRFs and TPRFs with ethanol, Fuel 180 (2016) 175-186. doi: $10.1016 / j$.fuel.2016.04.032.

[32] E. Singh, J. Badra, M. Mehl, S. M. Sarathy, Chemical kinetic insights into the octane number and octane sensitivity of gasoline surrogate mixtures, Energy \& Fuels 31 (2) (2017) 1945-1960. doi:10.1021/acs.energyfuels.6b02659.

[33] G. Kalghatgi, R. Head, J. Chang, Y. Viollet, H. Babiker, A. Amer, An alternative method based on toluene/n-heptane surrogate fuels for rating the anti-knock quality of practical gasolines, SAE International Journal of Fuels and Lubricants 2014-01-2609. doi:10.4271/2014-01-2609.

[34] T. M. Foong, K. J. Morganti, M. J. Brear, G. da Silva, Y. Yang, F. L. Dryer, The octane numbers of ethanol blended with gasoline and its surrogates, Fuel 115 (2014) 727-739. doi:10.1016/j.fuel.2013.07.105

[35] M. Mehl, J.-Y. Chen, W. J. Pitz, S. M. Sarathy, C. K. Westbrook, An approach for formulating surrogates for gasoline with application toward a reduced surrogate 
mechanism for CFD engine modeling, Energy \& Fuels 25 (11) (2011) 5215-5223. doi:10.1021/ef201099y.

[36] G. Kukkadapu, K. Kumar, C.-J. Sung, M. Mehl, W. J. Pitz, Experimental and surrogate modeling study of gasoline ignition in a rapid compression machine, Combustion and Flame 159 (10) (2012) 3066-3078. doi:10.1016/j.combustflame 2012.05.008.

[37] G. Kukkadapu, K. Kumar, C.-J. Sung, M. Mehl, W. J. Pitz, Autoignition of gasoline and its surrogates in a rapid compression machine, Proceedings of the Combustion Institute 34 (1) (2013) 345-352. doi:10.1016/j . proci.2012.06.135

[38] S. M. Sarathy, G. Kukkadapu, M. Mehl, W. Wang, T. Javed, S. Park, M. A. Oehlschlaeger, A. Farooq, W. J. Pitz, C.-J. Sung, Ignition of alkane-rich FACE gasoline fuels and their surrogate mixtures, Proceedings of the Combustion Institute 35 (1) (2015) 249-257. doi:10.1016/j proci.2014.05.122.

[39] K. Anand, Y. Ra, R. Reitz, B. Bunting, Surrogate model development for fuels for advanced combustion engines, Energy \& Fuels 25 (4) (2011) 1474-1484. doi: $10.1021 /$ ef $101719 a$

[40] A. Ahmed, G. Goteng, V. S. Shankar, K. Al-Qurashi, W. L. Roberts, S. M. Sarathy, A computational methodology for formulating gasoline surrogate fuels with accurate physical and chemical kinetic properties, Fuel 143 (2015) 290-300. doi: 10.1016/j.fuel.2014.11.022.

[41] Y. Ra, R. D. Reitz, A combustion model for multi-component fuels using a physical surrogate group chemistry representation (PSGCR), Combustion and Flame 162 (10) (2015) 3456-3481. doi:10.1016/j.combustflame.2015.05.014.

[42] S. M. Sarathy, G. Kukkadapu, M. Mehl, T. Javed, A. Ahmed, N. Naser, A. Tekawade, G. Kosiba, M. AlAbbad, E. Singh, et al., Compositional effects on the ignition of FACE gasolines, Combustion and Flame 169 (2016) 171-193. doi:10.1016/j.combustflame.2016.04.010.

[43] C. K. Westbrook, M. Mehl, W. J. Pitz, M. Sjöberg, Chemical kinetics of octane sensitivity in a spark-ignition engine, Combustion and Flame 175 (2017) 2-15. doi:10.1016/j.combustflame.2016.05.022.

[44] J. Griffiths, P. Halford-Maw, C. Mohamed, Spontaneous ignition delays as a diagnostic of the propensity of alkanes to cause engine knock, Combustion and flame 111 (4) (1997) 327-337. doi:10.1016/S0010-2180(97)00004-7.

[45] S. M. Sarathy, T. Javed, F. Karsenty, A. Heufer, W. Wang, S. Park, A. Elwardany, A. Farooq, C. K. Westbrook, W. J. Pitz, M. A. Oehlschlaeger, G. Dayma, 
H. J. Curran, P. Dagaut, A comprehensive combustion chemistry study of 2,5-dimethylhexane, Combustion and Flame 161 (6) (2014) 1444-1459. doi: $10.1016 / j$.combustflame.2013.12.010.

[46] J. A. Badra, N. Bokhumseen, N. Mulla, S. M. Sarathy, A. Farooq, G. Kalghatgi, P. Gaillard, A methodology to relate octane numbers of binary and ternary nheptane, iso-octane and toluene mixtures with simulated ignition delay times, Fuel 160 (2015) 458-469. doi:10.1016/j.fuel.2015.08.007.

[47] D. Bradley, R. A. Head, Engine autoignition: The relationship between octane numbers and autoignition delay times, Combustion and Flame 147 (3) (2006) 171-184. doi:10.1016/j.combustflame.2006.09.001.

[48] N. Naser, S. Y. Yang, G. Kalghatgi, S. H. Chung, Relating the octane numbers of fuels to ignition delay times measured in an ignition quality tester (IQT), Fuel 187 (2017) 117-127. doi:10.1016/j.fuel.2016.09.013.

[49] T. Lu, C. K. Law, Toward accommodating realistic fuel chemistry in large-scale computations, Progress in Energy and Combustion Science 35 (2) (2009) 192-215. doi:10.1016/j.pecs.2008.10.002.

[50] G. Shibata, T. Urushihara, Auto-ignition characteristics of hydrocarbons and development of HCCI fuel index, Tech. rep., SAE Technical Paper (2007). doi: 10.4271/2007-01-0220.

[51] V. H. Rapp, W. J. Cannella, J.-Y. Chen, R. W. Dibble, Predicting fuel performance for future HCCI engines, Combustion Science and Technology 185 (5) (2013) 735-748. doi:10.1080/00102202.2012.750309.

[52] I. Truedsson, W. Cannella, B. Johansson, M. Tuner, Development of new test method for evaluating HCCI fuel performance, Tech. rep., SAE Technical Paper (2014). doi:10.4271/2014-01-2667.

[53] K. E. Niemeyer, S. R. Daly, W. J. Cannella, C. L. Hagen, A novel fuel performance index for low-temperature combustion engines based on operating envelopes in light-duty driving cycle simulations, Journal of Engineering for Gas Turbines and Power 137 (10) (2015) 101601. doi:10.1115/1.4029948.

[54] K. E. Niemeyer, S. R. Daly, W. J. Cannella, C. L. Hagen, Investigation of the LTC fuel performance index for oxygenated reference fuel blends, Fuel 155 (2015) 14-24. doi:10.1016/j.fuel.2015.04.010.

[55] M. Waqas, N. Naser, M. Sarathy, K. Morganti, K. Al-Qurashi, B. Johansson, Blending octane number of ethanol in HCCI, SI and CI combustion modes, SAE International Journal of Fuels and Lubricants 9 (2016-01-2298) (2016) 659-682. 
[56] T. M. Foong, M. J. Brear, K. J. Morganti, G. da Silva, Y. Yang, F. L. Dryer, Modeling end-gas autoignition of ethanol/gasoline surrogate blends in the cooperative fuel research engine, Energy \& Fuels 31 (3) (2017) 2378-2389. doi:10.1021/acs. energyfuels.6b02380.

[57] G. T. Kalghatgi, Auto-ignition quality of practical fuels and implications for fuel requirements of future SI and HCCI engines, SAE Technical Paper 2005-01-0239. doi:10.4271/2005-01-0239.

[58] T. Javed, C. Lee, M. AlAbbad, K. Djebbi, M. Beshir, J. Badra, H. Curran, A. Farooq, Ignition studies of n-heptane/iso-octane/toluene blends, Combustion and Flame 171 (2016) 223-233. doi:10.1016/j.combustflame.2016.06.008

[59] M. Mehl, T. Faravelli, F. Giavazzi, E. Ranzi, P. Scorletti, A. Tardani, D. Terna, Detailed chemistry promotes understanding of octane numbers and gasoline sensitivity, Energy \& fuels 20 (6) (2006) 2391-2398. doi:10.1021/ef060339s.

[6o] D. Goodwin, H. K. Moffat, R. L. Speth, Cantera: An object-oriented software toolkit for chemical kinetics, thermodynamics and transport processes, 2009, http://www. cantera.org/

[61] M. Mehl, W. J. Pitz, C. K. Westbrook, H. J. Curran, Kinetic modeling of gasoline surrogate components and mixtures under engine conditions, Proceedings of the Combustion Institute 33 (1) (2011) 193-200. doi:10.1016/j.proci.2010.05.027.

[62] L. Cai, H. Pitsch, Optimized chemical mechanism for combustion of gasoline surrogate fuels, Combustion and Flame 162 (5) (2015) 1623-1637. doi:10.1016/ j.combustflame.2014.11.018.

[63] A. Frassoldati, A. Cuoci, T. Faravelli, E. Ranzi, Kinetic modeling of the oxidation of ethanol and gasoline surrogate mixtures, Combustion Science and Technology 182 (4-6) (2010) 653-667. doi:10.1080/00102200903466368

[64] I. Hunwartzen, Modification of CFR test engine unit to determine octane numbers of pure alcohols and gasoline-alcohol blends, SAE Technical Paper 820002. doi: 10.4271/820002.

[65] T. M. Foong, K. J. Morganti, M. J. Brear, G. da Silva, Y. Yang, F. L. Dryer, The effect of charge cooling on the RON of ethanol/gasoline blends, SAE International Journal of Fuels and Lubricants 6 (2013-01-0886) (2013) 34-43. doi:10.4271/ 2013-01-0886.

[66] E. Kasseris, J. B. Heywood, Charge cooling effects on knock limits in SI DI engines using gasoline/ethanol blends: Part 1-Quantifying charge cooling 2012-01-1275. doi:10.4271/2012-01-1275 
[67] E. Kasseris, J. B. Heywood, Charge cooling effects on knock limits in SI DI engines using gasoline/ethanol blends: Part 2-Effective octane numbers, SAE International Journal of Fuels and Lubricants 5 (2012-01-1284) (2012) 844-854. doi:10.4271/2012-01-1284.

[68] R. A. Stein, D. Polovina, K. Roth, M. Foster, M. Lynskey, T. Whiting, J. E. Anderson, M. H. Shelby, T. G. Leone, S. VanderGriend, Effect of heat of vaporization, chemical octane, and sensitivity on knock limit for ethanol-gasoline blends, SAE International Journal of Fuels and Lubricants 5 (2012-01-1277) (2012) 823-843. doi:10.4271/2012-01-1277.

[69] C. S. Sluder, J. P. Szybist, R. L. McCormick, M. A. Ratcliff, B. T. Zigler, Exploring the relationship between octane sensitivity and heat-of-vaporization, SAE International Journal of Fuels and Lubricants 9 (2016-01-0836) (2016) 80-90. doi:10.4271/2016-01-0836.

[70] J. P. Szybist, D. A. Splitter, Pressure and temperature effects on fuels with varying octane sensitivity at high load in SI engines, Combustion and Flame 177 (2017) 49-66. doi:10.1016/j.combustflame.2016.12.002.

[71] G. T. Kalghatgi, K. Nakata, K. Mogi, Octane appetite studies in direct injection spark ignition DISI engines, SAE Technical Paper 2005-01-0244. doi:10.4271/ 2005-01-0244.

[72] V. Mittal, J. B. Heywood, The relevance of fuel RON and MON to knock onset in modern SI engines, SAE Technical Paper 2008-01-2414. doi:10.4271/ 2008-01-2414.

[73] D. Davidson, R. Hanson, Interpreting shock tube ignition data, International Journal of Chemical Kinetics 36 (9) (2004) 510-523. doi:10.1002/kin.20024.

[74] E. L. Petersen, R. K. Hanson, Nonideal effects behind reflected shock waves in a high-pressure shock tube, Shock Waves 10 (6) (2001) 405-420. doi:10.1007/ PL00004051.

[75] M. Chaos, F. L. Dryer, Chemical-kinetic modeling of ignition delay: Considerations in interpreting shock tube data, International Journal of Chemical Kinetics 42 (3) (2010) 143-150. doi:10.1002/kin.20471.

[76] C.-J. Sung, H. J. Curran, Using rapid compression machines for chemical kinetics studies, Progress in Energy and Combustion Science 44 (2014) 1-18. doi:10. $1016 / j \cdot$ pecs.2014.04.001

[77] D. Bradley, M. Lawes, M. Materego, Interpretation of auto-ignition delay times measured in different rapid compression machines, in: 25th International Collo- 
quium on the Dynamics of Explosions and Reactive systems, Leeds, 2015. URL http://eprints . whiterose .ac .uk/87762/

[78] O. Lemaire, M. Ribaucour, M. Carlier, R. Minetti, The production of benzene in the low-temperature oxidation of cyclohexane, cyclohexene, and cyclohexa-1,3-diene, Combustion and flame 127 (1) (2001) 1971-1980. doi:10.1016/S0010-2180(01) 00301-7.

[79] G. Vanhove, M. Ribaucour, R. Minetti, On the influence of the position of the double bond on the low-temperature chemistry of hexenes, Proceedings of the Combustion Institute 30 (1) (2005) 1065-1072. doi:10.1016/j.proci.2004.08 042 .

[8o] K. Heufer, J. Bugler, H. Curran, A comparison of longer alkane and alcohol ignition including new experimental results for n-pentanol and n-hexanol, Proceedings of the Combustion Institute 34 (1) (2013) 511-518. doi:10.1016/j proci.2012.05.103

[81] D. Darcy, H. Nakamura, C. J. Tobin, M. Mehl, W. K. Metcalfe, W. J. Pitz, C. K. Westbrook, H. J. Curran, A high-pressure rapid compression machine study of n-propylbenzene ignition, Combustion and Flame 161 (1) (2014) 65-74. doi: $10.1016 / j$.combustflame.2013.08.001.

[82] E. Agbro, A. S. Tomlin, M. Lawes, S. Park, S. M. Sarathy, The influence of nbutanol blending on the ignition delay times of gasoline and its surrogate at high pressures, Fuel 187 (2017) 211-219. doi:10.1016/j.fuel.2016.09.052.

[83] S. M. Gallagher, H. J. Curran, W. Metcalfe, D. Healy, J. M. Simmie, G. Bourque, A rapid compression machine study of the oxidation of propane in the negative temperature coefficient regime, Combustion and Flame 153 (1) (2008) 316-333. doi:10.1016/j.combustflame.2007.09.004.

[84] K. J. Morganti, T. M. Foong, M. J. Brear, G. da Silva, Y. Yang, F. L. Dryer, The research and motor octane numbers of liquefied petroleum gas (LPG), Fuel 108 (2013) 797-811. doi:10.1016/j.fuel.2013.01.072

[85] S. Gersen, A. V. Mokhov, J. Darmeveil, H. B. Levinsky, Ignition properties of n-butane and iso-butane in a rapid compression machine, Combustion and Flame 157 (2) (2010) 240-245. doi:10.1016/j.combustflame.2009.10.012.

[86] J. F. Griffiths, P. A. Halford-Maw, D. J. Rose, Fundamental features of hydrocarbon autoignition in a rapid compression machine, Combustion and flame 95 (3) (1993) 291-306. doi:10.1016/0010-2180(93) 90133-N. 
[87] D. Healy, N. Donato, C. Aul, E. Petersen, C. Zinner, G. Bourque, H. Curran, n-butane: Ignition delay measurements at high pressure and detailed chemical kinetic simulations, Combustion and Flame 157 (8) (2010) 1526-1539. doi:10. 1016/j.combustflame.2010.01.016

[88] R. Minetti, M. Ribaucour, M. Carlier, C. Fittschen, L. R. Sochet, Experimental and modeling study of oxidation and autoignition of butane at high pressure, Combustion and Flame 96 (3) (1994) 201-211. doi:10.1016/0010-2180(94) 90009-4.

[89] J. Bugler, B. Marks, O. Mathieu, R. Archuleta, A. Camou, C. Grégoire, K. A. Heufer, E. L. Petersen, H. J. Curran, An ignition delay time and chemical kinetic modeling study of the pentane isomers, Combustion and Flame 163 (2016) 138156. doi:10.1016/j.combustflame.2015.09.014.

[9o] A. De Klerk, Fischer-Tropsch Refining, John Wiley \& Sons, 2012. doi:10.1002/ 9783527635603

[91] B. Marks, O. Mathieu, R. Archuleta, E. L. Petersen, J. Bugler, A. Heufer, H. J. Curran, Ignition delay time measurements and modeling of n-pentane and iso-pentane at elevated pressures, in: 51st AIAA Aerospace Sciences Meeting including the New Horizons Forum and Aerospace Exposition, 2013, p. 160. doi:10.2514/6.2013-160.

[92] K. Zhang, C. Banyon, C. Togbé, P. Dagaut, J. Bugler, H. J. Curran, An experimental and kinetic modeling study of n-hexane oxidation, Combustion and Flame 162 (11) (2015) 4194-4207. doi:10.1016/j.combustflame.2015.08.001.

[93] J. C. Guibet, Carburants et moteurs, tome 1 et 2, publications de lInstitut Français du Pétrole, ed, Technip, Paris.

[94] E. J. Silke, H. J. Curran, J. M. Simmie, The influence of fuel structure on combustion as demonstrated by the isomers of heptane: a rapid compression machine study, Proceedings of the Combustion Institute 30 (2) (2005) 2639-2647. doi:10.1016/j.proci.2004.08.180

[95] M. Fikri, L. Cancino, M. Hartmann, C. Schulz, High-pressure shock-tube investigation of the impact of 3-pentanone on the ignition properties of primary reference fuels, Proceedings of the Combustion Institute 34 (1) (2013) 393-400. doi:10.1016/j.proci.2012.05.101

[96] K. Fieweger, R. Blumenthal, G. Adomeit, Self-ignition of SI engine model fuels: A shock tube investigation at high pressure, Combustion and Flame 109 (4) (1997) 599-619. doi:10.1016/S0010-2180(97)00049-7. 
[97] K. Yong, J. He, W. Zhang, L. Xian, C. Zhang, P. Li, X. Li, Shock tube study of n-nonane/air ignition over a wide range of temperatures, Fuel 188 (2017) 567-574. doi:10.1016/j.fuel.2016.09.054.

[98] U. Pfahl, K. Fieweger, G. Adomeit, Self-ignition of diesel-relevant hydrocarbon-air mixtures under engine conditions, in: Symposium (International) on Combustion, Vol. 26, Elsevier, 1996, pp. 781-789. doi:10.1016/S0082-0784(96)80287-6.

[99] V. Simanzhenkov, R. Idem, Crude oil chemistry, CRC Press, 2003.

[10o] S. S. Vasu, D. F. Davidson, Z. Hong, V. Vasudevan, R. K. Hanson, n-dodecane oxidation at high-pressures: Measurements of ignition delay times and $\mathrm{OH}$ concentration time-histories, Proceedings of the Combustion Institute 32 (1) (2009) 173-180. doi:10.1016/j.proci.2008.05.006

[101] D. Healy, N. S. Donato, C. J. Aul, E. L. Petersen, C. M. Zinner, G. Bourque, H. J. Curran, Isobutane ignition delay time measurements at high pressure and detailed chemical kinetic simulations, Combustion and Flame 157 (8) (2010) 1540-1551. doi:10.1016/j.combustflame.2010.01.011.

[102] K. Zhang, C. Banyon, J. Bugler, H. J. Curran, A kinetic modeling study on the oxidation of five hexane isomers, in: Proceedings of the 7 th European Combustion Meeting, Budapest, Hungary, 2015.

[103] R. Stone, Introduction to internal combustion engines, Springer, 1999. doi: 10.1007/978-1-349-14916-2.

[104] D. S. J. Jones, P. P. Pujadó, Handbook of petroleum processing, Springer Science \& Business Media, 2006. doi:10.1007/1-4020-2820-2.

[105] P. Leprince, Petroleum Refining: Vol. 3: Conversion Processes, Editions Technip, 2000.

[106] S. Y. Mohamed, L. Cai, F. Khaled, C. Banyon, Z. Wang, M. J. Al Rashidi, H. Pitsch, H. J. Curran, A. Farooq, S. M. Sarathy, Modeling ignition of a heptane isomer: improved thermodynamics, reaction pathways, kinetics, and rate rule optimizations for 2-methylhexane, The Journal of Physical Chemistry A 120 (14) (2016) 2201-2217. doi:10.1021/acs.jpca.6b00907.

[107] C. Callahan, T. Held, F. Dryer, R. Minetti, M. Ribaucour, L. Sochet, T. Faravelli, P. Gaffuri, E. Rani, Experimental data and kinetic modeling of primary reference fuel mixtures, in: Symposium (International) on Combustion, Vol. 26, Elsevier, 1996, pp. 739-746. doi:10.1016/S0082-0784(96)80282-7.

[108] N. Atef, G. Kukkadapu, S. Y. Mohamed, M. Al Rashidi, C. Banyon, M. Mehl, K. A. Heufer, E. F. Nasir, A. Alfazazi, A. K. Das, C. K. Westborrk, W. J. Pitz, 
T. Lu, A. Farooq, C.-J. Sung, H. J. Curran, S. M. Sarathy, A comprehensive isooctane combustion model with improved thermochemistry and chemical kinetics, Combustion and Flame 178 (2017) 111-134. doi:10.1016/j.combustflame.2016. 12.029 .

[109] S. M. Burke, U. Burke, R. Mc Donagh, O. Mathieu, I. Osorio, C. Keesee, A. Morones, E. L. Petersen, W. Wang, T. A. DeVerter, et al., An experimental and modeling study of propene oxidation. part 2: Ignition delay time and flame speed measurements, Combustion and Flame 162 (2) (2015) 296-314. doi:10.1016/j.combustflame.2014.07.032.

[110] Y. Li, C.-W. Zhou, K. P. Somers, K. Zhang, H. J. Curran, The oxidation of 2-butene: A high pressure ignition delay, kinetic modeling study and reactivity comparison with isobutene and 1-butene, Proceedings of the Combustion Institute 36 (1) (2017) 403-411. doi:10.1016/j.proci.2016.05.052

[111] C.-W. Zhou, Y. Li, E. O'Connor, K. P. Somers, S. Thion, C. Keesee, O. Mathieu, E. L. Petersen, T. A. DeVerter, M. A. Oehlschlaeger, et al., A comprehensive experimental and modeling study of isobutene oxidation, Combustion and Flame 167 (2016) 353-379. doi:10.1016/j.combustflame.2016.01.021.

[112] W. L. Kubic Jr, A group contribution method for estimating cetane and octane numbers, Tech. rep., Los Alamos National Lab.(LANL), Los Alamos, NM (United States) (2016).

[113] W. J. Pitz, C. V. Naik, T. N. Mhaoldúin, C. K. Westbrook, H. J. Curran, J. P. Orme, J. M. Simmie, Modeling and experimental investigation of methylcyclohexane ignition in a rapid compression machine, Proceedings of the combustion institute 31 (1) (2007) 267-275. doi:10.1016/j.proci.2006.08.041.

[114] J. Vanderover, M. A. Oehlschlaeger, Ignition time measurements for methylcylcohexane-and ethylcyclohexane-air mixtures at elevated pressures, International Journal of Chemical Kinetics 41 (2) (2009) 82-91. doi:10.1002/kin. 20370 .

[115] S. Vasu, N. N. Parikh, R. K. Hanson, Modeling and experimental investigation of methylcyclohexane ignition in a rapid compression machine, Proceedings of the

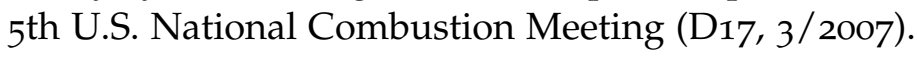

[116] D. Lee, Autoignition measurements for oxygenated fuels in a rapid compression machine, Ph.D. thesis, Massachusetts Institute of Technology (1993).

[117] S. B. Saharin, Vaporization and autoignition characteristics of ethanol and 1propanol droplets: influence of water, Ph.D. thesis, Université de Bourgogne (2013).

URL https://tel. archives-ouvertes.fr/tel-00909646 
[118] C. Lee, S. Vranckx, K. A. Heufer, S. V. Khomik, Y. Uygun, H. Olivier, R. X. Fernandez, On the chemical kinetics of ethanol oxidation: shock tube, rapid compression machine and detailed modeling study, Zeitschrift für Physikalische Chemie International journal of research in physical chemistry and chemical physics 226 (1) (2012) 1-28. doi:10.1524/zpch.2012.0185.

[119] S. Pischinger, M. Günther, O. Budak, Abnormal combustion phenomena with different fuels in a spark ignition engine with direct fuel injection, Combustion and Flame 175 (2017) 123-137. doi:10.1016/j.combustflame.2016.09.010.

[120] E. Christensen, J. Yanowitz, M. Ratcliff, R. L. McCormick, Renewable oxygenate blending effects on gasoline properties, Energy \& Fuels 25 (10) (2011) 4723-4733. doi:10.1021/es402793p.

[121] B. W. Weber, K. Kumar, Y. Zhang, C.-J. Sung, Autoignition of n-butanol at elevated pressure and low-to-intermediate temperature, Combustion and Flame 158 (5) (2011) 809-819. doi:10.1016/j.combustflame.2011.02.005

[122] B. W. Weber, C.-J. Sung, Comparative autoignition trends in butanol isomers at elevated pressure, Energy \& Fuels 27 (3) (2013) 1688-1698. doi:10.1021/ ef302195c.

[123] A. S. AlRamadan, J. Badra, T. Javed, M. Al-Abbad, N. Bokhumseen, P. Gaillard, H. Babiker, A. Farooq, S. M. Sarathy, Mixed butanols addition to gasoline surrogates: Shock tube ignition delay time measurements and chemical kinetic modeling, Combustion and Flame 162 (10) (2015) 3971-3979. doi: $10.1016 / j$.combustflame.2015.07.035.

[124] T. Tsujimura, W. J. Pitz, F. Gillespie, H. J. Curran, B. W. Weber, Y. Zhang, C.-J. Sung, Development of isopentanol reaction mechanism reproducing autoignition character at high and low temperatures, Energy \& Fuels 26 (8) (2012) 4871-4886. doi:10.1021/ef300879k.

[125] L. Cai, Y. Uygun, C. Togbé, H. Pitsch, H. Olivier, P. Dagaut, S. M. Sarathy, An experimental and modeling study of n-octanol combustion, Proceedings of the Combustion Institute 35 (1) (2015) 419-427. doi:10.1016/j.proci.2014.05.088

[126] M. Graboski, An analysis of alternatives for unleaded petrol additives for South Africa, http://www .unep.org/transport/pcfv/pdf/pubgraboskireport.pdf.

[127] A. Brassat, M. Thewes, M. Müther, S. Pischinger, C. Lee, R. X. Fernandes, H. Olivier, Y. Uygun, Analysis of the effects of certain alcohol and furanbased biofuels on controlled auto ignition, SAE Technical Paper 2012-01-1135. doi:10.4271/2012-01-1135. 
[128] H. Nakamura, D. Darcy, M. Mehl, C. J. Tobin, W. K. Metcalfe, W. J. Pitz, C. K. Westbrook, H. J. Curran, An experimental and modeling study of shock tube and rapid compression machine ignition of n-butylbenzene/air mixtures, Combustion and Flame 161 (1) (2014) 49-64. doi:10.1016/j.combustflame.2013.08.002.

[129] G. Kukkadapu, B. W. Weber, C.-J. Sung, Autoignition study of tetralin in a rapid compression machine at elevated pressures and low-to-intermediate temperatures, Fuel 159 (2015) 436-445. doi:10.1016/j.fuel.2015.06.093.

[130] W. Cannella, M. Foster, G. Gunter, W. Leppard, FACE gasolines and blends with ethanol: detailed characterization of physical and chemical properties (2014). URL http://www . crcao . com/reports/recentstudies2014/AVFL-24/AVFL-24\% 20FACE $\% 20$ Gasolines $\% 20$ Report $\% 20-\% 20071414$.pdf

[131] T. Javed, E. F. Nasir, A. Ahmed, J. Badra, K. Djebbi, M. Beshir, W. Ji, S. M. Sarathy, A. Farooq, Ignition delay measurements of light naphtha: A fully blended low octane fuel, Proceedings of the Combustion Institute 36 (1) (2017) 315-322. doi:10.1016/j.proci.2016.05.043

[132] M. AlAbbad, T. Javed, F. Khaled, J. Badra, A. Farooq, Ignition delay time measurements of primary reference fuel blends, Combustion and Flame 178 (2017) 205-216. doi:10.1016/j.combustflame.2016.12.027.

[133] R. Di Sante, Measurements of the auto-ignition of n-heptane/toluene mixtures using a rapid compression machine, Combustion and flame 159 (1) (2012) 55-63. doi:10.1016/j.combustflame.2011.05.020

[134] J. Herzler, M. Fikri, K. Hitzbleck, R. Starke, C. Schulz, P. Roth, G. T. Kalghatgi, Shock-tube study of the autoignition of n-heptane/toluene/air mixtures at intermediate temperatures and high pressures, Combustion and flame 149 (1) (2007) 25-31. doi:10.1016/j.combustflame.2006.12.015.

[135] M. Fikri, J. Herzler, R. Starke, C. Schulz, P. Roth, G. T. Kalghatgi, Autoignition of gasoline surrogates mixtures at intermediate temperatures and high pressures, Combustion and flame 152 (1) (2008) 276-281. doi:10.1016/j.combustflame 2007.07.010.

[136] L. Cancino, M. Fikri, A. Oliveira, C. Schulz, Autoignition of gasoline surrogate mixtures at intermediate temperatures and high pressures: Experimental and numerical approaches, Proceedings of the Combustion Institute 32 (1) (2009) 501-508. doi:10.1016/j.proci.2008.06.180

[137] G. T. Kalghatgi, The outlook for fuels for internal combustion engines, International Journal of Engine Research 15 (4) (2014) 383-398. doi:10.1177/ 1468087414526189 
[138] T. Javed, Combustion kinetic studies of gasolines and surrogates, Ph.D. thesis, King Abdullah University of Science and Technology (2016).

URL http://hdl.handle.net/10754/621837

[139] E. O. Lebigot, Uncertainties: A python package for calculations with uncertainties (2016).

URL https://pypi.python.org/pypi/uncertainties/

[140] X. He, M. Donovan, B. Zigler, T. Palmer, S. Walton, M. Wooldridge, A. Atreya, An experimental and modeling study of iso-octane ignition delay times under homogeneous charge compression ignition conditions, Combustion and Flame 142 (3) (2005) 266-275. doi:10.1016/j.combustflame.2005.02.014.

[141] B. Gauthier, D. F. Davidson, R. K. Hanson, Shock tube determination of ignition delay times in full-blend and surrogate fuel mixtures, Combustion and Flame 139 (4) (2004) 300-311. doi:10.1016/j.combustflame.2004.08.015. 
Table S1: Fuel matrix of PRF

\begin{tabular}{|c|c|c|c|c|c|c|}
\hline \multirow[t]{2}{*}{ Fuel } & \multicolumn{2}{|c|}{ Volume fraction } & \multicolumn{2}{|c|}{ Mole fraction } & \multirow[t]{2}{*}{$\mathrm{RON}^{1}$} & \multirow[t]{2}{*}{$\mathrm{MON}^{1}$} \\
\hline & iso-Octane & $n$-Heptane & iso-Octane & n-Heptane & & \\
\hline PRF o & 0.000 & 1.000 & 0.000 & 1.000 & 0.0 & 0.0 \\
\hline PRF 5 & 0.050 & 0.950 & 0.045 & 0.955 & 5.0 & 5.0 \\
\hline PRF 10 & 0.100 & 0.900 & 0.090 & 0.910 & 10.0 & 10.0 \\
\hline PRF 15 & 0.150 & 0.850 & 0.135 & 0.865 & 15.0 & 15.0 \\
\hline PRF 20 & 0.200 & 0.800 & 0.182 & 0.818 & 20.0 & 20.0 \\
\hline PRF 25 & 0.250 & 0.750 & 0.228 & 0.772 & 25.0 & 25.0 \\
\hline PRF 30 & 0.300 & 0.700 & 0.276 & 0.724 & 30.0 & 30.0 \\
\hline PRF 35 & 0.350 & 0.650 & 0.323 & 0.677 & $35 \cdot 0$ & 35.0 \\
\hline PRF 40 & 0.400 & 0.600 & 0.372 & 0.628 & 40.0 & 40.0 \\
\hline PRF 45 & 0.450 & 0.550 & 0.421 & 0.579 & $45 \cdot 0$ & $45 \cdot 0$ \\
\hline PRF 50 & 0.500 & 0.500 & 0.470 & 0.530 & 50.0 & 50.0 \\
\hline PRF 55 & 0.550 & 0.450 & 0.520 & 0.480 & 55.0 & 55.0 \\
\hline PRF 6o & 0.600 & 0.400 & 0.571 & 0.429 & 60.0 & 60.0 \\
\hline PRF 65 & 0.650 & 0.350 & 0.622 & 0.378 & 65.0 & 65.0 \\
\hline PRF 70 & 0.700 & 0.300 & 0.674 & 0.326 & 70.0 & 70.0 \\
\hline PRF 75 & 0.750 & 0.250 & 0.727 & 0.273 & 75.0 & 75.0 \\
\hline PRF 8o & 0.800 & 0.200 & 0.780 & 0.220 & 80.0 & 80.0 \\
\hline PRF 85 & 0.850 & 0.150 & 0.834 & 0.166 & 85.0 & 85.0 \\
\hline PRF 90 & 0.900 & 0.100 & 0.889 & 0.111 & 90.0 & 90.0 \\
\hline PRF 95 & 0.950 & 0.050 & 0.944 & 0.056 & 95.0 & 95.0 \\
\hline PRF 100 & 1.000 & 0.000 & 1.000 & 0.000 & 100.0 & 100.0 \\
\hline
\end{tabular}

${ }^{1}$ ASTM D2699, D2700 [3, 4] 
Table S2: Fuel matrix of TRF

\begin{tabular}{|c|c|c|c|c|c|c|}
\hline \multirow[t]{2}{*}{ Fuel } & \multicolumn{2}{|c|}{ Volume fraction } & \multicolumn{2}{|c|}{ Mole fraction } & \multirow[t]{2}{*}{ RON } & \multirow[t]{2}{*}{ MON } \\
\hline & Toluene & n-Heptane & Toluene & n-Heptane & & \\
\hline TRF 5 & 0.050 & 0.950 & 0.067 & 0.933 & $5 \cdot 9^{1}$ & $5 \cdot 0^{1}$ \\
\hline TRF 10 & 0.100 & 0.900 & 0.132 & 0.868 & $13.4^{1}$ & $11.6^{1}$ \\
\hline TRF 15 & 0.150 & 0.850 & 0.195 & 0.805 & $20.7^{1}$ & $18.0^{1}$ \\
\hline TRF 20 & 0.200 & 0.800 & 0.256 & 0.744 & $27 \cdot 7^{1}$ & $24 \cdot 2^{1}$ \\
\hline TRF 25 & 0.250 & 0.750 & 0.314 & 0.686 & $34 \cdot 5^{1}$ & $30.2^{1}$ \\
\hline TRF 30 & 0.300 & 0.700 & 0.371 & 0.629 & $41.1^{1}$ & $36.0^{1}$ \\
\hline TRF 35 & 0.350 & 0.650 & 0.425 & 0.575 & $47 \cdot 5^{1}$ & $41.6^{1}$ \\
\hline TRF 40 & 0.400 & 0.600 & 0.478 & 0.522 & $53 \cdot 7^{1}$ & $47 \cdot 1^{1}$ \\
\hline TRF 45 & 0.450 & $0.55^{0}$ & 0.529 & 0.471 & $59 \cdot 7^{1}$ & $52 \cdot 4^{1}$ \\
\hline TRF 50 & 0.500 & 0.500 & 0.579 & 0.421 & $65.1^{2}$ & $58.0^{2}$ \\
\hline TRF 55 & 0.550 & 0.450 & 0.627 & 0.373 & $7^{1} \cdot 3^{1}$ & $62.6^{1}$ \\
\hline TRF 60 & 0.600 & 0.400 & 0.673 & 0.327 & $77 \cdot 9^{2}$ & $68.5^{2}$ \\
\hline TRF 65 & 0.650 & 0.350 & 0.718 & 0.282 & $84 \cdot 5^{2}$ & $74 \cdot 5^{2}$ \\
\hline TRF 70 & 0.700 & 0.300 & 0.762 & 0.238 & $89 \cdot 3^{2}$ & $78.2^{2}$ \\
\hline TRF 75 & 0.750 & 0.250 & 0.805 & 0.195 & $94.2^{2}$ & $82.6^{2}$ \\
\hline TRF 8o & 0.800 & 0.200 & 0.846 & 0.154 & $97 \cdot 6^{1}$ & $85.8^{1}$ \\
\hline TRF 85 & 0.850 & 0.150 & 0.886 & 0.114 & $102.3^{2}$ & $91.6^{2}$ \\
\hline TRF 90 & 0.900 & 0.100 & 0.925 & 0.075 & $107.2^{1}$ & $94.2^{1}$ \\
\hline TRF 95 & 0.950 & 0.050 & 0.963 & 0.037 & $111.8^{1}$ & $98.3^{1}$ \\
\hline TRF 100 & 1.000 & 0.000 & 1.000 & 0.000 & $116.3^{1}$ & $102.2^{1}$ \\
\hline
\end{tabular}

${ }^{1}$ Blending rule in [30]

${ }^{2}$ ASTM D2699, D2700 measurements [3, 4] in [33]

Table S3: Fuel matrix of TPRF

\begin{tabular}{|c|c|c|c|c|c|c|c|c|}
\hline \multirow[t]{2}{*}{ Fuel } & \multicolumn{3}{|c|}{ Volume fraction } & \multicolumn{3}{|c|}{ Mole fraction } & \multirow[t]{2}{*}{$\mathrm{RON}^{1}$} & \multirow[t]{2}{*}{$\mathrm{MON}^{1}$} \\
\hline & Toluene & iso-octane & n-heptane & Toluene & iso-octane & $n$-heptane & & \\
\hline TPRF 5-5 & 0.050 & 0.050 & 0.900 & 0.068 & 0.044 & 0.888 & 10.9 & 10.0 \\
\hline TPRF 5-10 & 0.050 & 0.100 & 0.850 & 0.068 & 0.088 & 0.844 & 15.9 & 14.9 \\
\hline TPRF 5-15 & 0.050 & 0.150 & 0.800 & 0.069 & 0.133 & 0.799 & 20.8 & 19.9 \\
\hline TPRF 5-20 & 0.050 & 0.200 & 0.750 & 0.069 & 0.178 & 0.753 & 25.8 & 24.9 \\
\hline TPRF 5-25 & 0.050 & 0.250 & 0.700 & 0.069 & 0.224 & 0.707 & 30.8 & 29.8 \\
\hline TPRF 5-30 & 0.050 & 0.300 & 0.650 & 0.070 & 0.270 & 0.660 & $35 \cdot 7$ & $34 \cdot 7$ \\
\hline TPRF 5-35 & 0.050 & 0.350 & 0.600 & 0.070 & 0.317 & 0.613 & 40.6 & 39.7 \\
\hline TPRF 5-40 & 0.050 & 0.400 & $0.55^{0}$ & 0.071 & 0.365 & 0.565 & 45.6 & 44.6 \\
\hline TPRF 5-45 & 0.050 & 0.450 & 0.500 & 0.071 & 0.413 & 0.516 & 50.5 & $49 \cdot 5$ \\
\hline TPRF 5-50 & 0.050 & 0.500 & 0.450 & 0.071 & 0.461 & 0.468 & $55 \cdot 5$ & 54.5 \\
\hline TPRF 5-55 & 0.050 & 0.550 & 0.400 & 0.072 & 0.510 & 0.418 & 60.4 & 59.4 \\
\hline TPRF 5-60 & 0.050 & 0.600 & 0.350 & 0.072 & 0.560 & 0.368 & $65 \cdot 3$ & $64 \cdot 3$ \\
\hline
\end{tabular}


Table S3: (continued) Fuel matrix of TPRF

\begin{tabular}{|c|c|c|c|c|c|c|c|c|}
\hline \multirow[t]{2}{*}{ Fuel } & \multicolumn{3}{|c|}{ Volume fraction } & \multicolumn{3}{|c|}{ Mole fraction } & \multirow[t]{2}{*}{$\mathrm{RON}^{1}$} & \multirow[t]{2}{*}{$\mathrm{MON}^{1}$} \\
\hline & Toluene & iso-Octane & n-Heptane & Toluene & iso-Octane & n-Heptane & & \\
\hline TPRF 5-65 & 0.050 & 0.650 & 0.300 & 0.073 & 0.610 & 0.317 & 70.2 & 69.2 \\
\hline TPRF 5-70 & 0.050 & 0.700 & 0.250 & 0.073 & 0.661 & 0.266 & 75.1 & 74.1 \\
\hline TPRF 5-75 & 0.050 & 0.750 & 0.200 & 0.074 & 0.712 & 0.214 & 80.0 & 79.0 \\
\hline TPRF 5-80 & 0.050 & 0.800 & 0.150 & 0.074 & 0.765 & 0.162 & 84.9 & 83.9 \\
\hline TPRF 5-85 & 0.050 & 0.850 & 0.100 & 0.074 & 0.817 & 0.108 & 89.8 & 88.7 \\
\hline TPRF 5-90 & 0.050 & 0.900 & 0.050 & 0.075 & 0.871 & 0.054 & 94.7 & 93.6 \\
\hline TPRF 5-95 & 0.050 & 0.950 & 0.000 & 0.075 & 0.925 & 0.000 & 99.6 & 98.5 \\
\hline TPRF 10-5 & 0.100 & 0.050 & 0.850 & 0.133 & 0.043 & 0.824 & 18.3 & 16.5 \\
\hline TPRF 10-10 & 0.100 & 0.100 & 0.800 & 0.134 & 0.086 & 0.780 & $23 \cdot 3$ & 21.4 \\
\hline TPRF 10-15 & 0.100 & 0.150 & 0.750 & 0.135 & 0.130 & 0.735 & 28.2 & 26.3 \\
\hline TPRF 10-20 & 0.100 & 0.200 & 0.700 & 0.135 & 0.175 & 0.690 & 33.1 & 31.2 \\
\hline TPRF 10-25 & 0.100 & 0.250 & 0.650 & 0.136 & 0.220 & 0.644 & 38.0 & 36.1 \\
\hline TPRF 10-30 & 0.100 & 0.300 & 0.600 & 0.137 & 0.265 & 0.598 & 42.9 & 41.0 \\
\hline TPRF 10-35 & 0.100 & 0.350 & 0.550 & 0.138 & 0.311 & $0.55^{1}$ & $47 \cdot 7$ & 45.8 \\
\hline TPRF 10-40 & 0.100 & 0.400 & 0.500 & 0.138 & 0.358 & 0.504 & 52.6 & 50.7 \\
\hline TPRF 10-45 & 0.100 & 0.450 & $0.45^{\circ}$ & 0.139 & 0.405 & 0.456 & $57 \cdot 4$ & $55 \cdot 5$ \\
\hline TPRF 10-50 & 0.100 & 0.500 & 0.400 & 0.140 & 0.452 & 0.408 & 62.3 & 60.3 \\
\hline TPRF 10-55 & 0.100 & 0.550 & 0.350 & 0.141 & 0.500 & 0.359 & 67.1 & 65.2 \\
\hline TPRF 10-60 & 0.100 & 0.600 & 0.300 & 0.142 & 0.549 & 0.309 & 71.9 & 70.0 \\
\hline TPRF $10-65$ & 0.100 & 0.650 & 0.250 & 0.142 & 0.598 & 0.259 & 76.7 & 74.7 \\
\hline TPRF 10-70 & 0.100 & 0.700 & 0.200 & 0.143 & 0.648 & 0.209 & 81.5 & 79.5 \\
\hline TPRF 10-75 & 0.100 & 0.750 & 0.150 & 0.144 & 0.698 & 0.157 & 86.3 & $84 \cdot 3$ \\
\hline TPRF 10-80 & 0.100 & 0.800 & 0.100 & 0.145 & 0.749 & 0.106 & 91.1 & 89.1 \\
\hline TPRF $10-85$ & 0.100 & 0.850 & 0.050 & 0.146 & 0.801 & 0.053 & 95.8 & 93.8 \\
\hline TPRF 10-90 & 0.100 & 0.900 & 0.000 & 0.147 & 0.853 & 0.000 & 100.6 & 98.5 \\
\hline TPRF 15-5 & 0.150 & 0.050 & 0.800 & 0.196 & 0.042 & 0.762 & 25.5 & 22.9 \\
\hline TPRF 15-10 & 0.150 & 0.100 & 0.750 & 0.197 & 0.085 & 0.718 & 30.4 & 27.7 \\
\hline TPRF 15-15 & 0.150 & 0.150 & 0.700 & 0.198 & 0.128 & 0.674 & $35 \cdot 3$ & 32.5 \\
\hline TPRF 15-20 & 0.150 & 0.200 & 0.650 & 0.199 & 0.172 & 0.629 & 40.1 & $37 \cdot 4$ \\
\hline TPRF $15-25$ & 0.150 & 0.250 & 0.600 & 0.200 & 0.216 & 0.584 & 44.9 & 42.2 \\
\hline TPRF $15-30$ & 0.150 & 0.300 & 0.550 & 0.202 & 0.260 & 0.538 & 49.8 & 47.0 \\
\hline TPRF $15-35$ & 0.150 & 0.350 & 0.500 & 0.203 & 0.306 & 0.492 & 54.6 & 51.7 \\
\hline TPRF $15-40$ & 0.150 & 0.400 & 0.450 & 0.204 & 0.351 & 0.445 & $59 \cdot 3$ & 56.5 \\
\hline TPRF 15-45 & 0.150 & 0.450 & 0.400 & 0.205 & 0.397 & 0.398 & 64.1 & 61.2 \\
\hline TPRF $15-50$ & 0.150 & 0.500 & 0.350 & 0.206 & 0.444 & 0.350 & 68.8 & 66.0 \\
\hline TPRF 15-55 & 0.150 & 0.550 & 0.300 & 0.207 & 0.491 & 0.302 & 73.6 & 70.7 \\
\hline TPRF $15-60$ & 0.150 & 0.600 & 0.250 & 0.208 & 0.539 & 0.253 & 78.3 & $75 \cdot 4$ \\
\hline TPRF $15-65$ & 0.150 & 0.650 & 0.200 & 0.210 & 0.587 & 0.203 & 83.0 & 80.1 \\
\hline TPRF $15-70$ & 0.150 & 0.700 & 0.150 & 0.211 & 0.636 & 0.153 & 87.7 & 84.7 \\
\hline TPRF $15-75$ & 0.150 & 0.750 & 0.100 & 0.212 & 0.685 & 0.103 & 92.3 & 89.3 \\
\hline TPRF $15-80$ & 0.150 & 0.800 & 0.050 & 0.213 & 0.735 & 0.052 & 97.0 & 94.0 \\
\hline TPRF $15-85$ & 0.150 & 0.850 & 0.000 & 0.215 & 0.785 & 0.000 & 101.6 & 98.6 \\
\hline TPRF 20-5 & 0.200 & 0.050 & 0.750 & 0.257 & 0.042 & 0.702 & 32.5 & 29.0 \\
\hline TPRF 20-10 & 0.200 & 0.100 & 0.700 & 0.258 & 0.083 & 0.658 & $37 \cdot 3$ & 33.8 \\
\hline TPRF 20-15 & 0.200 & 0.150 & 0.650 & 0.260 & 0.126 & 0.614 & 42.1 & 38.6 \\
\hline TPRF 20-20 & 0.200 & 0.200 & 0.600 & 0.261 & 0.169 & 0.570 & 46.9 & $43 \cdot 3$ \\
\hline TPRF 20-25 & 0.200 & 0.250 & 0.550 & 0.263 & 0.212 & 0.525 & 51.7 & 48.0 \\
\hline TPRF 20-30 & 0.200 & 0.300 & 0.500 & 0.264 & 0.256 & 0.480 & 56.4 & 52.8 \\
\hline TPRF 20-35 & 0.200 & 0.350 & 0.450 & 0.265 & 0.300 & 0.435 & 61.1 & $57 \cdot 4$ \\
\hline
\end{tabular}


Table S3: (continued) Fuel matrix of TPRF

\begin{tabular}{|c|c|c|c|c|c|c|c|c|}
\hline \multirow[t]{2}{*}{ Fuel } & \multicolumn{3}{|c|}{ Volume fraction } & \multicolumn{3}{|c|}{ Mole fraction } & \multirow[t]{2}{*}{$\mathrm{RON}^{1}$} & \multirow[t]{2}{*}{$\mathrm{MON}^{1}$} \\
\hline & Toluene & iso-Octane & n-Heptane & Toluene & iso-Octane & n-Heptane & & \\
\hline TPRF 20-40 & 0.200 & 0.400 & 0.400 & 0.267 & 0.345 & 0.388 & 65.8 & 62.1 \\
\hline TPRF 20-45 & 0.200 & 0.450 & 0.350 & 0.268 & 0.390 & 0.342 & 70.5 & 66.8 \\
\hline TPRF 20-50 & 0.200 & 0.500 & 0.300 & 0.270 & 0.436 & 0.295 & 75.1 & 71.4 \\
\hline TPRF 20-55 & 0.200 & 0.550 & 0.250 & 0.271 & 0.482 & 0.247 & 79.8 & 76.0 \\
\hline TPRF 20-60 & 0.200 & 0.600 & 0.200 & 0.273 & 0.529 & 0.199 & 84.4 & 80.6 \\
\hline TPRF 20-65 & 0.200 & 0.650 & 0.150 & 0.274 & 0.576 & 0.150 & 88.9 & 85.1 \\
\hline TPRF 20-70 & 0.200 & 0.700 & 0.100 & 0.276 & 0.624 & 0.100 & $93 \cdot 5$ & 89.6 \\
\hline TPRF 20-75 & 0.200 & 0.750 & 0.050 & 0.277 & 0.672 & 0.050 & 98.0 & 94.1 \\
\hline TPRF 20-80 & 0.200 & 0.800 & 0.000 & 0.279 & 0.721 & 0.000 & 102.5 & 98.6 \\
\hline TPRF 25-5 & 0.250 & 0.050 & 0.700 & 0.316 & 0.041 & 0.643 & 39.3 & 34.9 \\
\hline TPRF 25-10 & 0.250 & 0.100 & 0.650 & 0.317 & 0.082 & 0.601 & 44.0 & 39.7 \\
\hline TPRF 25-15 & 0.250 & 0.150 & 0.600 & 0.319 & 0.124 & 0.557 & 48.8 & $44 \cdot 4$ \\
\hline TPRF 25-20 & 0.250 & 0.200 & $0.55^{0}$ & 0.321 & 0.166 & 0.514 & $53 \cdot 5$ & 49.0 \\
\hline TPRF 25-25 & 0.250 & 0.250 & 0.500 & 0.322 & 0.208 & 0.469 & 58.2 & 53.7 \\
\hline TPRF 25-30 & 0.250 & 0.300 & $0.45^{0}$ & 0.324 & 0.251 & 0.425 & 62.8 & 58.3 \\
\hline TPRF 25-35 & 0.250 & 0.350 & 0.400 & 0.326 & 0.295 & 0.379 & $67 \cdot 5$ & 62.9 \\
\hline TPRF 25-40 & 0.250 & 0.400 & 0.350 & 0.328 & 0.339 & 0.334 & 72.1 & $67 \cdot 5$ \\
\hline TPRF 25-45 & 0.250 & 0.450 & 0.300 & 0.329 & 0.383 & 0.288 & 76.6 & 72.0 \\
\hline TPRF 25-50 & 0.250 & 0.500 & 0.250 & 0.331 & 0.428 & 0.241 & 81.2 & 76.6 \\
\hline TPRF 25-55 & 0.250 & 0.550 & 0.200 & 0.333 & 0.473 & 0.194 & 85.7 & 81.0 \\
\hline TPRF 25-60 & 0.250 & 0.600 & 0.150 & 0.335 & 0.519 & 0.146 & 90.2 & $85 \cdot 5$ \\
\hline TPRF 25-65 & 0.250 & 0.650 & 0.100 & 0.337 & 0.565 & 0.098 & 94.6 & 89.9 \\
\hline TPRF 25-70 & 0.250 & 0.700 & 0.050 & 0.338 & 0.612 & 0.049 & 99.0 & $94 \cdot 3$ \\
\hline TPRF 25-75 & 0.250 & 0.750 & 0.000 & 0.340 & 0.660 & 0.000 & 103.4 & 98.6 \\
\hline TPRF 30-5 & 0.300 & 0.050 & 0.650 & 0.372 & 0.040 & 0.587 & 45.8 & 40.7 \\
\hline TPRF 30-10 & 0.300 & 0.100 & 0.600 & 0.374 & 0.081 & 0.545 & 50.5 & $45 \cdot 4$ \\
\hline TPRF 30-15 & 0.300 & 0.150 & 0.550 & 0.376 & 0.122 & 0.502 & 55.2 & 50.0 \\
\hline TPRF 30-20 & 0.300 & 0.200 & 0.500 & 0.378 & 0.163 & 0.459 & 59.8 & 54.6 \\
\hline TPRF 30-25 & 0.300 & 0.250 & 0.450 & 0.380 & 0.205 & 0.415 & $64 \cdot 5$ & 59.2 \\
\hline TPRF 30-30 & 0.300 & 0.300 & 0.400 & 0.382 & 0.247 & 0.371 & 69.0 & 63.7 \\
\hline TPRF 30-35 & 0.300 & 0.350 & 0.350 & 0.384 & 0.290 & 0.326 & 73.6 & 68.2 \\
\hline TPRF 30-40 & 0.300 & 0.400 & 0.300 & 0.386 & 0.333 & 0.281 & 78.1 & 72.7 \\
\hline TPRF 30-45 & 0.300 & 0.450 & 0.250 & 0.388 & 0.376 & 0.236 & 82.5 & 77.1 \\
\hline TPRF 30-50 & 0.300 & 0.500 & 0.200 & 0.390 & 0.420 & 0.189 & 87.0 & 81.5 \\
\hline TPRF 30-55 & 0.300 & $0.55^{0}$ & 0.150 & 0.392 & 0.465 & 0.143 & 91.3 & 85.8 \\
\hline TPRF 30-60 & 0.300 & 0.600 & 0.100 & 0.395 & 0.510 & 0.096 & 95.7 & 90.1 \\
\hline TPRF 30-65 & 0.300 & 0.650 & 0.050 & 0.397 & 0.555 & 0.048 & 100.0 & $94 \cdot 4$ \\
\hline TPRF 30-70 & 0.300 & 0.700 & 0.000 & 0.399 & 0.601 & 0.000 & $104 \cdot 3$ & 98.6 \\
\hline TPRF 35-5 & 0.350 & 0.050 & 0.600 & 0.427 & 0.039 & 0.533 & 52.2 & 46.3 \\
\hline TPRF 35-10 & 0.350 & 0.100 & 0.550 & 0.429 & 0.079 & 0.491 & 56.8 & 50.9 \\
\hline TPRF 35-15 & 0.350 & 0.150 & 0.500 & 0.432 & 0.120 & 0.449 & 61.4 & $55 \cdot 4$ \\
\hline TPRF 35-20 & 0.350 & 0.200 & 0.450 & 0.434 & 0.160 & 0.406 & 66.0 & 60.0 \\
\hline TPRF $35-25$ & 0.350 & 0.250 & 0.400 & 0.436 & 0.201 & 0.363 & 70.5 & $64 \cdot 4$ \\
\hline TPRF 35-30 & 0.350 & 0.300 & 0.350 & 0.438 & 0.243 & 0.319 & 75.0 & 68.9 \\
\hline TPRF 35-35 & 0.350 & 0.350 & 0.300 & 0.441 & 0.285 & 0.275 & 79.4 & $73 \cdot 3$ \\
\hline TPRF $35-40$ & 0.350 & 0.400 & 0.250 & 0.443 & 0.327 & 0.230 & 83.8 & 77.6 \\
\hline TPRF 35-45 & 0.350 & $0.45^{\circ}$ & 0.200 & 0.445 & 0.370 & 0.185 & 88.2 & 81.9 \\
\hline TPRF $35-50$ & 0.350 & 0.500 & 0.150 & 0.447 & 0.413 & 0.140 & 92.5 & 86.2 \\
\hline TPRF 35-55 & 0.350 & 0.550 & 0.100 & 0.450 & 0.457 & 0.094 & 96.7 & 90.4 \\
\hline
\end{tabular}


Table S3: (continued) Fuel matrix of TPRF

\begin{tabular}{|c|c|c|c|c|c|c|c|c|}
\hline \multirow[t]{2}{*}{ Fuel } & \multicolumn{3}{|c|}{ Volume fraction } & \multicolumn{3}{|c|}{ Mole fraction } & \multirow[t]{2}{*}{$\mathrm{RON}^{1}$} & \multirow[t]{2}{*}{$\mathrm{MON}^{-}$} \\
\hline & Toluene & iso-Octane & n-Heptane & Toluene & iso-Octane & n-Heptane & & \\
\hline TPRF 35-6o & 0.350 & 0.600 & 0.050 & 0.452 & 0.501 & 0.047 & 100.9 & 94.6 \\
\hline TPRF $35-65$ & 0.350 & 0.650 & 0.000 & 0.455 & 0.545 & 0.000 & 105.1 & 98.7 \\
\hline TPRF 40-5 & 0.400 & 0.050 & $0.55^{\circ}$ & 0.480 & 0.039 & 0.481 & 58.3 & 51.7 \\
\hline TPRF 40-10 & 0.400 & 0.100 & 0.500 & 0.483 & 0.078 & 0.439 & 62.9 & 56.2 \\
\hline TPRF 40-15 & 0.400 & 0.150 & 0.450 & 0.485 & 0.118 & 0.397 & $67 \cdot 4$ & 60.7 \\
\hline TPRF 40-20 & 0.400 & 0.200 & 0.400 & 0.488 & 0.157 & 0.355 & 71.9 & 65.1 \\
\hline TPRF 40-25 & 0.400 & 0.250 & 0.350 & 0.490 & 0.198 & 0.312 & 76.4 & 69.5 \\
\hline TPRF 40-30 & 0.400 & 0.300 & 0.300 & 0.492 & 0.239 & 0.269 & 80.7 & 73.9 \\
\hline TPRF 40-35 & 0.400 & 0.350 & 0.250 & 0.495 & 0.280 & 0.225 & 85.1 & 78.1 \\
\hline TPRF $40-40$ & 0.400 & 0.400 & 0.200 & 0.498 & 0.321 & 0.181 & 89.3 & 82.4 \\
\hline TPRF 40-45 & 0.400 & 0.450 & 0.150 & 0.500 & 0.363 & 0.136 & 93.5 & 86.5 \\
\hline TPRF 40-50 & 0.400 & 0.500 & 0.100 & 0.503 & 0.406 & 0.091 & $97 \cdot 7$ & 90.6 \\
\hline TPRF 40-55 & 0.400 & 0.550 & 0.050 & 0.505 & 0.449 & 0.046 & 101.8 & 94.7 \\
\hline TPRF 40-6o & 0.400 & 0.600 & 0.000 & 0.508 & 0.492 & 0.000 & 105.9 & 98.7 \\
\hline TPRF 45-5 & 0.450 & 0.050 & 0.500 & 0.532 & 0.038 & 0.430 & $64 \cdot 3$ & 56.9 \\
\hline TPRF $45-10$ & 0.450 & 0.100 & 0.450 & 0.534 & 0.077 & 0.389 & 68.8 & 61.4 \\
\hline TPRF 45-15 & 0.450 & 0.150 & 0.400 & 0.537 & 0.116 & 0.347 & $73 \cdot 3$ & 65.8 \\
\hline TPRF 45-20 & 0.450 & 0.200 & 0.350 & 0.540 & 0.155 & 0.305 & $77 \cdot 7$ & 70.1 \\
\hline TPRF $45-25$ & 0.450 & 0.250 & 0.300 & 0.542 & 0.195 & 0.263 & 82.0 & 74.4 \\
\hline TPRF 45-30 & 0.450 & 0.300 & 0.250 & 0.545 & 0.235 & 0.220 & 86.2 & 78.6 \\
\hline TPRF $45-35$ & 0.450 & 0.350 & 0.200 & 0.548 & 0.275 & 0.177 & 90.4 & 82.8 \\
\hline TPRF $45-40$ & 0.450 & 0.400 & 0.150 & 0.550 & 0.316 & 0.134 & 94.6 & 86.9 \\
\hline TPRF $45-45$ & 0.450 & 0.450 & 0.100 & 0.553 & 0.357 & 0.089 & 98.7 & 90.9 \\
\hline TPRF $45-50$ & 0.450 & 0.500 & 0.050 & 0.556 & 0.399 & 0.045 & 102.7 & 94.8 \\
\hline TPRF $45-55$ & 0.450 & 0.550 & 0.000 & 0.559 & 0.441 & 0.000 & 106.6 & 98.7 \\
\hline TPRF 50-5 & 0.500 & 0.050 & $0.45^{0}$ & 0.581 & 0.038 & 0.381 & 70.1 & 62.0 \\
\hline TPRF 50-10 & 0.500 & 0.100 & 0.400 & 0.584 & 0.075 & 0.340 & $74 \cdot 5$ & 66.4 \\
\hline TPRF 50-15 & 0.500 & 0.150 & 0.350 & 0.587 & 0.114 & 0.299 & 78.9 & 70.7 \\
\hline TPRF $50-20$ & 0.500 & 0.200 & 0.300 & 0.590 & 0.152 & 0.258 & 83.2 & 74.9 \\
\hline TPRF $50-25$ & 0.500 & 0.250 & 0.250 & 0.593 & 0.191 & 0.216 & 87.4 & 79.1 \\
\hline TPRF 50-30 & 0.500 & 0.300 & 0.200 & 0.596 & 0.231 & 0.173 & 91.5 & 83.2 \\
\hline TPRF 50-35 & 0.500 & 0.350 & 0.150 & 0.599 & 0.271 & 0.131 & 95.6 & 87.2 \\
\hline TPRF $50-40$ & 0.500 & 0.400 & 0.100 & 0.602 & 0.311 & 0.088 & 99.6 & 91.1 \\
\hline TPRF 50-45 & 0.500 & 0.450 & 0.050 & 0.605 & 0.351 & 0.044 & 103.5 & 95.0 \\
\hline TPRF $50-50$ & 0.500 & 0.500 & 0.000 & 0.608 & 0.392 & 0.000 & $107 \cdot 3$ & 98.7 \\
\hline TPRF 55-5 & 0.550 & 0.050 & 0.400 & 0.630 & 0.037 & 0.333 & $75 \cdot 7$ & 67.0 \\
\hline TPRF 55-10 & 0.550 & 0.100 & 0.350 & 0.633 & 0.074 & 0.293 & 80.1 & 71.3 \\
\hline TPRF 55-15 & 0.550 & 0.150 & 0.300 & 0.636 & 0.112 & 0.252 & $84 \cdot 3$ & $75 \cdot 5$ \\
\hline TPRF 55-20 & 0.550 & 0.200 & 0.250 & 0.639 & 0.150 & 0.211 & 88.5 & 79.6 \\
\hline TPRF 55-25 & 0.550 & 0.250 & 0.200 & 0.642 & 0.188 & 0.170 & 92.6 & 83.6 \\
\hline TPRF 55-30 & 0.550 & 0.300 & 0.150 & 0.645 & 0.227 & 0.128 & 96.6 & 87.5 \\
\hline TPRF 55-35 & 0.550 & 0.350 & 0.100 & 0.648 & 0.266 & 0.086 & 100.5 & 91.4 \\
\hline TPRF 55-40 & 0.550 & 0.400 & 0.050 & 0.651 & 0.306 & 0.043 & $104 \cdot 3$ & 95.1 \\
\hline TPRF 55-45 & 0.550 & 0.450 & 0.000 & 0.654 & 0.346 & 0.000 & 108.0 & 98.8 \\
\hline TPRF 60-5 & 0.600 & 0.050 & 0.350 & 0.676 & 0.036 & 0.287 & 81.2 & 71.8 \\
\hline TPRF 60-10 & 0.600 & 0.100 & 0.300 & 0.680 & 0.073 & 0.247 & 85.4 & 75.9 \\
\hline TPRF 6o-15 & 0.600 & 0.150 & 0.250 & 0.683 & 0.110 & 0.207 & 89.6 & 80.0 \\
\hline TPRF 6o-20 & 0.600 & 0.200 & 0.200 & 0.686 & 0.148 & 0.166 & 93.6 & 84.0 \\
\hline
\end{tabular}


Table S3: (continued) Fuel matrix of TPRF

\begin{tabular}{|c|c|c|c|c|c|c|c|c|}
\hline \multirow[t]{2}{*}{ Fuel } & \multicolumn{3}{|c|}{ Volume fraction } & \multicolumn{3}{|c|}{ Mole fraction } & \multirow[t]{2}{*}{$\mathrm{RON}^{1}$} & \multirow[t]{2}{*}{$\mathrm{MON}$} \\
\hline & Toluene & iso-Octane & n-Heptane & Toluene & iso-Octane & n-Heptane & & \\
\hline TPRF 6o-25 & 0.600 & 0.250 & 0.150 & 0.689 & 0.185 & 0.125 & $97 \cdot 5$ & 87.9 \\
\hline TPRF 60-30 & 0.600 & 0.300 & 0.100 & 0.692 & 0.224 & 0.084 & 101.3 & 91.6 \\
\hline TPRF 6o-35 & 0.600 & 0.350 & 0.050 & 0.696 & 0.262 & 0.042 & 105.0 & $95 \cdot 3$ \\
\hline TPRF 6o-40 & 0.600 & 0.400 & 0.000 & 0.699 & 0.301 & 0.000 & 108.6 & 98.8 \\
\hline TPRF 65-5 & 0.650 & 0.050 & 0.300 & 0.722 & 0.036 & 0.242 & 86.5 & 76.4 \\
\hline TPRF 65-10 & 0.650 & 0.100 & 0.250 & 0.725 & 0.072 & 0.203 & 90.6 & 80.5 \\
\hline TPRF 65-15 & 0.650 & 0.150 & 0.200 & 0.728 & 0.109 & 0.163 & 94.6 & 84.4 \\
\hline TPRF 65-20 & 0.650 & 0.200 & 0.150 & 0.732 & 0.145 & 0.123 & 98.4 & 88.2 \\
\hline TPRF 65-25 & 0.650 & 0.250 & 0.100 & 0.735 & 0.183 & 0.082 & 102.2 & 91.9 \\
\hline TPRF 65-30 & 0.650 & 0.300 & 0.050 & 0.738 & 0.220 & 0.041 & 105.8 & $95 \cdot 4$ \\
\hline TPRF 65-35 & 0.650 & 0.350 & 0.000 & 0.742 & 0.258 & 0.000 & 109.3 & 98.8 \\
\hline TPRF 70-5 & 0.700 & 0.050 & 0.250 & 0.766 & 0.035 & 0.199 & 91.6 & 80.9 \\
\hline TPRF 70-10 & 0.700 & 0.100 & 0.200 & 0.769 & 0.071 & 0.160 & 95.6 & 84.8 \\
\hline TPRF 70-15 & 0.700 & 0.150 & 0.150 & 0.773 & 0.107 & 0.121 & 99.4 & 88.6 \\
\hline TPRF 70-20 & 0.700 & 0.200 & 0.100 & 0.776 & 0.143 & 0.081 & 103.0 & 92.1 \\
\hline TPRF 70-25 & 0.700 & 0.250 & 0.050 & 0.780 & 0.180 & 0.041 & 106.5 & 95.6 \\
\hline TPRF 70-30 & 0.700 & 0.300 & 0.000 & 0.783 & 0.217 & 0.000 & 109.8 & 98.8 \\
\hline TPRF 75-5 & 0.750 & 0.050 & 0.200 & 0.808 & 0.035 & 0.157 & 96.6 & $85 \cdot 3$ \\
\hline TPRF 75-10 & 0.750 & 0.100 & 0.150 & 0.812 & 0.070 & 0.118 & 100.3 & 88.9 \\
\hline TPRF 75-15 & 0.750 & 0.150 & 0.100 & 0.815 & 0.105 & 0.079 & 103.9 & 92.4 \\
\hline TPRF 75-20 & 0.750 & 0.200 & 0.050 & 0.819 & 0.141 & 0.040 & $107 \cdot 3$ & 95.7 \\
\hline TPRF 75-25 & 0.750 & 0.250 & 0.000 & 0.823 & 0.177 & 0.000 & 110.4 & 98.8 \\
\hline TPRF 80-5 & 0.800 & 0.050 & 0.150 & 0.850 & 0.034 & 0.116 & 101.3 & 89.4 \\
\hline TPRF 80-10 & 0.800 & 0.100 & 0.100 & 0.853 & 0.069 & 0.078 & 104.8 & 92.8 \\
\hline TPRF 80-15 & 0.800 & 0.150 & 0.050 & 0.857 & 0.104 & 0.039 & 108.0 & 96.0 \\
\hline TPRF 80-20 & 0.800 & 0.200 & 0.000 & 0.861 & 0.139 & 0.000 & 111.0 & 98.9 \\
\hline TPRF 85-5 & 0.850 & 0.050 & 0.100 & 0.890 & 0.034 & 0.076 & 105.8 & $93 \cdot 3$ \\
\hline TPRF 85-10 & 0.850 & 0.100 & 0.050 & 0.894 & 0.068 & 0.038 & 108.8 & 96.3 \\
\hline TPRF 85-15 & 0.850 & 0.150 & 0.000 & 0.898 & 0.102 & 0.000 & 111.5 & 98.9 \\
\hline TPRF 90-5 & 0.900 & 0.050 & 0.050 & 0.929 & 0.033 & 0.038 & 109.9 & 96.8 \\
\hline TPRF 90-10 & 0.900 & 0.100 & 0.000 & 0.933 & 0.067 & 0.000 & 112.0 & 98.9 \\
\hline TPRF 95-5 & 0.950 & 0.050 & 0.000 & 0.967 & 0.033 & 0.000 & 112.5 & 98.9 \\
\hline
\end{tabular}

${ }^{1}$ Blending rule in [30] 
Table S4: Fuel matrix of ERF

\begin{tabular}{|c|c|c|c|c|c|c|}
\hline \multirow[t]{2}{*}{ Fuel } & \multicolumn{2}{|c|}{ Volume fraction } & \multicolumn{2}{|c|}{ Mole fraction } & \multirow[t]{2}{*}{$\mathrm{RON}$} & \multirow[t]{2}{*}{ MON } \\
\hline & Ethanol & n-Heptane & Ethanol & n-Heptane & & \\
\hline ERF 5 & 0.050 & 0.950 & 0.385 & 0.615 & $12.6^{1}$ & $10.6^{1}$ \\
\hline ERF 10 & 0.100 & 0.900 & 0.455 & 0.545 & $23 \cdot 5^{1}$ & $19.8^{1}$ \\
\hline ERF 15 & 0.150 & 0.850 & 0.518 & 0.482 & $33.1^{1}$ & $27.8^{1}$ \\
\hline ERF 20 & 0.200 & 0.800 & 0.575 & 0.425 & $41.6^{1}$ & $35.0^{1}$ \\
\hline ERF 25 & 0.250 & 0.750 & 0.626 & 0.374 & $49.2^{1}$ & $41 \cdot 3^{1}$ \\
\hline ERF 30 & 0.300 & 0.700 & 0.672 & 0.328 & $54 \cdot 3^{2}$ & $47 \cdot 6^{1}$ \\
\hline ERF 35 & 0.350 & 0.650 & 0.715 & 0.285 & $62.1^{1}$ & $57.2^{1}$ \\
\hline ERF 40 & 0.400 & 0.600 & 0.754 & 0.246 & $69.7^{2}$ & $64 \cdot 5^{2}$ \\
\hline ERF 45 & 0.450 & 0.550 & 0.790 & 0.210 & $75 \cdot 1^{1}$ & $71.0^{1}$ \\
\hline ERF 50 & 0.500 & 0.500 & 0.823 & 0.177 & $83.8^{2}$ & $75 \cdot 9^{1}$ \\
\hline ERF 55 & 0.550 & 0.450 & 0.854 & 0.146 & $88.9^{1}$ & $79.8^{1}$ \\
\hline ERF 60 & 0.600 & 0.400 & 0.883 & 0.117 & $94.7^{2}$ & $83.8^{2}$ \\
\hline ERF 65 & 0.650 & 0.350 & 0.909 & 0.091 & $97 \cdot 7^{1}$ & $85.2^{1}$ \\
\hline ERF 70 & 0.700 & 0.300 & 0.934 & 0.066 & $101.6^{2}$ & $87.0^{1}$ \\
\hline ERF 75 & 0.750 & 0.250 & 0.958 & 0.042 & $103.1^{1}$ & $88.4^{1}$ \\
\hline ERF 8o & 0.800 & 0.200 & 0.979 & 0.021 & $104.7^{2}$ & $88.9^{2}$ \\
\hline ERF 85 & 0.850 & 0.150 & 1.000 & 0.000 & $106.2^{1}$ & $90.0^{1}$ \\
\hline ERF 90 & 0.900 & 0.100 & 0.391 & 0.499 & $106.5^{2}$ & $90.5^{1}$ \\
\hline ERF 95 & 0.950 & 0.050 & 0.524 & 0.390 & $107.7^{1}$ & $90.7^{1}$ \\
\hline ERF 100 & 1.000 & 0.000 & 0.631 & 0.302 & $109.0^{3}$ & $90.0^{3}$ \\
\hline
\end{tabular}

${ }^{1}$ Blending rule in [31]

2 ASTM D2699, D2700 measurements [3, 4] in [34]

3 ASTM D2699, D2700 measurements [3, 4] in [64] 
Table $\mathrm{S}_{5}$ : Fuel matrix of EPRF

\begin{tabular}{|c|c|c|c|c|c|c|c|c|}
\hline \multirow[t]{2}{*}{ Fuel } & \multicolumn{3}{|c|}{ Volume percentage } & \multicolumn{3}{|c|}{ Mole fraction } & \multirow[t]{2}{*}{$\mathrm{RON}$} & \multirow[t]{2}{*}{$\mathrm{MON}$} \\
\hline & Ethanol & iso-Octane & n-heptane & Ethanol & iso-Octane & n-Heptane & & \\
\hline EPRF $5-85.5$ & 0.050 & 0.855 & 0.095 & 0.128 & 0.775 & 0.097 & $94 \cdot 1^{2}$ & $90.4^{1}$ \\
\hline EPRF 10-90 & 0.100 & 0.900 & 0.000 & 0.239 & 0.761 & 0.000 & $106.8^{2}$ & $99 \cdot 9^{2}$ \\
\hline EPRF 10-81 & 0.100 & 0.810 & 0.090 & 0.237 & 0.678 & 0.085 & $97 \cdot 6^{2}$ & $92.1^{1}$ \\
\hline EPRF 10-72 & 0.100 & 0.720 & 0.180 & 0.235 & 0.597 & 0.168 & $89.5^{2}$ & $85 \cdot 3^{1}$ \\
\hline EPRF 10-54 & 0.100 & 0.540 & 0.360 & 0.230 & 0.440 & 0.330 & $72.8^{4}$ & $70.0^{4}$ \\
\hline EPRF 10-45 & 0.100 & 0.450 & 0.450 & 0.228 & 0.363 & 0.409 & $64 \cdot 5^{4}$ & $61.0^{4}$ \\
\hline EPRF 10-36 & 0.100 & 0.360 & 0.540 & 0.226 & 0.288 & 0.486 & $55.6^{4}$ & $53.0^{4}$ \\
\hline EPRF 20-80 & 0.200 & 0.800 & 0.000 & 0.414 & 0.586 & 0.000 & $109.4^{2}$ & $99.1^{2}$ \\
\hline EPRF 20-72 & 0.200 & 0.720 & 0.080 & 0.411 & 0.523 & 0.066 & $103.6^{2}$ & $93.8^{1}$ \\
\hline EPRF 20-64 & 0.200 & 0.640 & 0.160 & 0.408 & 0.462 & 0.130 & $97 \cdot 0^{2}$ & $89.5^{1}$ \\
\hline EPRF 20-48 & 0.200 & 0.480 & 0.320 & 0.402 & 0.341 & 0.256 & $83.4^{4}$ & $79 \cdot 3^{4}$ \\
\hline EPRF 20-40 & 0.200 & 0.400 & 0.400 & 0.399 & 0.282 & 0.318 & $76.7^{4}$ & $73.0^{4}$ \\
\hline EPRF 20-32 & 0.200 & 0.320 & 0.480 & 0.396 & 0.224 & 0.379 & $69.0^{4}$ & $64.0^{4}$ \\
\hline EPRF 20-16 & 0.200 & 0.160 & 0.640 & 0.391 & 0.111 & 0.499 & $53 \cdot 3^{2}$ & $46 \cdot 5^{1}$ \\
\hline EPRF 30-70 & 0.300 & 0.700 & 0.000 & 0.548 & 0.452 & 0.000 & $109.8^{1}$ & $97.0^{1}$ \\
\hline EPRF $30-56$ & 0.300 & 0.560 & 0.140 & 0.542 & 0.358 & 0.101 & $101.3^{1}$ & $91.5^{1}$ \\
\hline EPRF $30-42$ & 0.300 & 0.420 & 0.280 & 0.536 & 0.265 & 0.199 & $91.9^{4}$ & $86.0^{4}$ \\
\hline EPRF $30-42$ & 0.300 & 0.420 & 0.280 & 0.536 & 0.265 & 0.199 & $91.9^{4}$ & $86.0^{4}$ \\
\hline EPRF $30-35$ & 0.300 & 0.350 & 0.350 & 0.533 & 0.220 & 0.248 & $86.7^{4}$ & $81.0^{4}$ \\
\hline EPRF $30-28$ & 0.300 & 0.280 & 0.420 & 0.530 & 0.175 & 0.296 & $80.7^{4}$ & $76.0^{4}$ \\
\hline EPRF 30-14 & 0.300 & 0.140 & 0.560 & 0.524 & 0.086 & 0.390 & $67 \cdot 4^{2}$ & $57.1^{1}$ \\
\hline EPRF 40-6o & 0.400 & 0.600 & 0.000 & 0.653 & 0.347 & 0.000 & $110.2^{2}$ & $95 \cdot 9^{2}$ \\
\hline EPRF $40-48$ & 0.400 & 0.480 & 0.120 & 0.648 & 0.275 & 0.077 & $105.7^{2}$ & $92.4^{1}$ \\
\hline EPRF $40-36$ & 0.400 & 0.360 & 0.240 & 0.642 & 0.204 & 0.154 & $98.8^{4}$ & $89.1^{4}$ \\
\hline EPRF 40-30 & 0.400 & 0.300 & 0.300 & 0.639 & 0.170 & 0.191 & $94.9^{4}$ & $86.7^{4}$ \\
\hline EPRF 40-24 & 0.400 & 0.240 & 0.360 & 0.637 & 0.135 & 0.228 & $90.5^{4}$ & $83.6^{4}$ \\
\hline EPRF 40-24 & 0.400 & 0.240 & 0.360 & 0.637 & 0.135 & 0.228 & $90.5^{4}$ & $83.6^{4}$ \\
\hline EPRF $40-12$ & 0.400 & 0.120 & 0.480 & 0.631 & 0.067 & 0.302 & $80.7^{2}$ & $7^{2} \cdot 4^{1}$ \\
\hline EPRF 50-50 & 0.500 & 0.500 & 0.000 & 0.739 & 0.261 & 0.000 & $109.6^{1}$ & $94.9^{1}$ \\
\hline EPRF 50-40 & 0.500 & 0.400 & 0.100 & 0.734 & 0.208 & 0.058 & $106.7^{1}$ & $92.6^{1}$ \\
\hline EPRF 50-30 & 0.500 & 0.300 & 0.200 & 0.729 & 0.155 & 0.116 & $103.0^{4}$ & $90.4^{4}$ \\
\hline EPRF 50-25 & 0.500 & 0.250 & 0.250 & 0.727 & 0.129 & 0.145 & $100.7^{4}$ & $88.8^{4}$ \\
\hline EPRF 50-20 & 0.500 & 0.200 & 0.300 & 0.724 & 0.102 & 0.173 & $97 \cdot 9^{4}$ & $87 \cdot 5^{4}$ \\
\hline EPRF 50-10 & 0.500 & 0.100 & 0.400 & 0.720 & 0.051 & 0.229 & $91.5^{2}$ & $81.6^{1}$ \\
\hline EPRF 60-40 & 0.600 & 0.400 & 0.000 & 0.809 & 0.191 & 0.000 & $109.6^{2}$ & $94.2^{2}$ \\
\hline EPRF 6o-32 & 0.600 & 0.320 & 0.080 & 0.805 & 0.152 & 0.043 & $107.7^{2}$ & $92.5^{1}$ \\
\hline EPRF 6o-24 & 0.600 & 0.240 & 0.160 & 0.801 & 0.113 & 0.085 & $105.0^{4}$ & $91.2^{4}$ \\
\hline EPRF 60-20 & 0.600 & 0.200 & 0.200 & 0.800 & 0.094 & 0.106 & $104.0^{4}$ & $90.2^{4}$ \\
\hline EPRF 6o-16 & 0.600 & 0.160 & 0.240 & 0.798 & 0.075 & 0.127 & $102.5^{4}$ & $89.0^{4}$ \\
\hline EPRF 6o-8 & 0.600 & 0.080 & 0.320 & 0.794 & 0.037 & 0.169 & $99.1^{2}$ & $86.9^{1}$ \\
\hline EPRF 70-30 & 0.700 & 0.300 & 0.000 & 0.868 & 0.132 & 0.000 & $109.6^{1}$ & $93.0^{1}$ \\
\hline EPRF 70-24 & 0.700 & 0.240 & 0.060 & 0.865 & 0.105 & 0.030 & $107.9^{1}$ & $92.2^{1}$ \\
\hline EPRF 70-18 & 0.700 & 0.180 & 0.120 & 0.863 & 0.078 & 0.059 & $107.0^{4}$ & $91.0^{4}$ \\
\hline EPRF 70-15 & 0.700 & 0.150 & 0.150 & 0.861 & 0.065 & 0.074 & $105.6^{4}$ & $91.5^{4}$ \\
\hline EPRF $70-12$ & 0.700 & 0.120 & 0.180 & 0.860 & 0.052 & 0.088 & $104.8^{4}$ & $89.8^{4}$ \\
\hline EPRF 70-6 & 0.700 & 0.060 & 0.240 & 0.857 & 0.026 & 0.117 & $102.7^{1}$ & $89.8^{1}$ \\
\hline EPRF 80-20 & 0.800 & 0.200 & 0.000 & 0.919 & 0.081 & 0.000 & $109.0^{2}$ & $92.6^{2}$ \\
\hline
\end{tabular}


Table S5: (continued) Fuel matrix of EPRF

\begin{tabular}{|c|c|c|c|c|c|c|c|c|}
\hline \multirow[t]{2}{*}{ Fuel } & \multicolumn{3}{|c|}{ Volume percentage } & \multicolumn{3}{|c|}{ Mole fraction } & \multirow[t]{2}{*}{ RON } & \multirow[t]{2}{*}{ MON } \\
\hline & Ethanol & iso-Octane & n-Heptane & Ethanol & iso-Octane & n-Heptane & & \\
\hline EPRF 80-16 & 0.800 & 0.160 & 0.040 & 0.917 & 0.065 & 0.018 & $108.3^{2}$ & $91.7^{1}$ \\
\hline EPRF 80-12 & 0.800 & 0.120 & & & 0.049 & & $108.0^{4}$ & $91.0^{4}$ \\
\hline EPRF 80-10 & 0.800 & 0.100 & 0.100 & 0.914 & 0.040 & 0.046 & $107.0^{4}$ & $90.4^{4}$ \\
\hline EPRF 8o-8 & 0.800 & 0.080 & 0.120 & 0.913 & 0.032 & 0.055 & $105.3^{4}$ & $90.2^{4}$ \\
\hline EPRF 8o-4 & 0.800 & 0.040 & 0.160 & 0.911 & 0.016 & 0.073 & $105.8^{2}$ & $91.1^{1}$ \\
\hline EPRF 90-10 & 0.900 & 0.100 & 0.000 & 0.962 & 0.038 & 0.000 & $108.8^{1}$ & $91.4^{1}$ \\
\hline EPRF 90-8 & 0.900 & 0.080 & 0.020 & 0.961 & 0.030 & 0.009 & $108.7^{2}$ & $91.2^{1}$ \\
\hline EPRF 9o-6 & 0.900 & 0.060 & 0.040 & 0.960 & 0.023 & 0.017 & $109.0^{4}$ & $91.6^{4}$ \\
\hline EPRF 90-5 & 0.900 & 0.050 & 0.050 & 0.960 & 0.019 & 0.021 & $108.0^{4}$ & $90.4^{4}$ \\
\hline EPRF 90-4 & 0.900 & 0.040 & 0.060 & 0.959 & 0.015 & 0.025 & $108.5^{4}$ & $91.0^{4}$ \\
\hline EPRF 90-2 & 0.900 & 0.020 & 0.080 & 0.959 & 0.008 & 0.034 & $107.2^{1}$ & $91.3^{1}$ \\
\hline
\end{tabular}

${ }^{1}$ Blending rule in [31]

2 ASTM D2699, D2700 measurements [3, 4] in [34]

3 ASTM D2699, D2700 measurements [3, 4] in [64]

4 ASTM D2699, D2700 measurements [3, 4] in [31] 


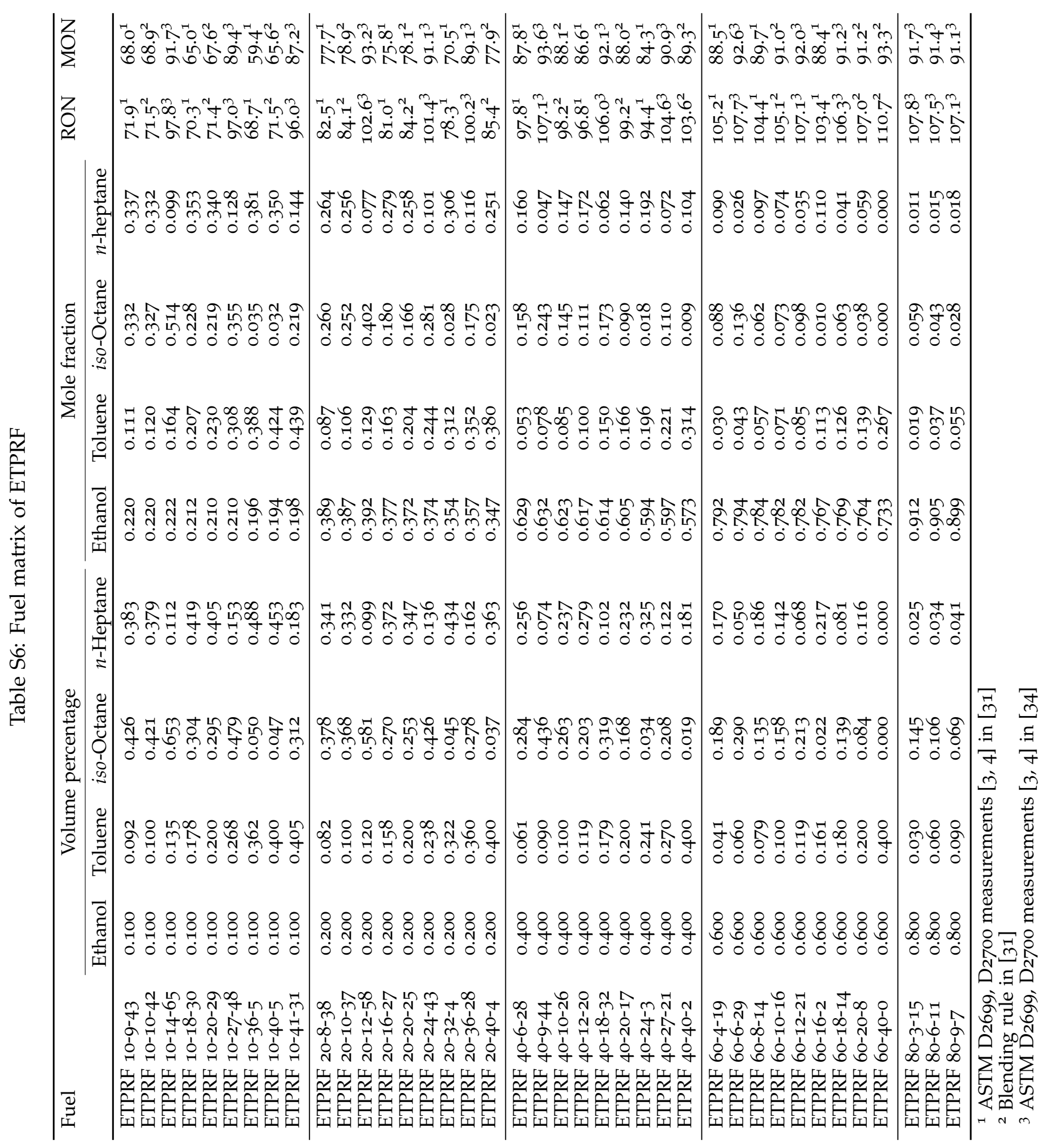




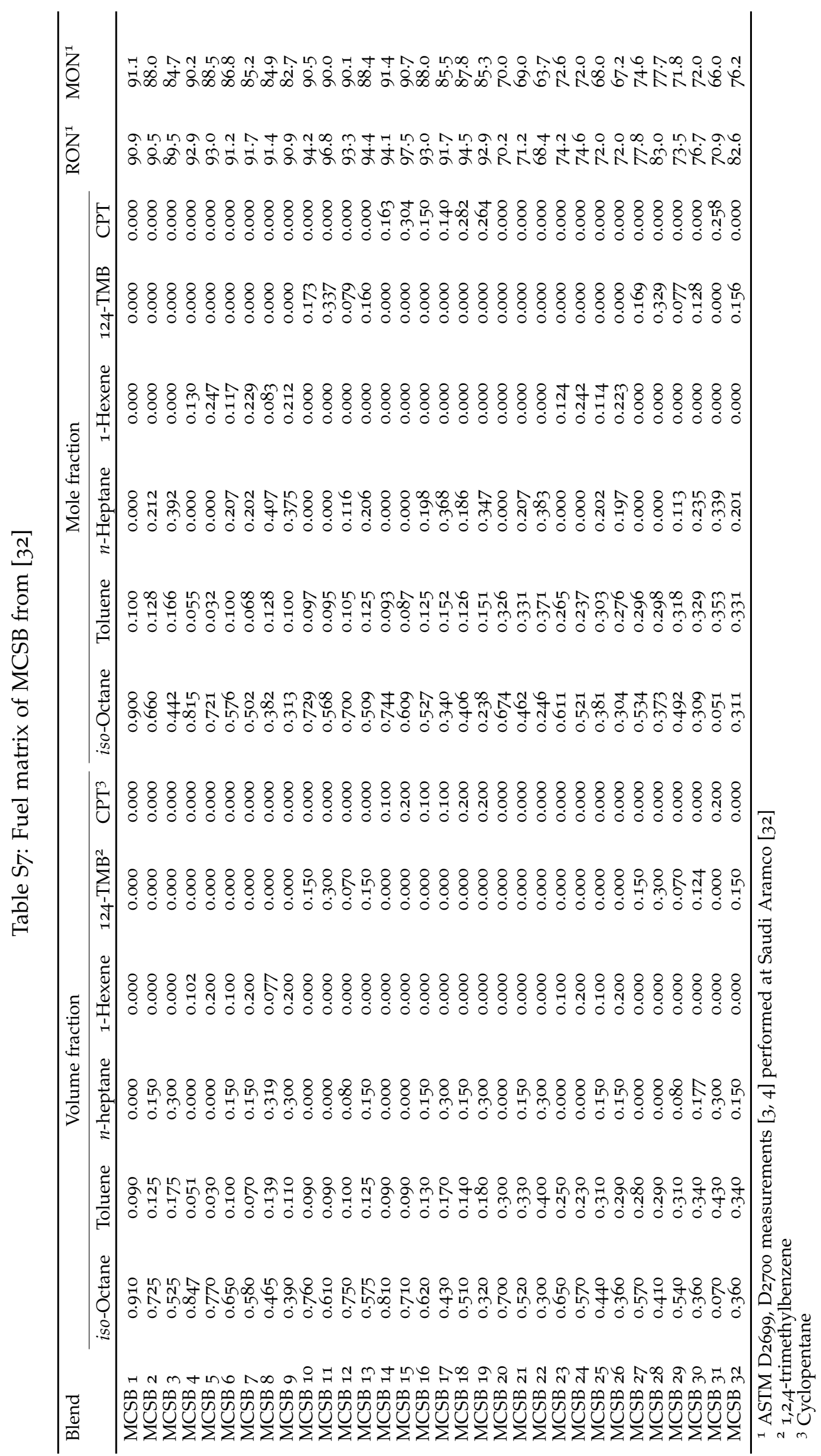



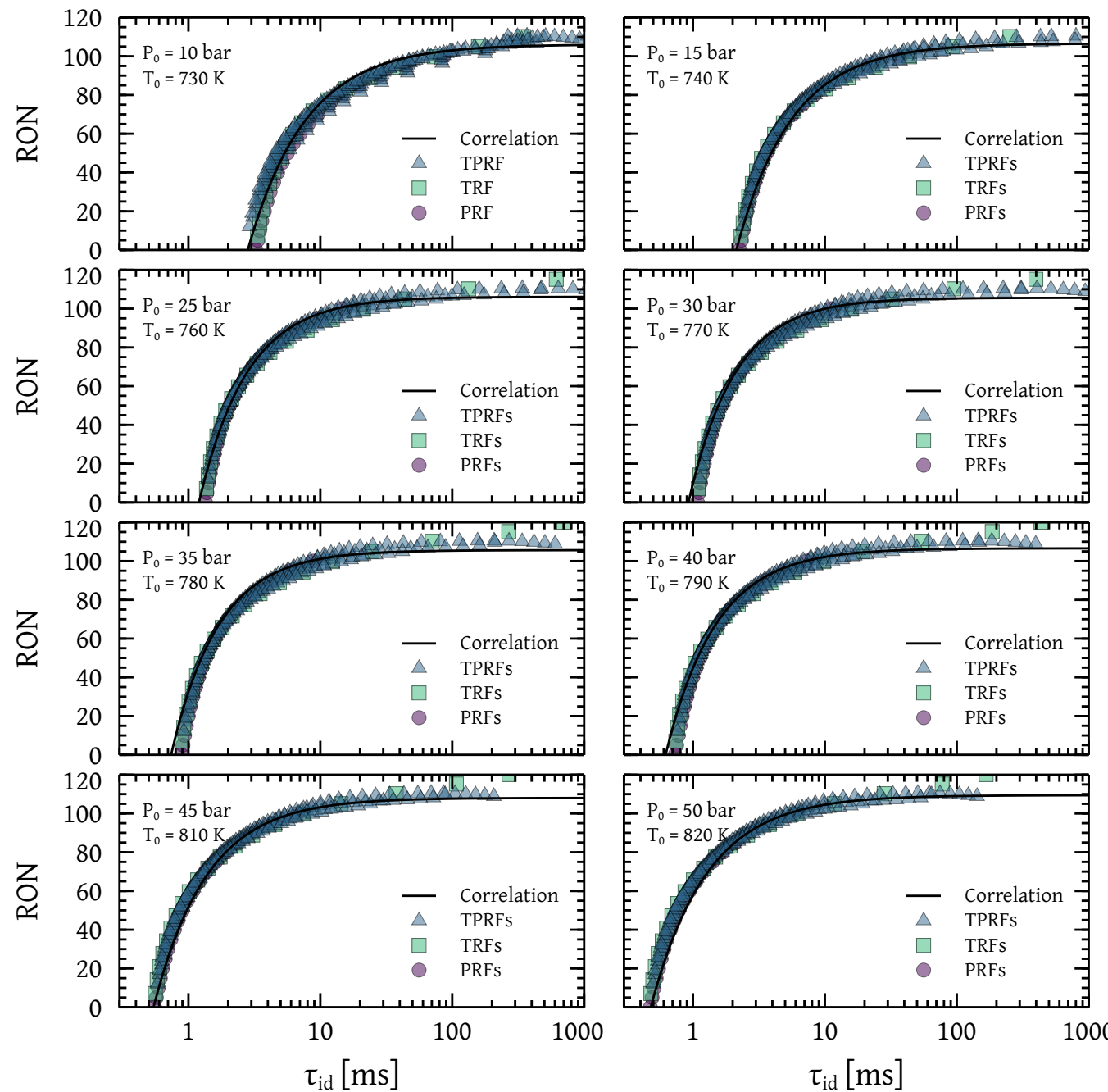

Figure S1: RON space 

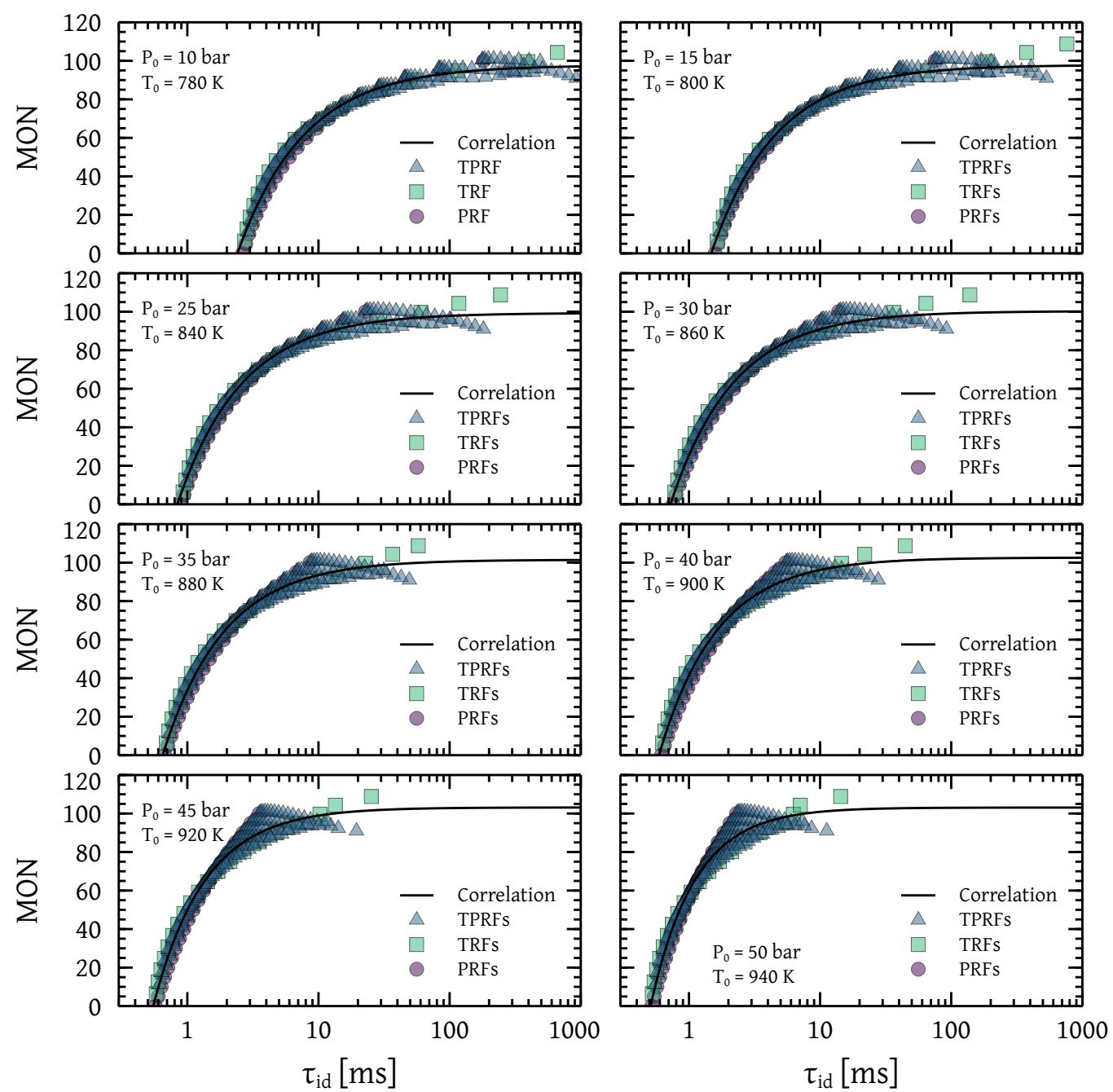

Figure S2: MON space 

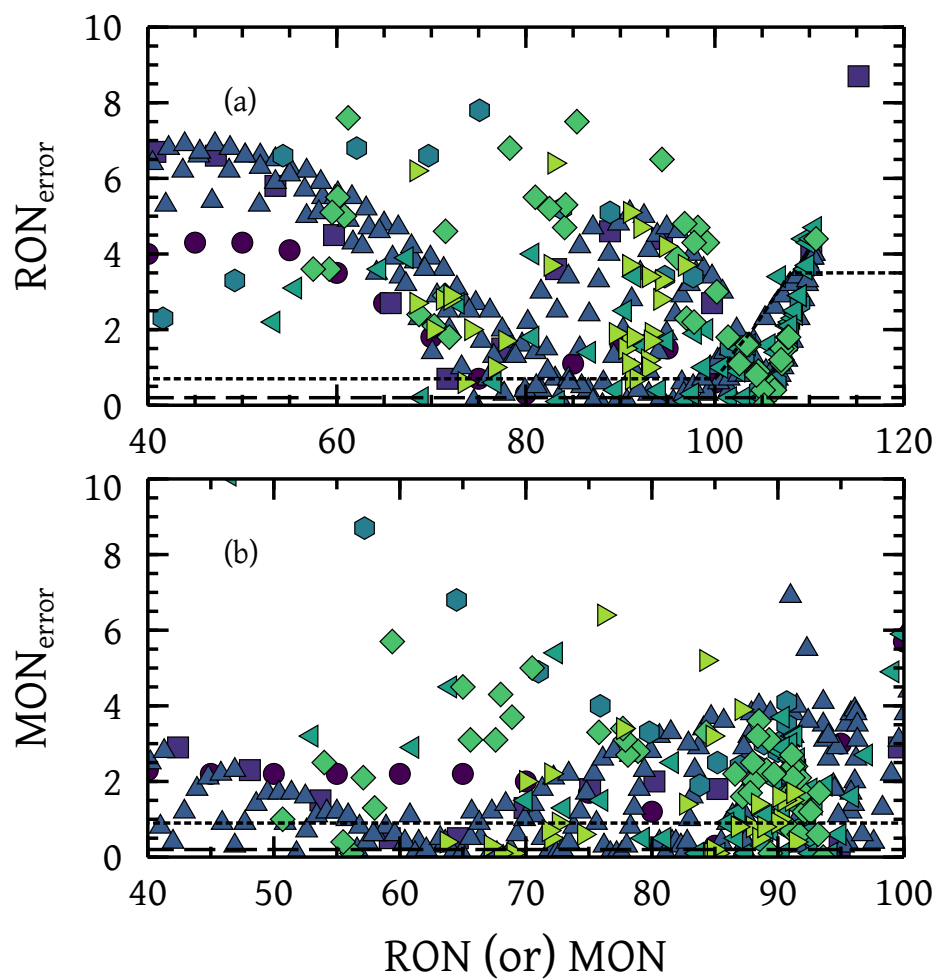

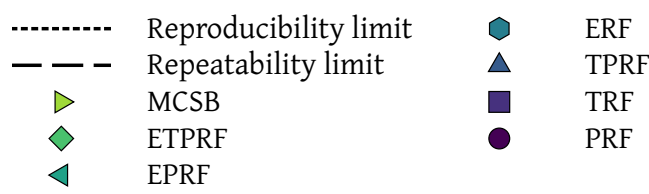

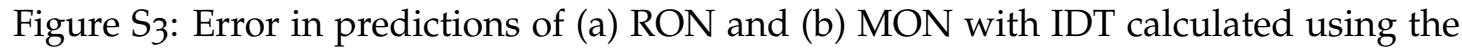
KAUST-LLNL-NUIG gasoline surrogate model [42] at 20 bar with reproducibility and repeatability limits 

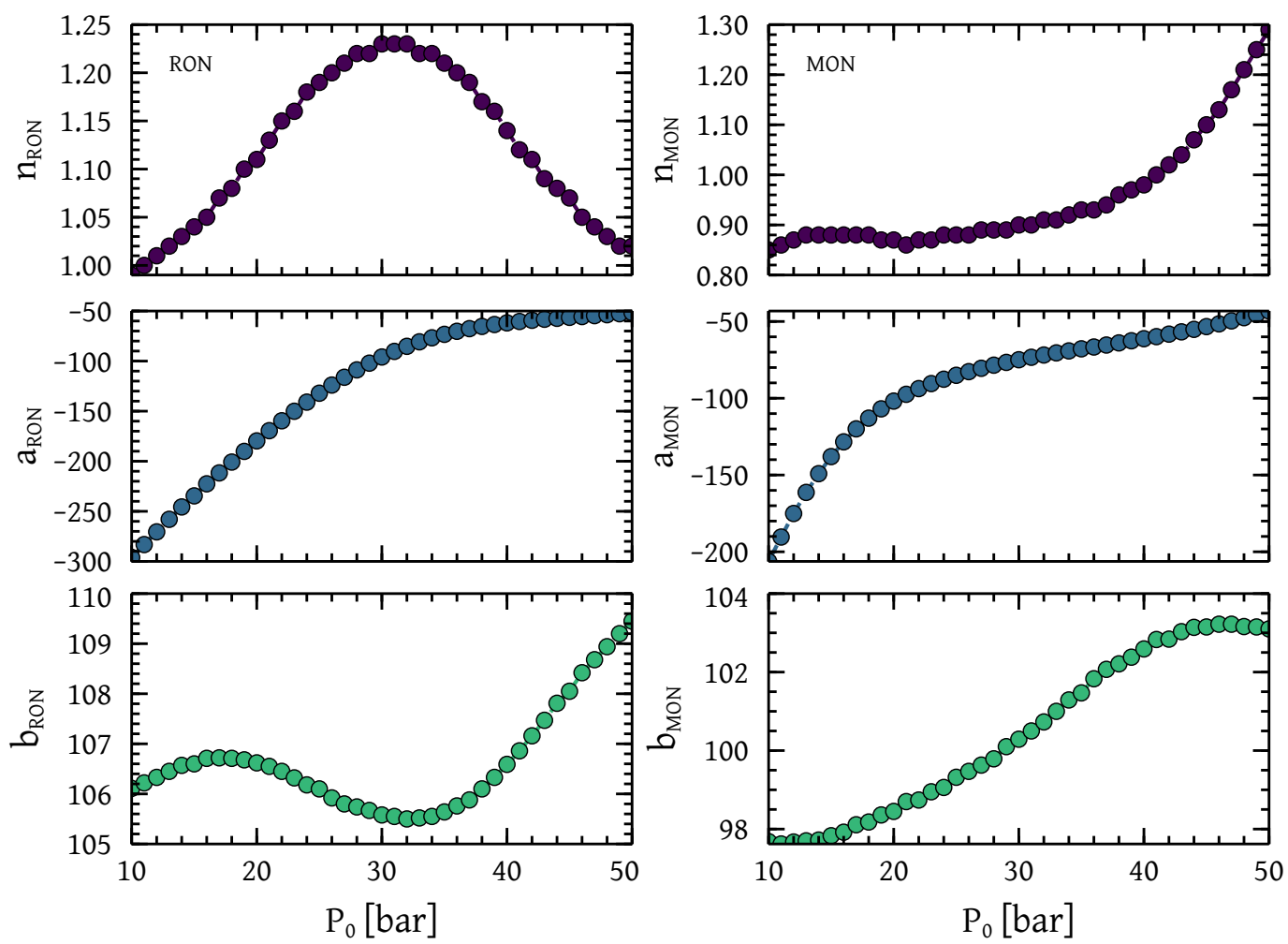

Figure S4: Exponent $n$ and coefficients $a, b$ in Eq. (2) to predict RON (left) and MON (right) 

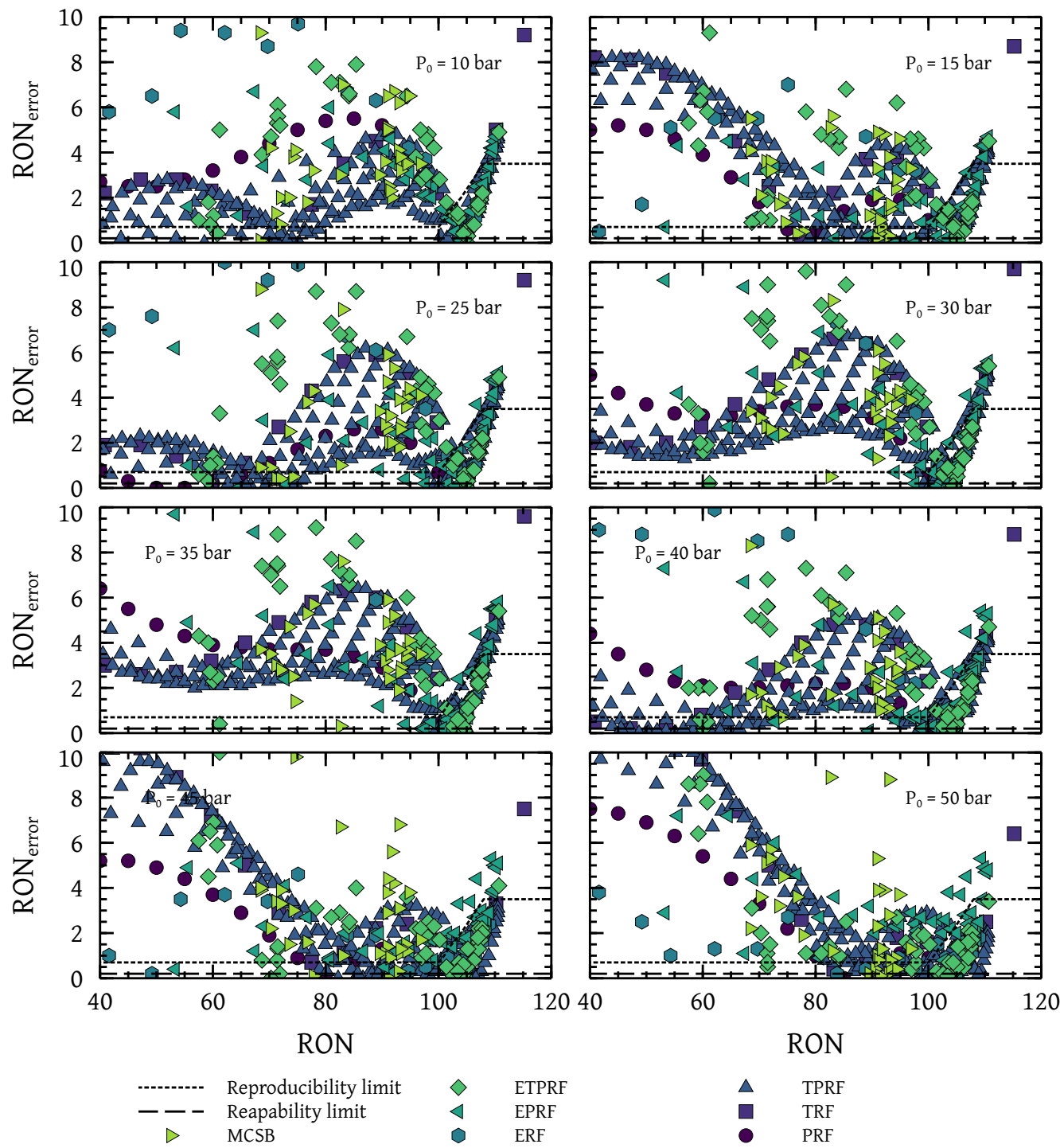

$\begin{array}{ll}\Delta & \text { TPRF } \\ \square & \text { TRF } \\ \square & \text { PRF }\end{array}$

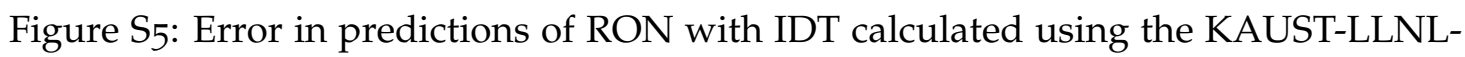
NUIG gasoline surrogate model [42] with reproducibility and repeatability limits 

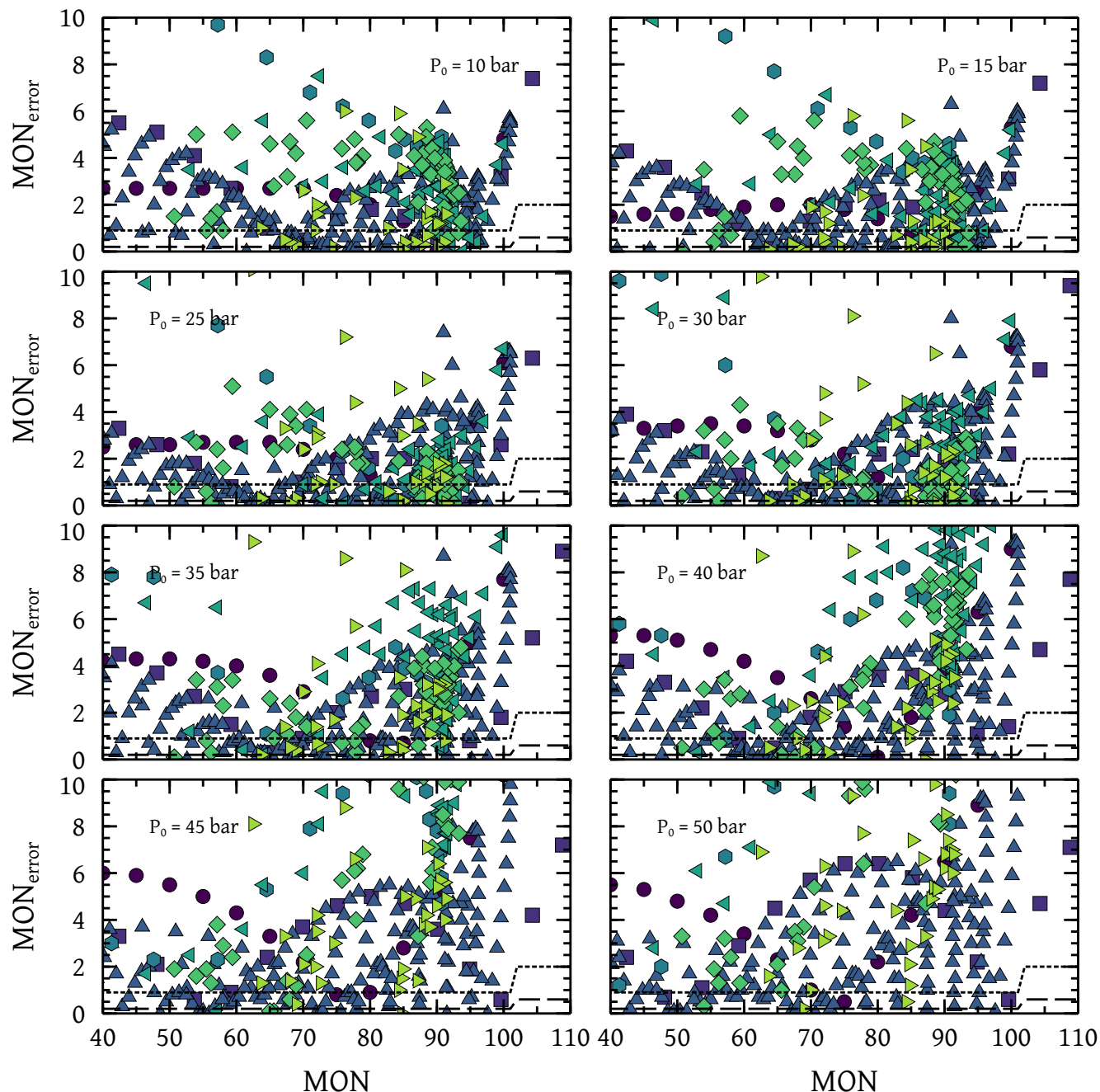

$\begin{array}{clll}-\cdots---- & \text { Reproducibility limit } & \diamond & \text { ETPRF } \\ -\square- & \text { Repeatability limit } & \triangleleft & \text { EPRF } \\ \square & \text { MCSB } & \diamond & \text { ERF }\end{array}$

$\begin{array}{ll}\Delta & \text { TPRF } \\ \square & \text { TRF } \\ & \text { PRF }\end{array}$

Figure S6: Error in predictions of MON with IDT calculated using the KAUST-LLNLNUIG gasoline surrogate model [42] with reproducibility and repeatability limits 

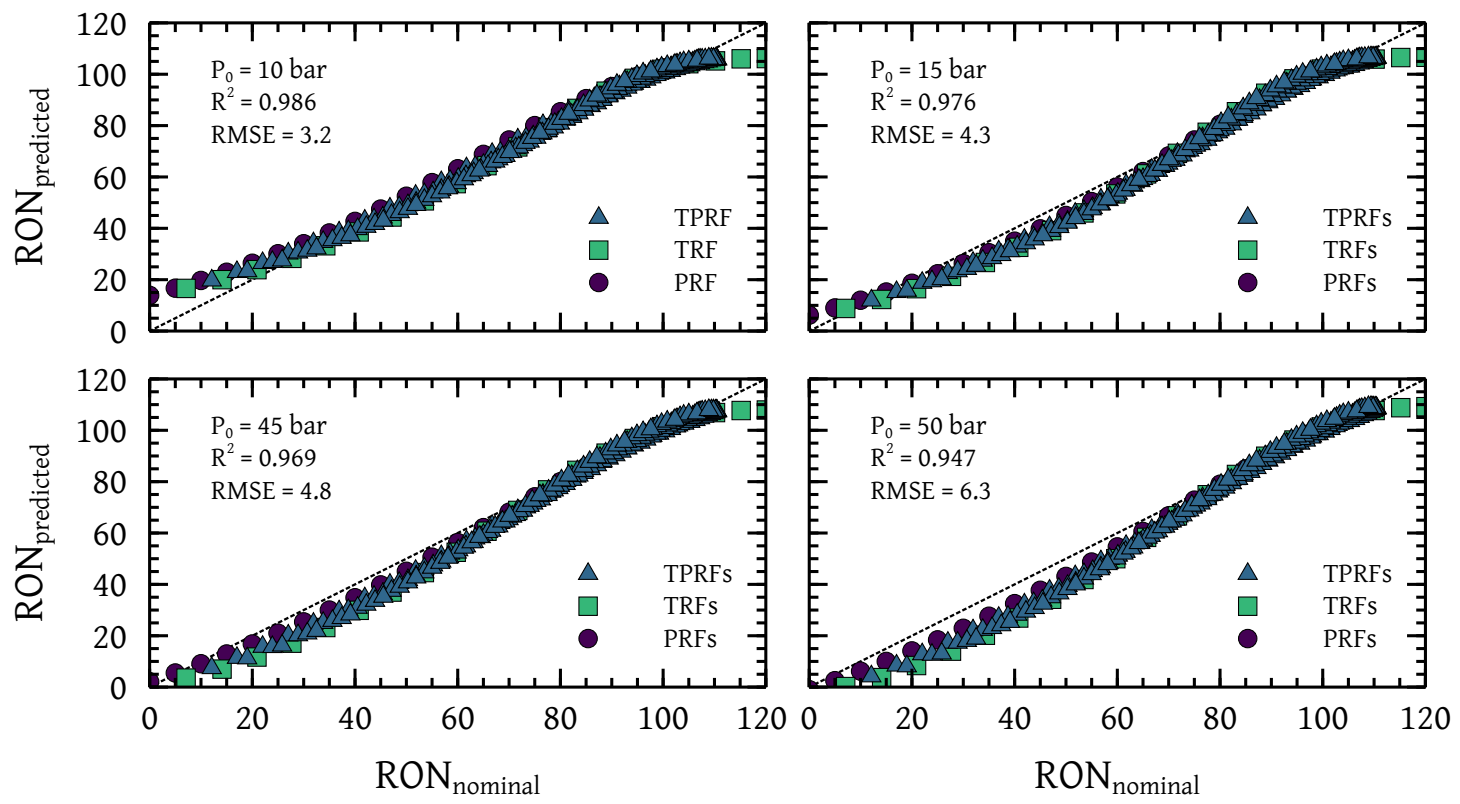

(a)
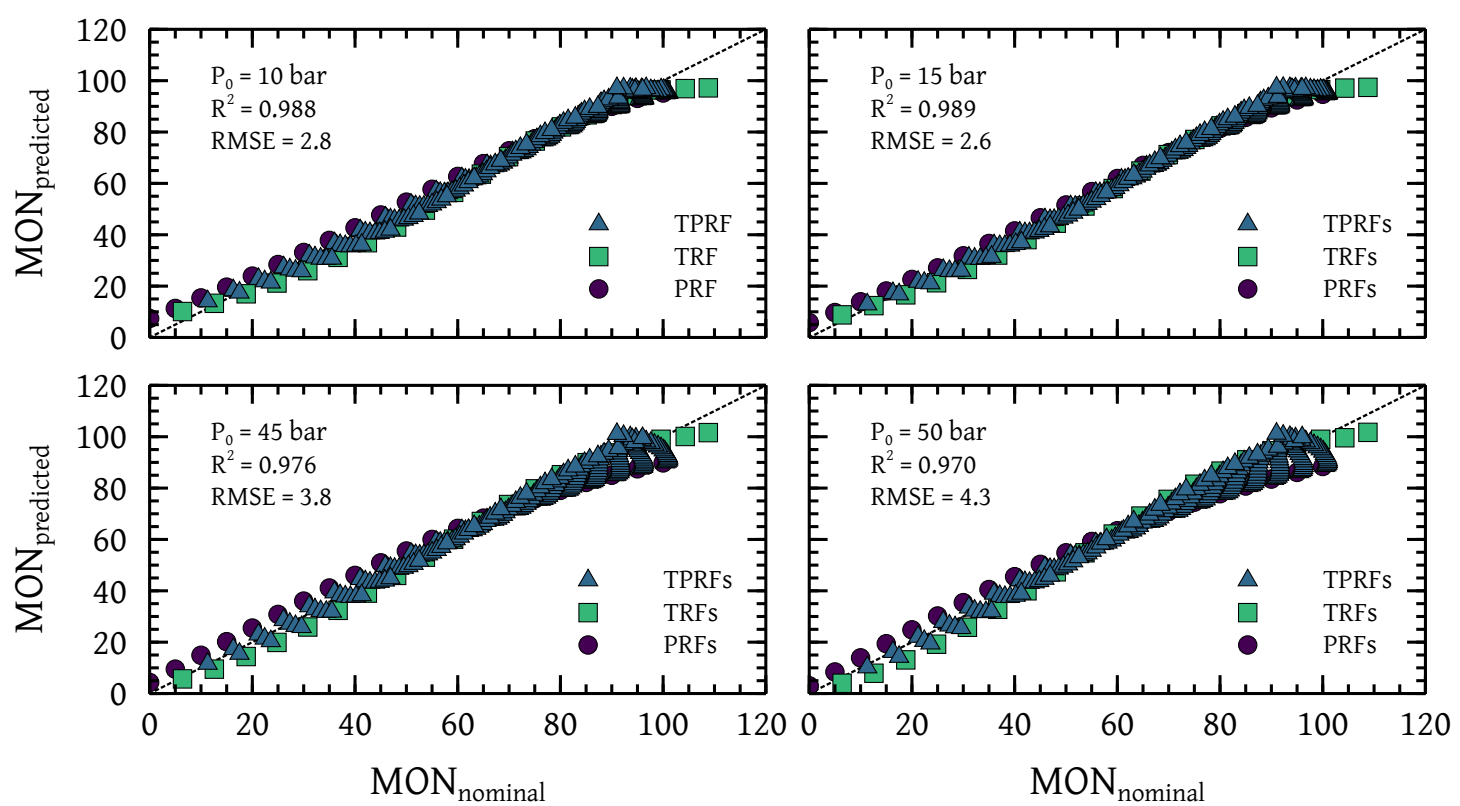

(b)

Figure S7: Predicted and nominal (a) RON and (b) MON of PRF, TRF and TPRF with IDT calculated using the KAUST-LLNL-NUIG gasoline surrogate model [42] at different pressures 

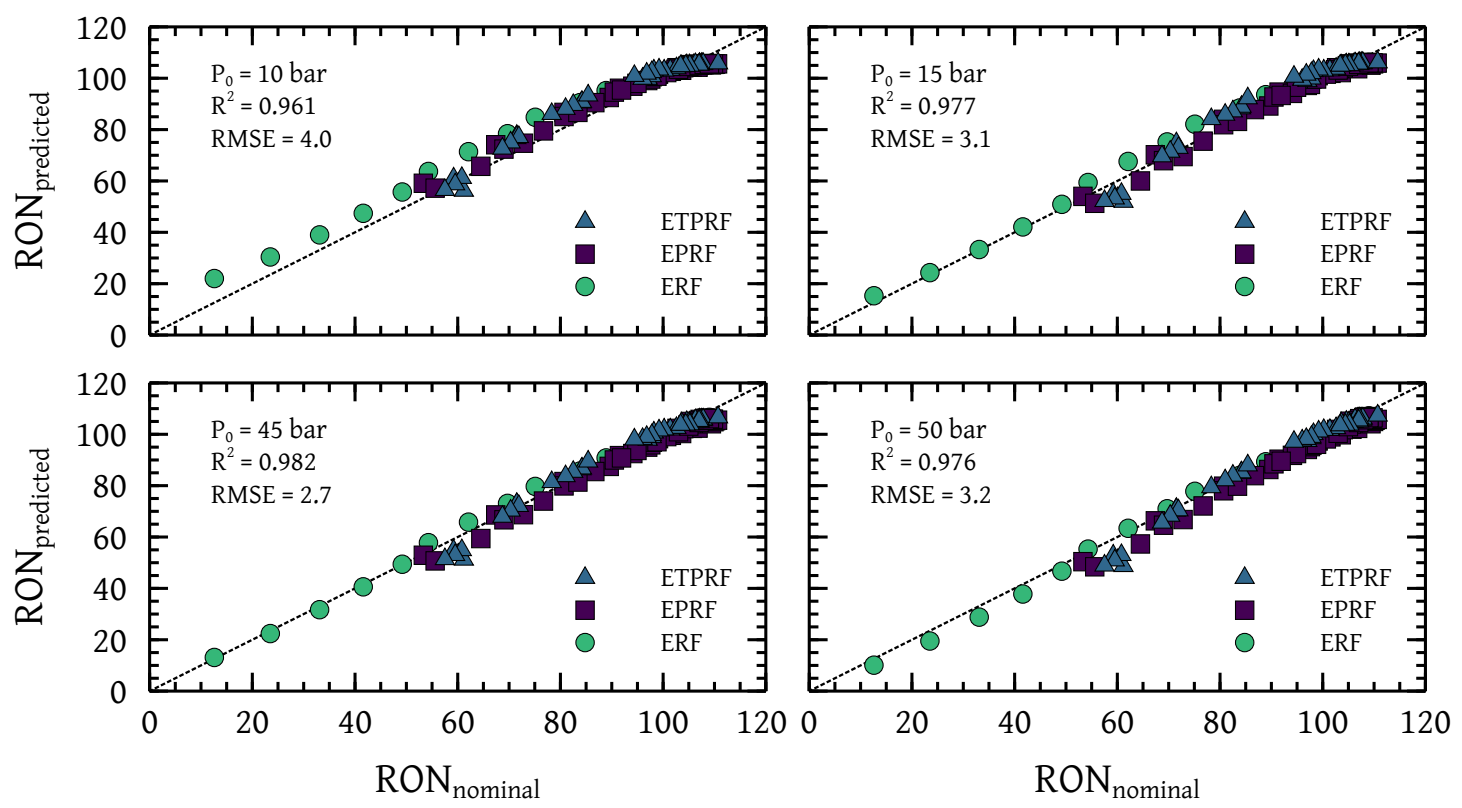

(a)
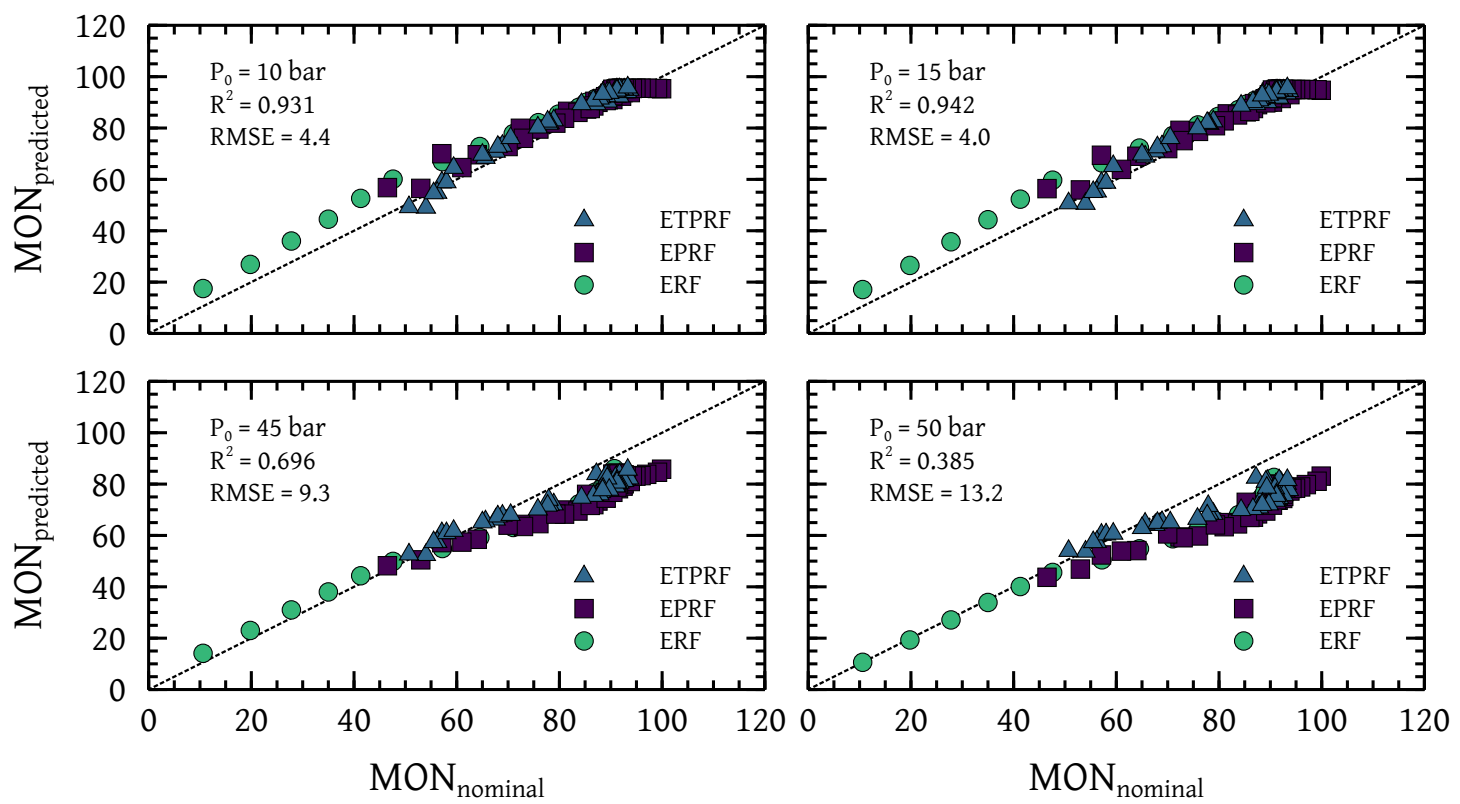

(b)

Figure S8: Predicted and nominal (a) RON and (b) MON of ERF, EPRF and ETPRF with IDT calculated using the KAUST-LLNL- NUIG gasoline surrogate model [42] at different pressures 

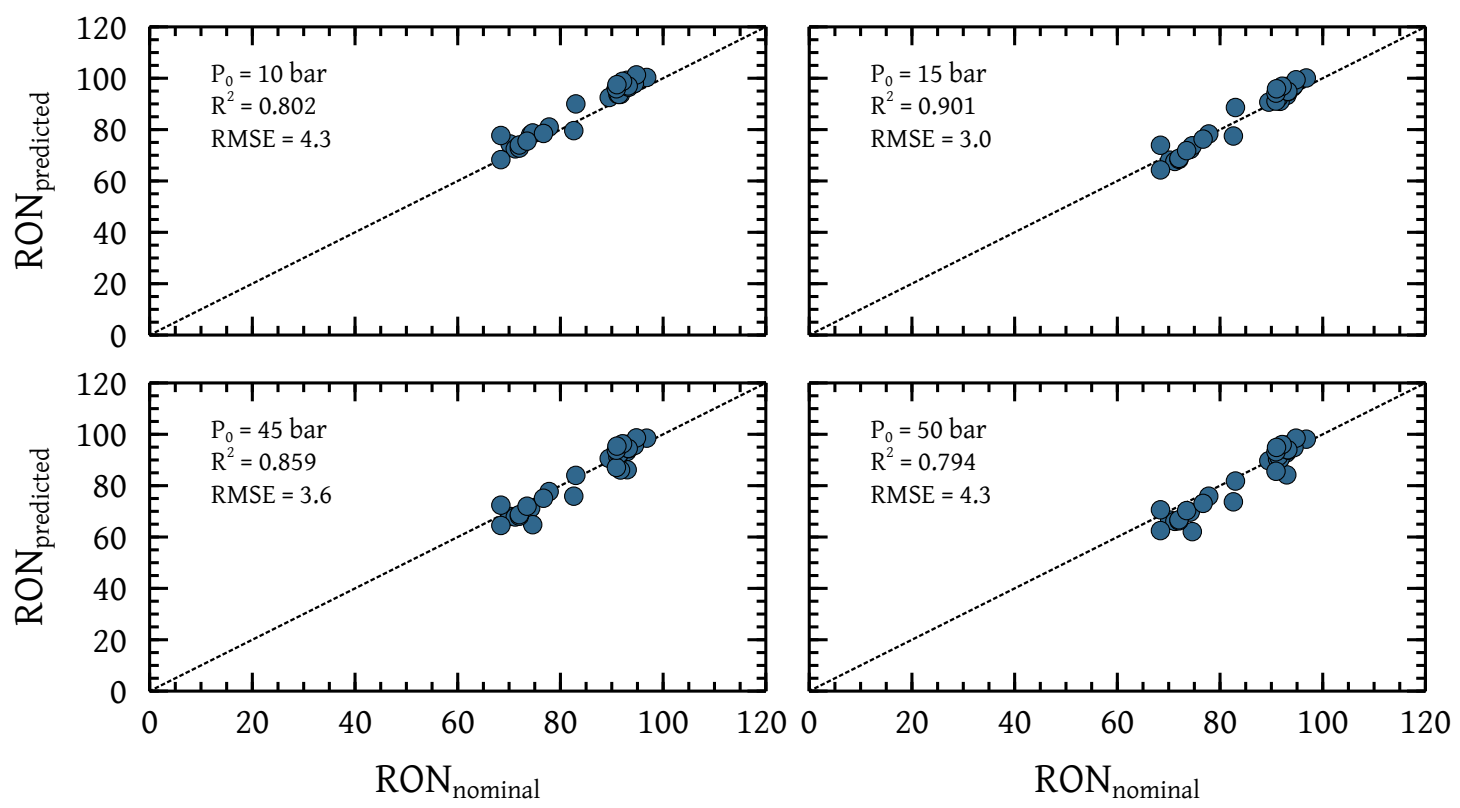

(a)
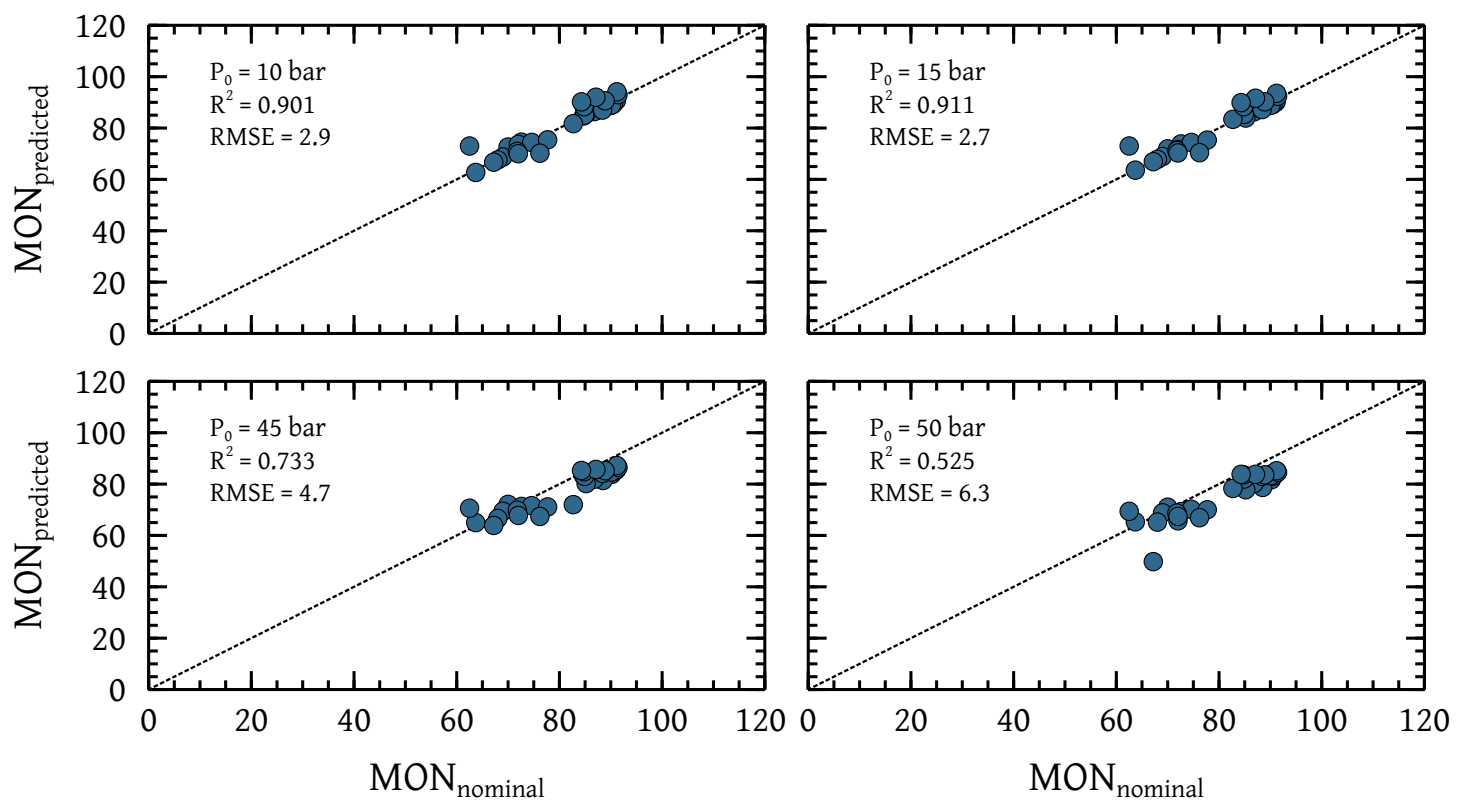

(b)

Figure S9: Predicted and nominal (a) RON and (b) MON of MCSB with IDT calculated using the KAUST-LLNL-NUIG gasoline surrogate model [42] at different pressures 

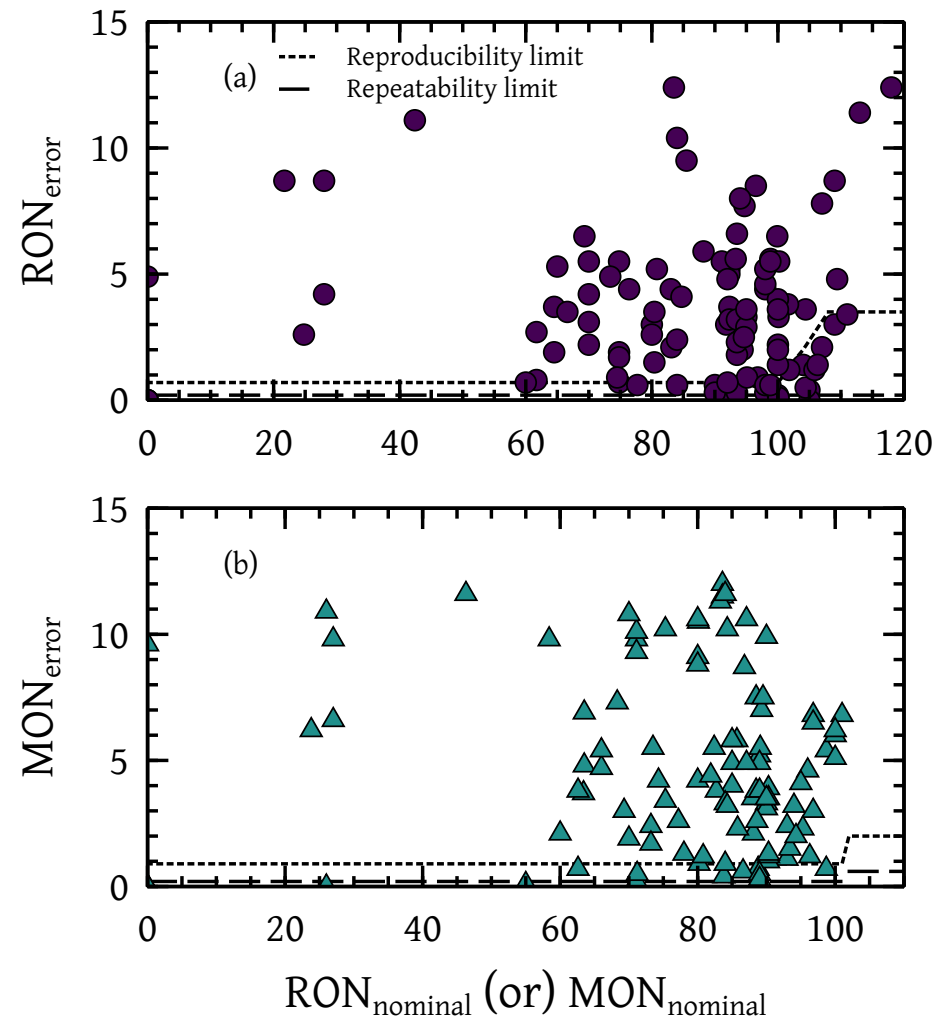

Figure Sio: Error in predictions of (a) RON and (b) MON with experimental IDT in Table 2 with reproducibility and repeatability limits 

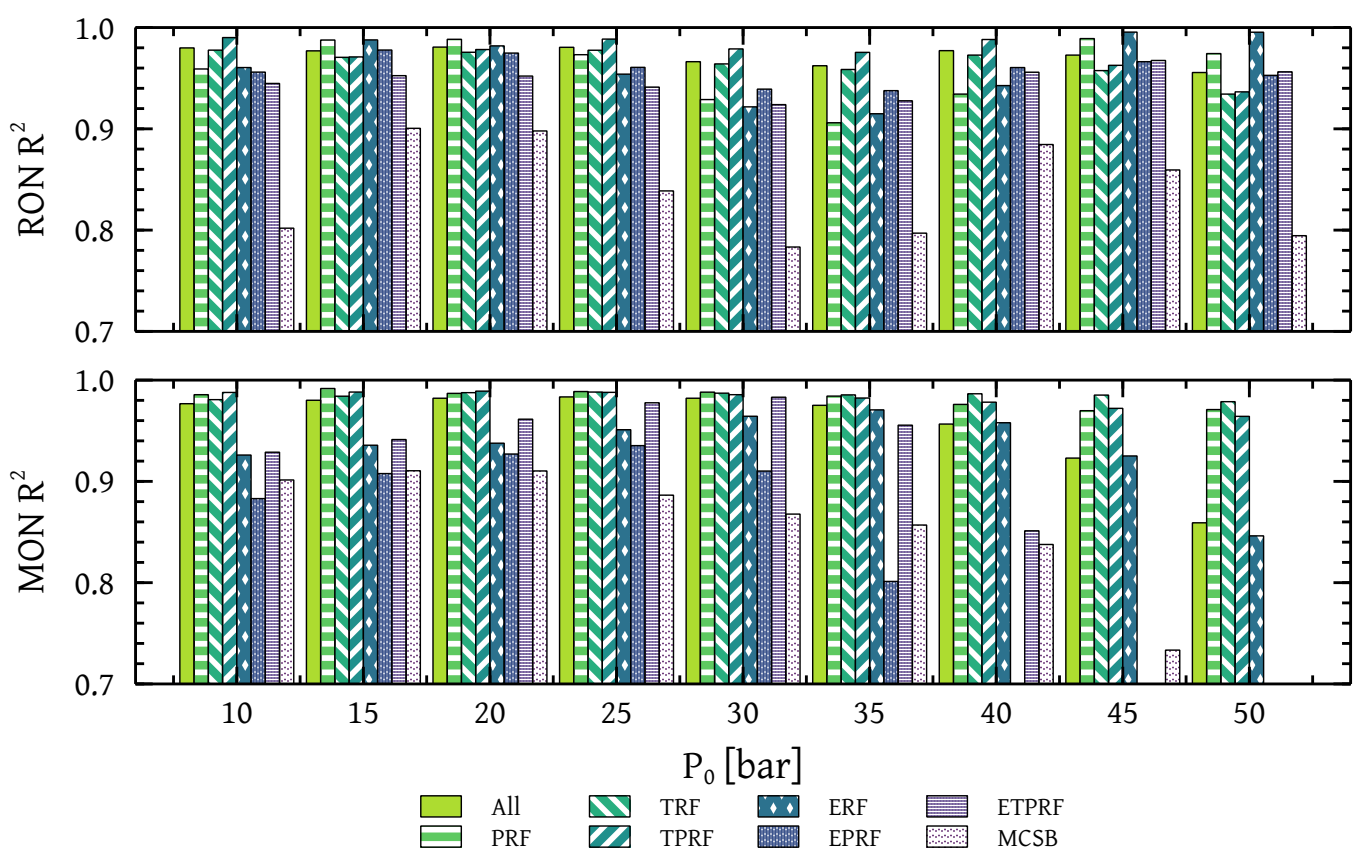

Figure S11: Comparison of $R^{2}$ of RON (top) and MON (bottom) predictions of various mixtures at different pressures 

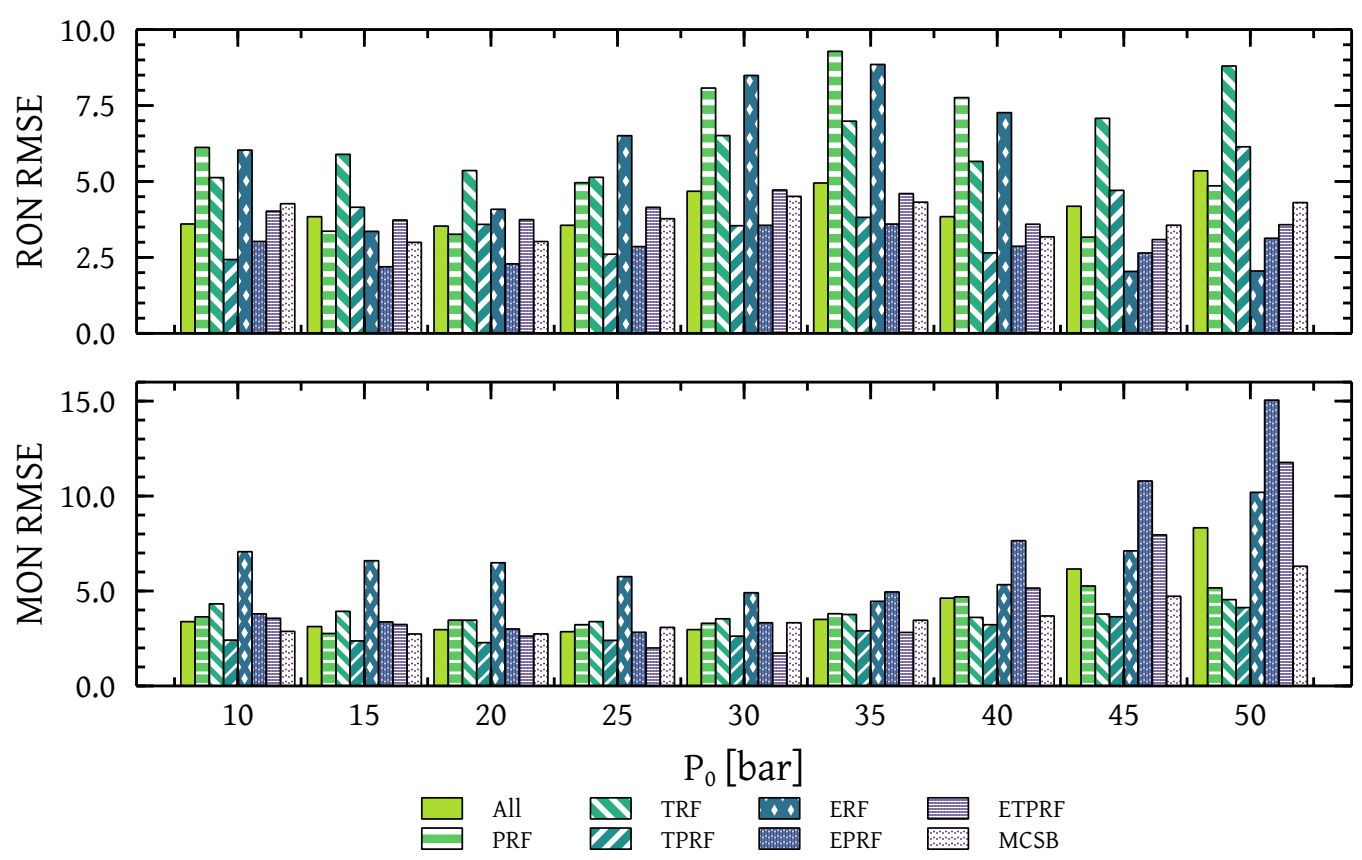

Figure S12: Comparison of RMSE of RON (top) and MON (bottom) predictions of various mixtures at different pressures

VALIDATION WITH TRF, TPRF AND PRF WITH OTHER KINETIC MODELS

The coefficients shown in Table 1 that were obtained from PRF, TRF and TPRF simulations were adopted for PRF, TRF and TPRF to predict RON and MON using Eq. (2); IDT is the simulated IDT of the chosen PRF, TRF and TPRF mixture. As previosly mentioned, the coefficients were determined using IDT simulations of PRF using the KAUST-LLNL-NUIG gasoline surrogate model [42]. To test the rigor of the present methodology, we attempted to predict RON and MON of various TRF, TPRF, and PRF mixtures by simulation with their IDTs calculated using other chemical kinetic models. To this end, three models were selected and utilized in the present study, specifically: (i) the LLNL gasoline surrogate model [61], (ii) the RWTH optimized gasoline surrogate model [62], (iii) and the POLIMI PRF surrogate model [63]. As shown in the following discussion, $\mathrm{RON}$ and MON predicted using simulated IDT with different chemical kinetic models show close agreement with nominal values, with some deviations in lower octane number range.

Figures $\mathrm{S}_{13}$ and $\mathrm{S}_{14}$ shows comparison between predicted RON and MON respectively with nominal values where IDTs were calculated using the detailed LLNL gasoline surrogate model [61]. In this case also, predictions of RON and MON were remarkably close to the nominal values. Comparisons of predicted and nominal RON 
and MON of PRFs, TRFs and TPRFs where IDTs were calculated using the RWTH optimized gasoline surrogate model [62] are shown in Figs. S15 and S16. In this case also, predictions of RON are remarkably close to the nominal values. Predictions of MON are reasonable at higher octane numbers. Even though the RWTH optimized gasoline surrogate model [62] not been validated at pressures higher than 40 bar, results are shown. For MON predictions, results at pressures higher than 40 bar indicate considerable differences with nominal values, which could be attributed to the model's ability to to reproduce IDT in the NTC regime at higher pressures. It is also interesting to note that predictions of TPRF are encompassed by predictions of TRF and PRF. 

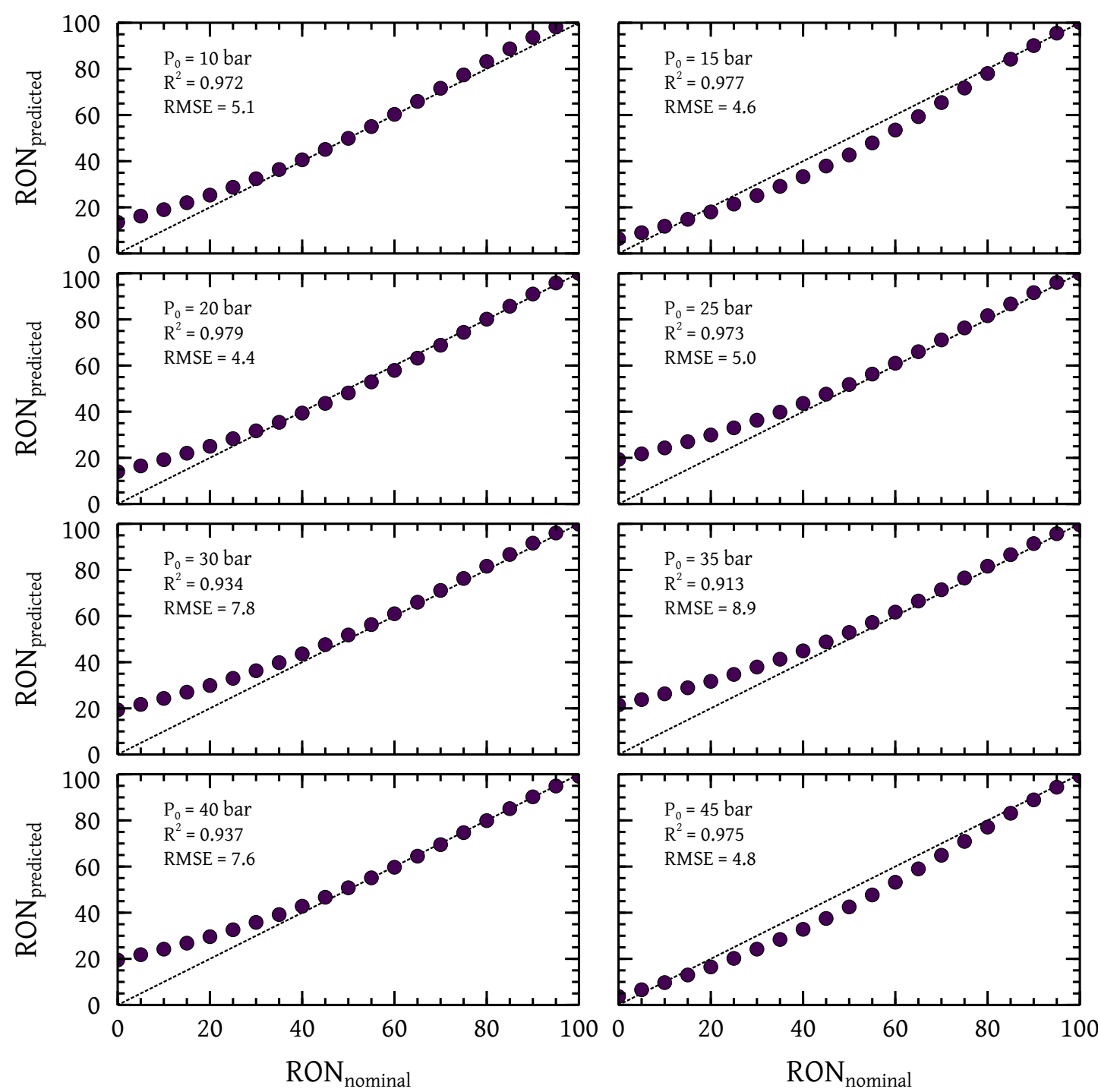

Figure S13: Predicted and nominal RON of PRF with IDT calculated using the LLNL gasoline surrogate model [61] at different pressures 

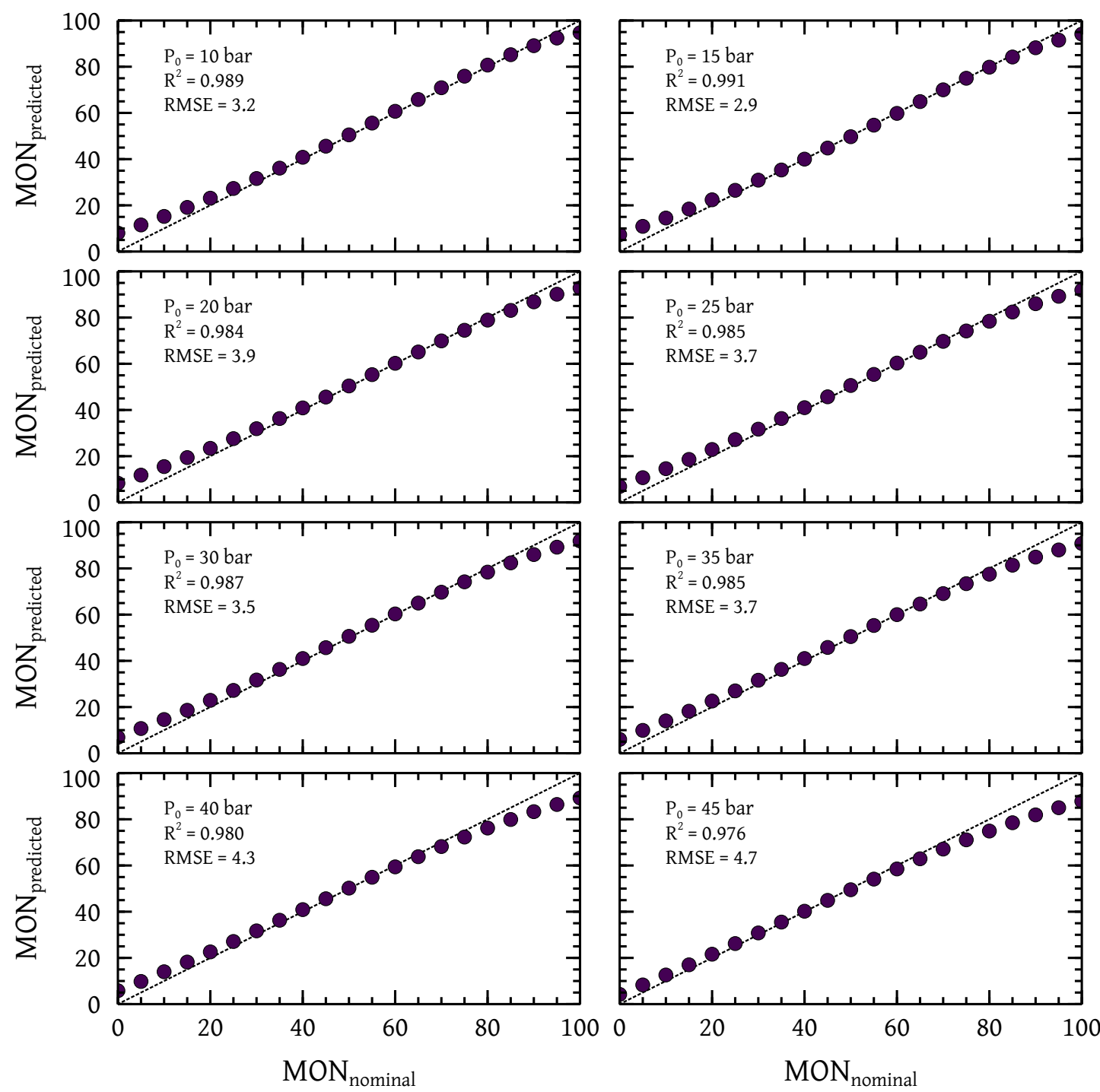

Figure S14: Predicted and nominal MON of PRF with IDT calculated using the LLNL gasoline surrogate model [61] at different pressures 

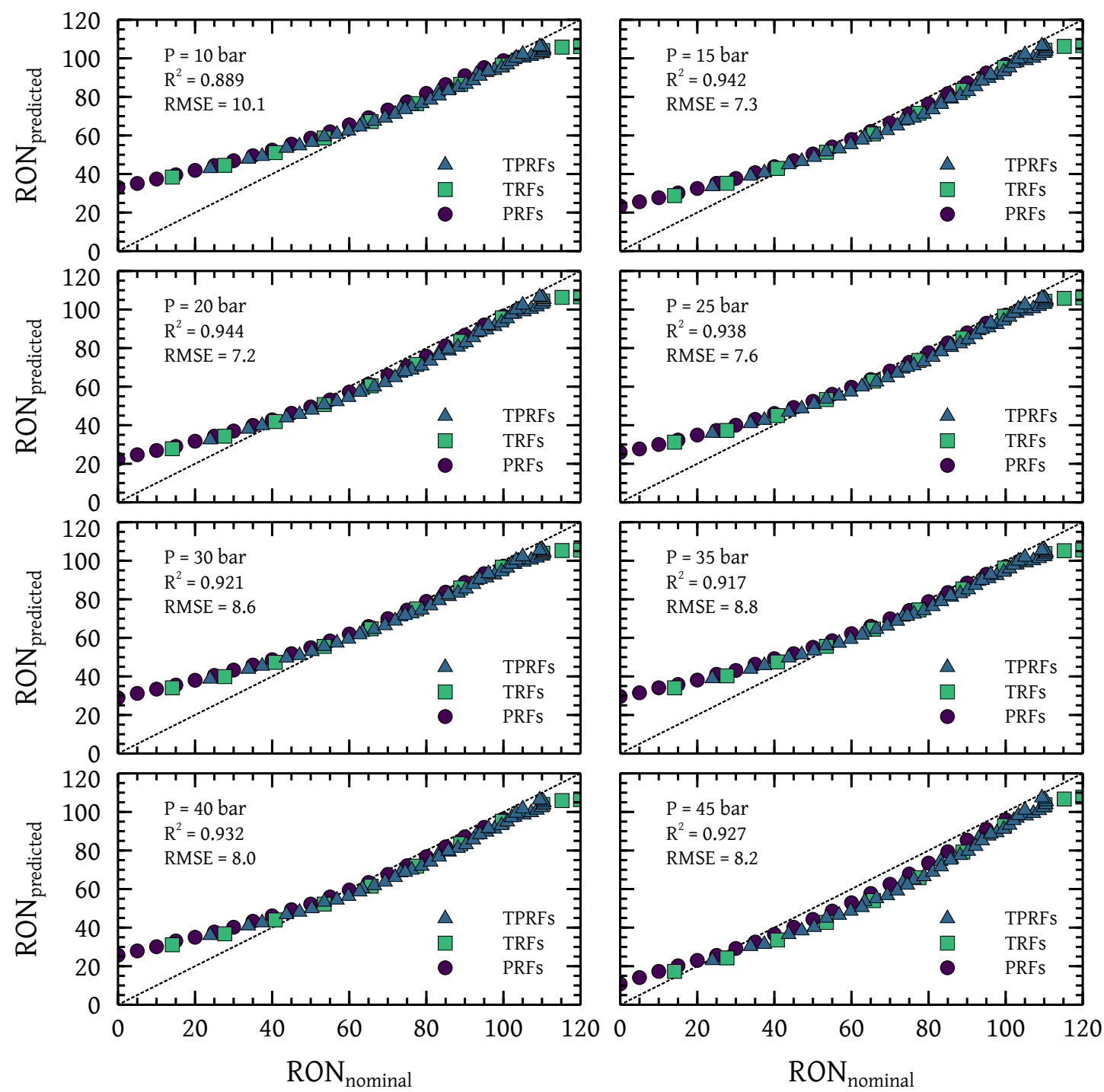

Figure S15: Predicted and nominal RON of PRF, TRF and TPRF with IDT calculated using the RWTH optimized gasoline surrogate model [62] at different pressures 

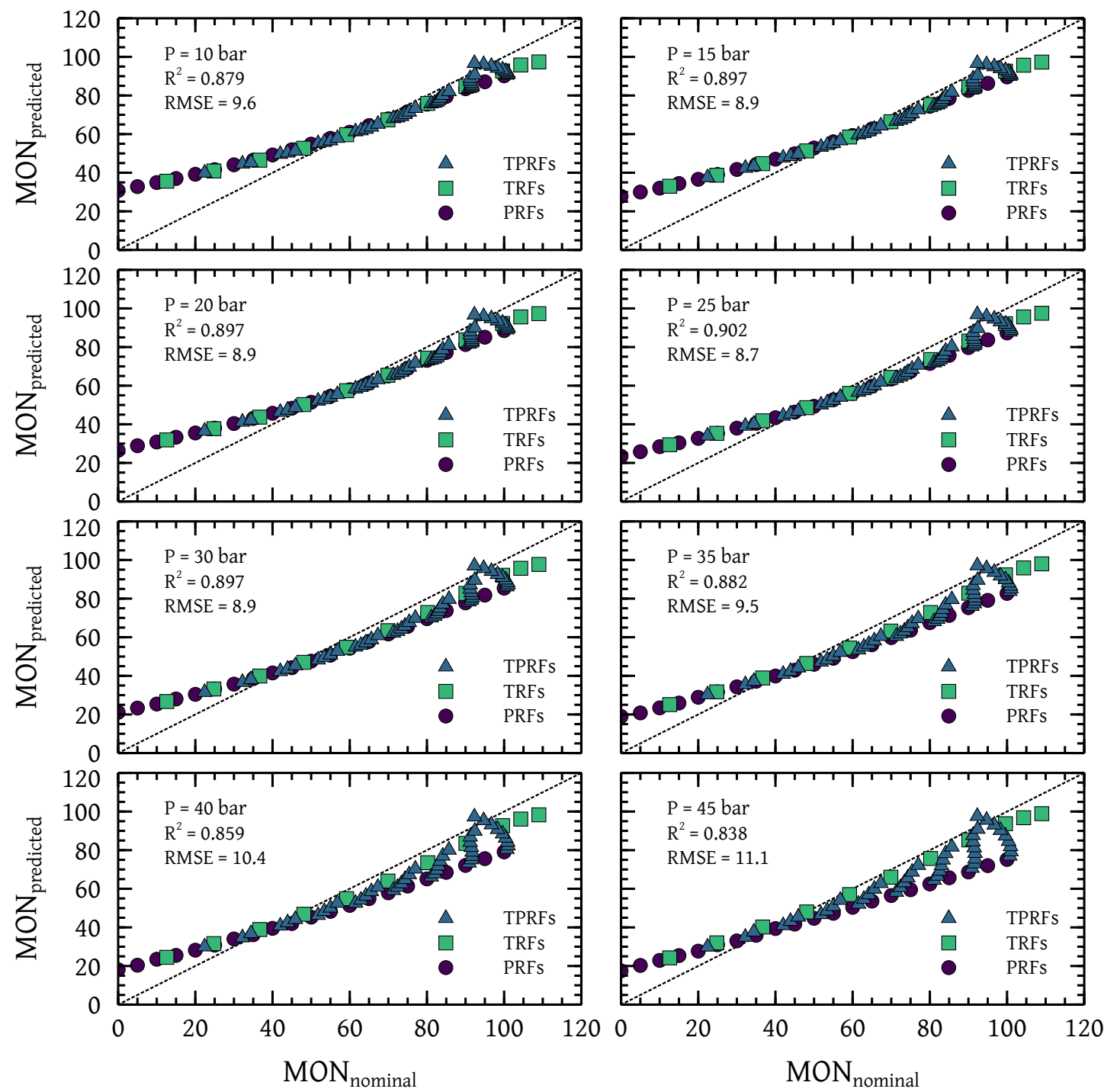

Figure S16: Predicted and nominal MON of PRF, TRF and TPRF with IDT calculated using the RWTH optimized gasoline surrogate model [62] at different pressures

Predicted RON and MON of PRFs with IDT calculated using the POLIMI PRF model [63] is shown in Figs. $S_{17}$ and $S_{18}$, respectively. Only predictions of PRF are shown as the model has not been validated for TRF and TPRF mixtures. As can be observed in the figures, predictions of RON and MON are good even when IDT are simulated with a model other than that used to determine the coefficients in Eq. (2). 

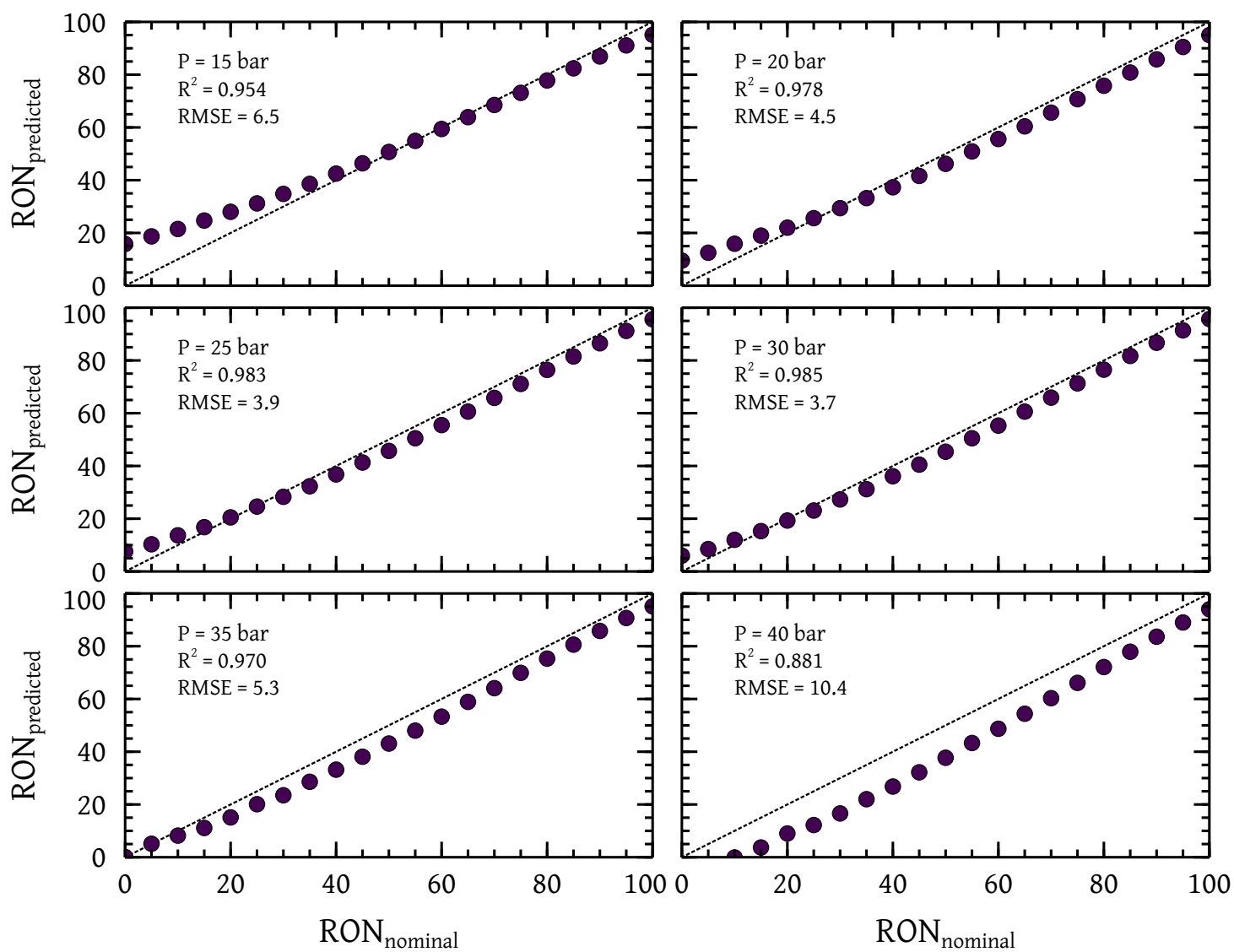

Figure S17: Predicted and nominal RON of PRF, TRF and TPRF with IDT calculated using the POLIMI PRF model [63] at different pressures 

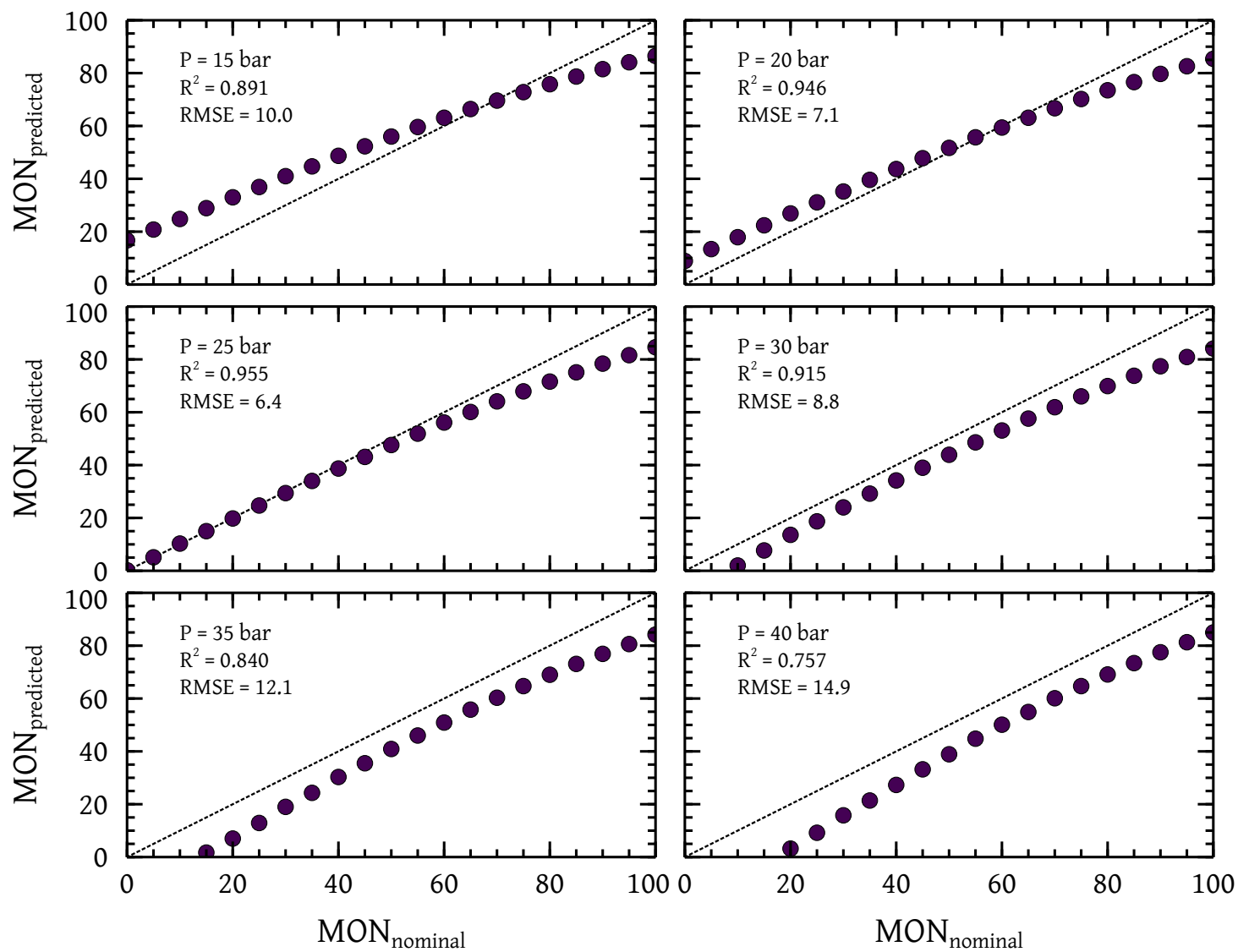

Figure S18: Predicted and nominal MON of PRF, TRF and TPRF with IDT calculated using the POLIMI PRF model [63] at different pressures 

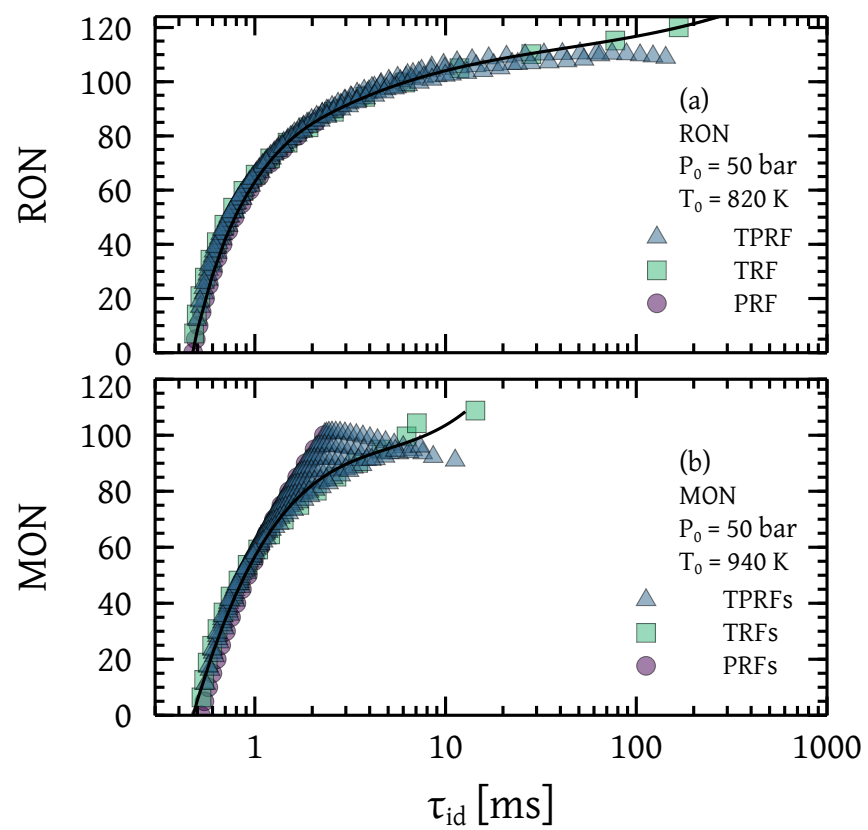

Figure S19: (a) RON and (b) MON space at $P_{0}=50$ bar 

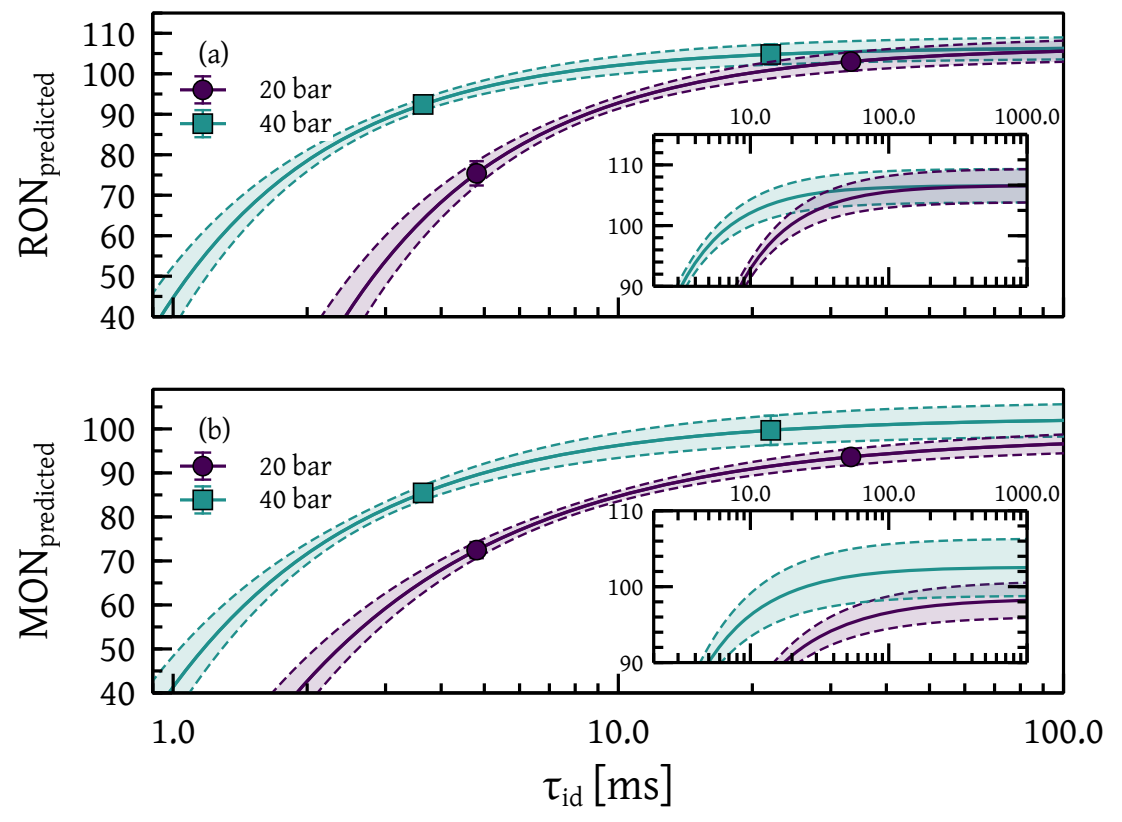

Figure S20: Uncertainty in estimation of (a) RON and (b) MON (bottom) at 20 and 40 bar with uncertainty in fit parameters given in Table 5 . Inset represents higher $\mathrm{ON}$ range. 

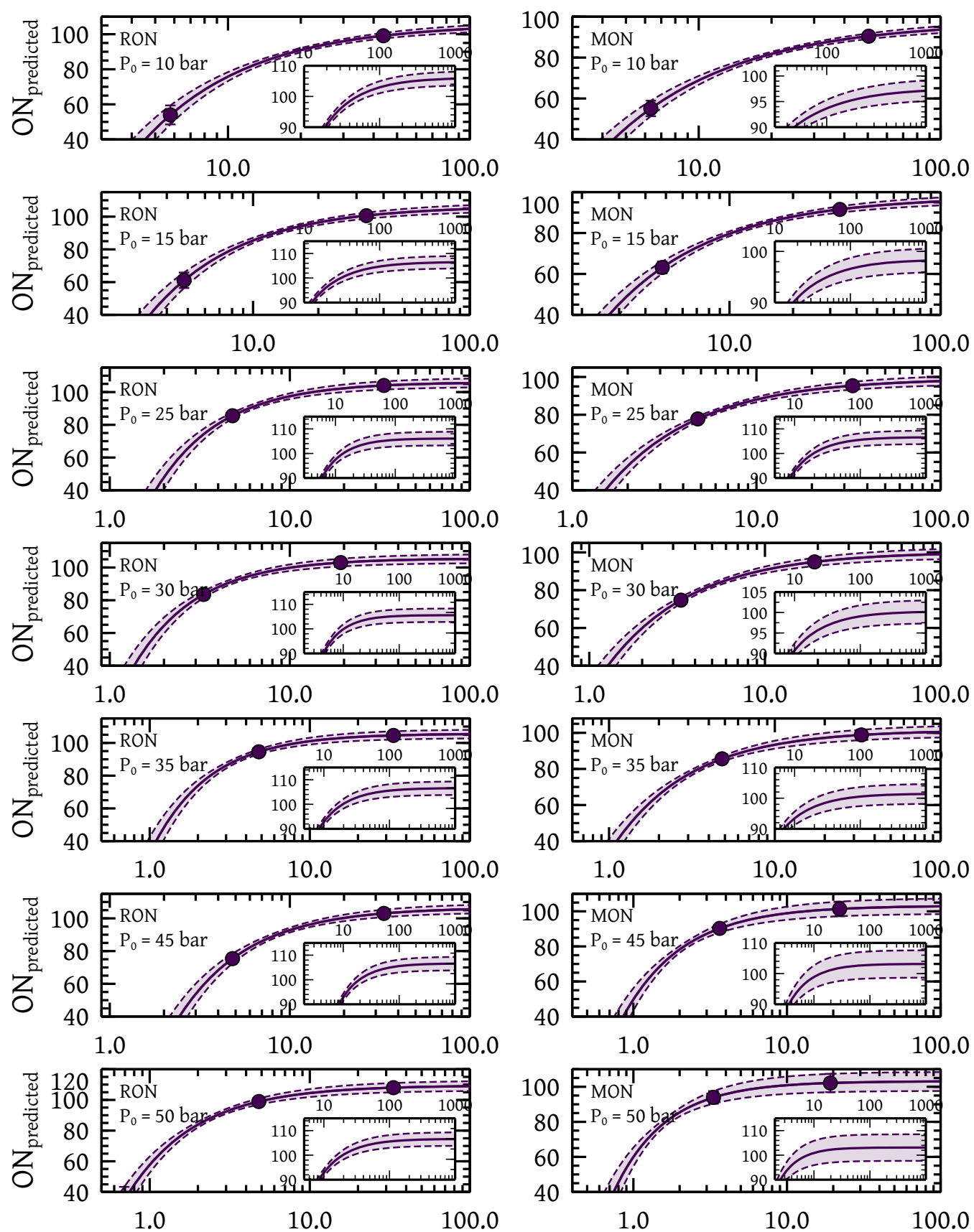

Figure S21: Uncertainty in estimation of RON (left) and MON (right) at different pressures with uncertainty in fit parameters given in Table 5 . Inset represents higher ON range. 

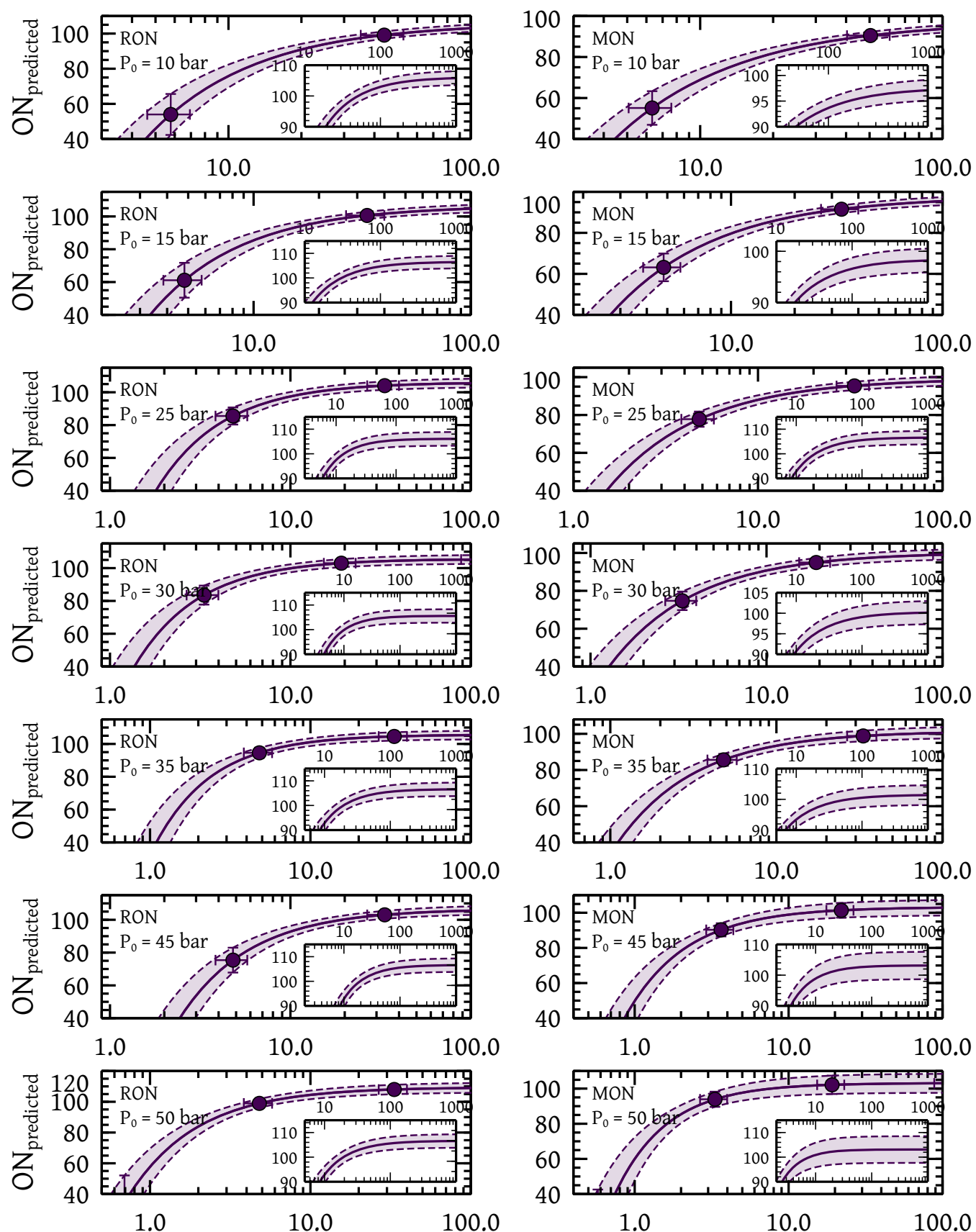

Figure S22: Uncertainty in estimation of RON (left) and MON (right) for $\pm 20 \%$ uncertainty in IDT at different pressures with uncertainty in fit parameters given in Table 5 . Inset represents higher $\mathrm{ON}$ range. 